AVALIAÇÃO NEUROPSICOLÓGICA DE PACIENTES EXPOSTOS AO VAPOR DE MERCÚRIO E DE PACIENTES DIABÉTICOS DO TIPO 2 


\section{ELAINE CRISTINA ZACHI}

\section{AVALIAÇÃO NEUROPSICOLÓGICA DE PACIENTES EXPOSTOS AO VAPOR DE MERCÚRIO E DE PACIENTES DIABÉTICOS DO TIPO 2}

Dissertação apresentada ao Instituto de Psicologia da Universidade de São Paulo, como parte dos requisitos para obtenção do título de Mestre em Psicologia.

Área de Concentração: Neurociências e Comportamento

Orientadora: Prof ${ }^{\mathrm{a}} \operatorname{Dr}^{\mathrm{a}}$ Dora Fix Ventura

\section{SÃO PAULO}


Zachi, Elaine Cristina.

Avaliação neuropsicológica de pacientes expostos ao vapor de mercúrio e de pacientes diabéticos do tipo 2 / Elaine Cristina Zachi; orientadora Dora Selma Fix Ventura. --São Paulo, 2005.

$117 \mathrm{p}$.

Dissertação (Mestrado - Programa de Pós-Graduação em Psicologia. Área de Concentração: Neurociências e Comportamento) Instituto de Psicologia da Universidade de São Paulo.

1. Neuropsicologia 2. Avaliação neuropsicológica 3. Intoxicação por mercúrio 4 Diabetes 5. Distúrbios cognitivos I. Título. 


\title{
AVALIAÇÃO NEUROPSICOLÓGICA DE PACIENTES EXPOSTOS AO VAPOR DE MERCÚRIO E DE PACIENTES DIABÉTICOS DO TIPO 2
}

\author{
ELAINE CRISTINA ZACHI
}

\section{BANCA EXAMINADORA}

(Nome e Assinatura)

(Nome e Assinatura)

(Nome e Assinatura)

Dissertação defendida e aprovada em: 
Aos meus pais, que me presentearam com a vida... 


\section{AGRADECIMENTOS}

À Profa Dora Ventura, pelo carinho, por toda orientação no estudo e pelo exemplo de sabedoria e dedicação à ciência,

À Anita Taub, pela amizade, orientação que tornou possível o desenvolvimento deste projeto de mestrado e pelo incentivo e apoio no estudo da neuropsicologia,

À Profa Clarice Gorenstein, pelas importantes sugestões e orientações quanto ao manejo de resultados do estudo,

À Dra Márcia Bernik, pelas sugestões fundamentais à conclusão do estudo, pelo encaminhamento de pacientes e pela parceria neste estudo,

Aos Drs Mauro Nishi e Marcos Lago pelo exame oftalmológico de pacientes,

Ao Prof Amauri Gouveia, pela amizade, pelas sugestões ao estudo e momentos de descontração,

Ao Shirley Lacerda, pela amizade e ajuda na discussão dos dados,

Ao Dr. Marcelo Costa, pela amizade e apoio no manejo de dados quantitativos,

Ao Prof John de Souza, pela ajuda quanto à língua inglesa,

Aos amigos do laboratório Ana Laura, Ana Luiza, André, Christine, Claúdia, Claudiel, Daniela, Fernando, Mirela B., Mirela G., Rosani,

Aos meus pais, pelo amor e apoio constantes em toda minha vida,

À minha irmã e ao meu irmão pelos momentos de descontração nas em tempos de alegria e de união nos momentos difíceis,

À Jully, ao Hugo, Frederico e Roger, pela alegria e amor incondicionais,

E ao meu querido Wagner, por tornar minha vida mais feliz, pelo apoio em todos os momentos, por toda compreensão e por completar minha vida com o sentido do amor... 


\section{Sumário}

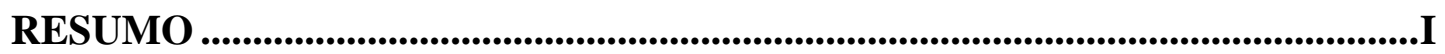

ABSTRACT …................................................................................................................. II

LISTA DE FIGURAS ............................................................................................... III

LISTA DE TABELAS .....................................................................................................VI

LISTA DE ABREVIATURAS ................................................................................ VII

LISTA DE ABREVIATURAS .......................................................................... VII

1. CONSIDERAÇÕES GERAIS SOBRE O ESTUDO .............................................1

2. INTRODUÇÃO ........................................................................................................

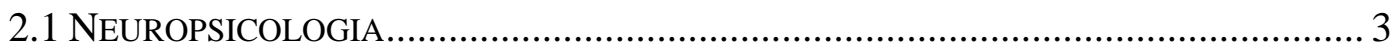

2.11 Considerações Gerais ................................................................................... 3

2.12 Avaliação Neuropsicológica ....................................................................... 7

3. AVALIAÇÃO NEUROPSICOLÓGICA DE PACIENTES EXPOSTOS AO

VAPOR DE MERCÚRIO ................................................................................ 10

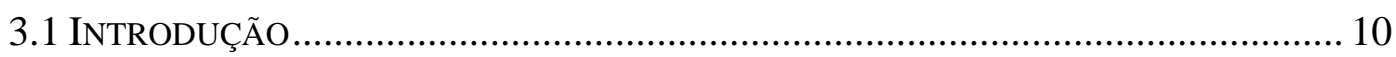

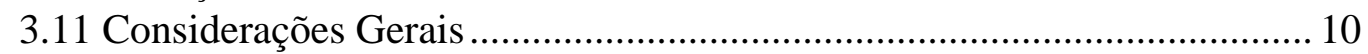

3.12 Intoxicação por Mercúrio Metálico.............................................................. 11

3.13 Fisiopatologia da Intoxicação pelo Vapor de Mercúrio e o SNC.................. 15

3.14 Exposição Crônica ao Vapor de Mercúrio e a Avaliação Neuropsicológica

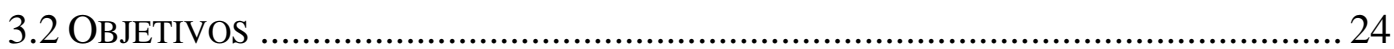

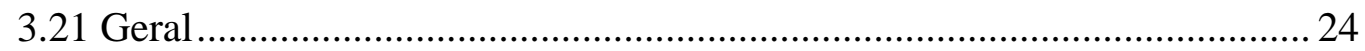

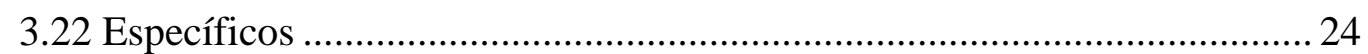

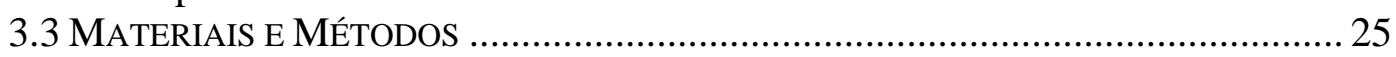

3.31 Procedimentos ..................................................................................... 25

3.32 Instrumentos de Avaliação Neuropsicológica.............................................. 27

3.321 Testes para exame das funções neuropsicológicas................................. 27

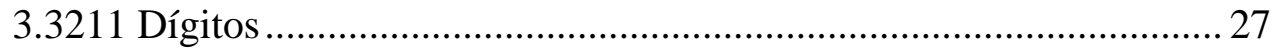

3.3212 Teste de Stroop (Stroop Interference Test) ……………………...... 27

3.3213 Teste de Buschke (Buschke Selective RemindingTest-SRT) ........ 28

3.3214 Reprodução Visual ..................................................................... 29

3.3215 Grooved Pegboard.......................................................................... 29

3.3216 Fluência Verbal Categoria Fonêmica (FAS).................................... 30

3.3217 Cubos ......................................................................................... 30

3.3218 Teste de Wisconsin (Wisconsin Card Sorting Test) ......................... 30

3.3219 Vocabulário ...................................................................................... 31

3.322 Inventários de Humor........................................................................... 31

3.3221 Inventário Beck de Depressão (Beck Depression Inventory -BDI)31

3.3222 Inventário de Ansiedade Traço-Estado (IDATE) ............................ 32 


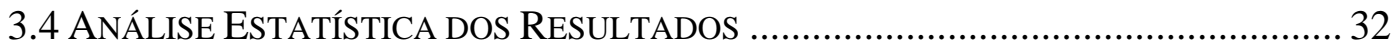

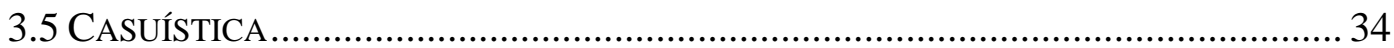

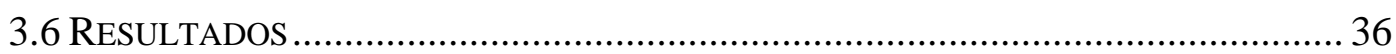

3.61 Apresentação dos Resultados Conforme os Domínios Examinados .......... 41

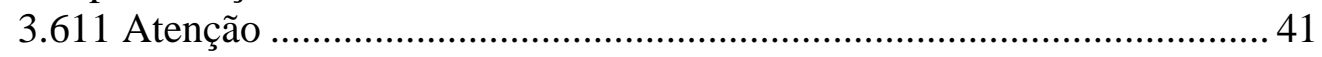

3.612 Memória ………………………………………………………… 43

3.613 Fluência Verbal ................................................................................. 45

3.614 Destreza Manual.............................................................................. 46

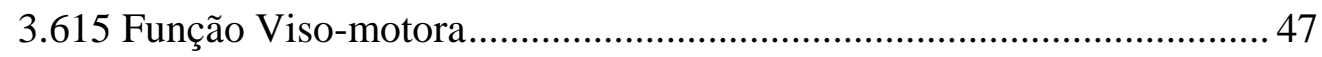

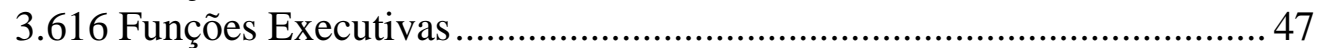

3.617 Conhecimento Semântico...………………………………………..... 49

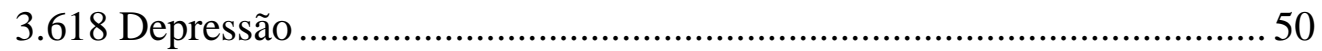

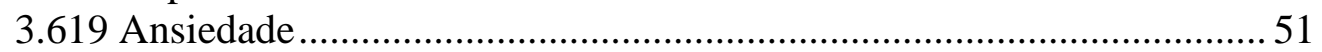

3.62 Resultados Relativos ao Grupo Exposto ....................................................... 53

3.621 Índices de Exposição............................................................................ 53

3.622 Tendinite ……………………………………………………….... 55

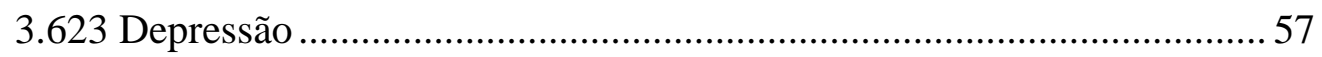

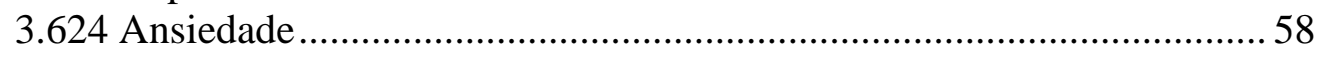

3.625 Uso de Medicamentos Psicotrópicos ........................................................60

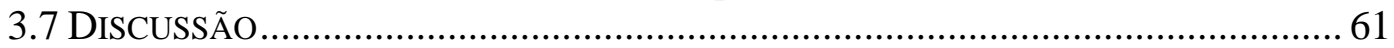

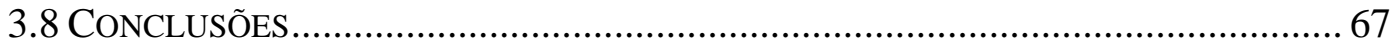

4. AVALIAÇÃO NEUROPSICOLÓGICA DE PACIENTES DIABÉTICOS DO

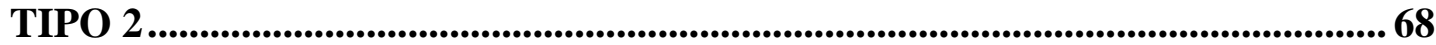

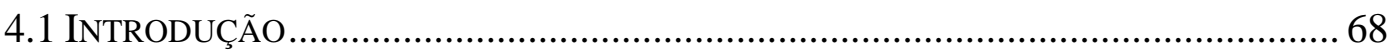

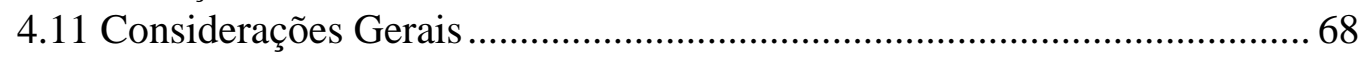

4.111 Diabetes Tipo 1 ................................................................................ 70

4.112 Diabetes Tipo 2 .............................................................................. 70

4.12 Fisiopatologia do DM e o Sistema Nervoso ……………………………..... 71

4.13 Retinopatia Diabética ................................................................................ 73

4.14 DM Tipo 2 e a Avaliação Neuropsicológica................................................ 74

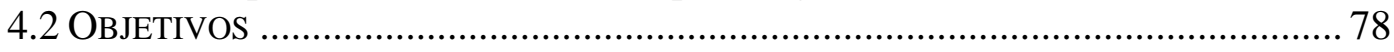

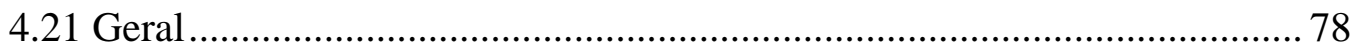

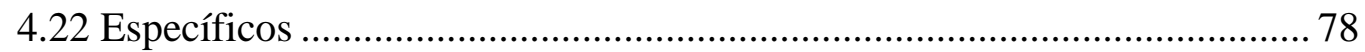

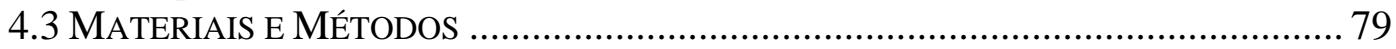

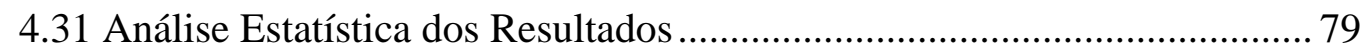

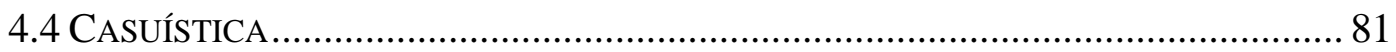

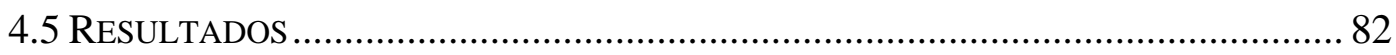

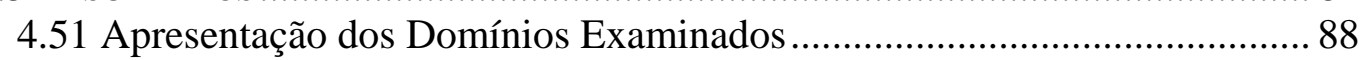

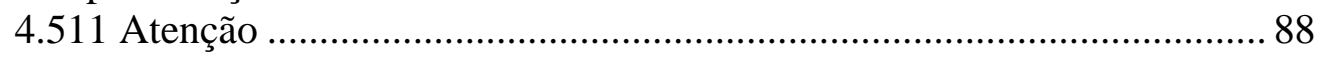

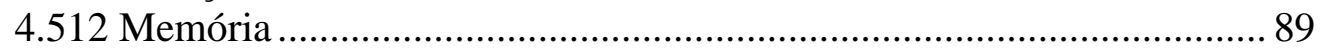

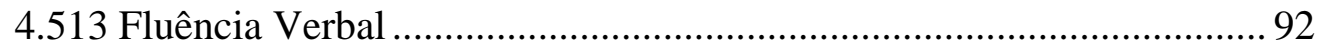

4.514 Destreza Manual................................................................................. 93

4.515 Função Viso-motora........................................................................... 94

4.516 Funções Executivas............................................................................. 95

4.517 Conhecimento Semântico................................................................... 97

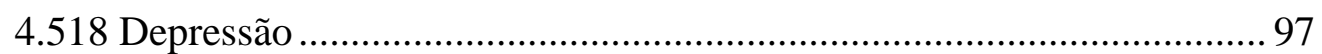

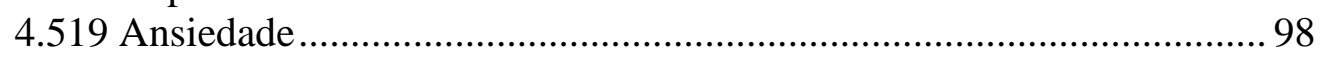

6.42 Resultados Relativos ao Grupo Diabético.................................................... 98 


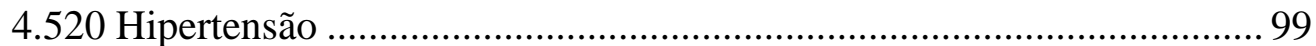

4.521 Depressão e Ansiedade .................................................................... 100

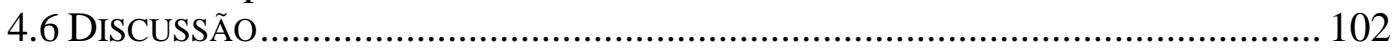

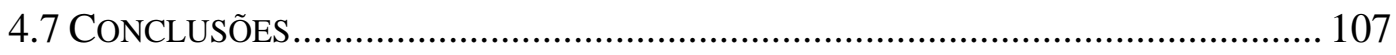

8. REFERÊNCIAS BIBLIOGRÁFICAS .......................................................... 108

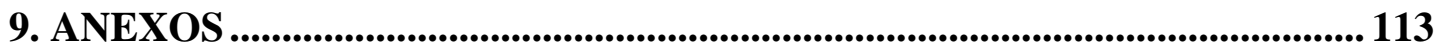

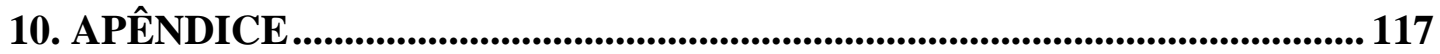




\section{RESUMO}

Zachi, E.C. Avaliação neuropsicológica de pacientes expostos ao vapor de mercúrio e de pacientes diabéticos do tipo 2. São Paulo, 2005. Dissertação (Mestrado). Instituto de Psicologia. Universidade de São Paulo.

Exposição a substâncias tóxicas e distúrbios metabólicos são fatores que afetam as funções neuropsicológicas. Foram realizados 2 estudos descritivos com os objetivos de verificar a possibilidade de disfunções neuropsicológicas em indivíduos com histórico de exposição ocupacional ao vapor de mercúrio e em pacientes diabéticos do tipo 2 sem diagnóstico de retinopatia, em ambos os casos, comparados com controles. A bateria neuropsicológica incluiu testes de atenção (Dígitos), controle inibitório (teste de stroop), memória verbal (teste de Buschke) e visual (Reprodução Visual), destreza manual (Grooved Pegboard), fluência verbal (FAS), habilidade viso-motora (Cubos), funções executivas (teste de Wisconsin), conhecimento semântico (Vocabulário) e sintomas de depressão (Inventário Beck de Depressão) e ansiedade (Inventário de Ansiedade Traço-Estado). Adotou-se $p<0,05$ como nível de significância. As avaliações neuropsicológicas de 26 extrabalhadores de fábricas de lâmpadas de mercúrio foram comparadas com 20 controles. Os ex-trabalhadores têm diagnóstico de mercurialismo crônico ocupacional, foram expostos ao vapor de mercúrio no trabalho durante 10,2 $\pm 3,8$ anos e estão afastados da função há $6 \pm 4,7$ anos. A concentração de mercúrio urinário medida um ano após o afastamento da exposição teve média de 1,8 $\pm 0,9$ $\mu \mathrm{g} / \mathrm{gCr}$. Comparados com os controles, os ex-trabalhadores demonstraram pior desempenho no teste de Stroop partes $1(p=0,004)$ e $2(0,010)$, no teste de Buschke para recuperação de longo prazo $(p=0,028)$, armazenamento de longo prazo $(p=0,045)$, recuperação consistente longo prazo $(p=0,006)$, e recuperação tadia $(p=0,008)$, fluência verbal $(p=0,010)$ e no Grooved Pegboard tanto para a mão dominante $(p=0,019)$ quanto a não dominante $(p=0,008)$. Os escores de depressão, de estado e traço de ansiedade foram significantemente superiores aos do grupo controle $(p<0,001)$. Os indivíduos com histórico de exposição ao vapor de mercúrio demonstraram redução da velocidade de processamento de informações e déficits de recuperação espontânea de informações verbais, fluência verbal, função motora, além de sintomas de depressão e ansiedade. Os escores altos de depressão e ansiedade são esperados em indivíduos com mercurialismo crônico, mas também podem se associar a problemas psicosociais relacionados ao desemprego. O outro estudo comparou o desempenho neuropsicológico de 19 pacientes diabéticos sem diagnóstico de retinopatia (avaliada através de exame de fundo de olho) e 20 sujeitos controles não diabéticos. Os pacientes têm diabetes há $8,2 \pm 8,1$ anos, média de hemoglobina glicada $\left(\mathrm{HbA}_{1 \mathrm{C}}\right)$ de $7 \pm 1,3 \%$, não fazem uso de insulina como tratamento, não manifestam queixas de neuropatia e apresentam valores de microalbuminúria dentro dos limites de normalidade. Nove $(47 \%)$ são hipertensos. Não foram encontradas diferenças significantes $(p<0,05)$ entre pacientes diabéticos e sujeitos controles em quaisquer medidas realizadas. Os resultados sugerem que o diabetes tipo 2 não se associa diretamente aos déficits neuropsicológicos. Há a possibilidade de que as alterações cognitivas e de humor observadas em pacientes diabéticos do tipo $2 \mathrm{em}$ estudos prévios estejam relacionadas à presença de complicações como retinopatia, hipoglicemia ou neuropatia com sinais clínicos. 


\section{ABSTRACT}

Zachi, E.C. Neuropsychological assessments of patients exposed to mercury vapor and of type 2 diabetic patients. São Paulo, 2005. MD dissertation. Instituto de Psicologia. Universidade de São Paulo.

Neuropsychological function is known to be affected by exposure to toxic substances and metabolic disorders. Two descriptive studies were performed. The aim was to examine possible neuropsychological dysfunction in individuals with history of occupational exposure to mercury vapor, and in type 2 diabetic patients without retinopathy, in comparison with controls. The neuropsychological assessment included measures of attention (WMS Digit Span), inhibitory control (Stroop Interference Test), verbal memory (Buschke Selective Reminding Test), visual memory (WMS Visual Reproduction), manual dexterity (Grooved Pegboard), verbal fluency (FAS), visuomotor ability (WAIS Block Design), executive function (Wisconsin Card Sorting Test), verbal knowledge (WAIS Vocabulary), and depression (Beck Depression Inventory) and anxiety (State-Trait Anxiety Inventory) symptoms. $\quad \mathrm{P}<0.05$ was taken as significance level. Neuropsychological assessments of 26 fluorescent lamp ex-workers with chronic mercurialism diagnosis who had been exposed to mercury vapor for $10.2 \pm 3.8$ years were compared with 20 controls. The time since the cessation of exposure was $6 \pm 4.7$ years and the mean urinary mercury concentration was $1.8 \pm 0.9 \mu \mathrm{g} / \mathrm{gCr}$. Compared with the controls, the ex-workers performed worse on the Stroop Test part $1(p=0.004)$ and $2(0.010)$, SRT long term recall $(p=0.028)$, long term storage $(p=0.045)$, consistent long term recall $(p=0.006)$, and delayed recall $(p=0.008)$, FAS $(p=0.010)$ and Grooved Pegboard dominant hand $(p=0.019)$ and nondominant hand $(p=0.008)$. Their depression, anxiety state and trait scores were higher than control's $(p<0.001)$. Individuals with history of exposure to mercury vapor presented slowed processing speed and verbal memory spontaneous recall, verbal fluency and motor function impairment along with symptoms of depression and anxiety. The high scores on depression and anxiety are expected in chronic mercurialism and may be also associated with psychosocial problems related to unemployment. The other study compared the neuropsychological performances of 19 diabetic patients without retinopathy diagnosis (assessed by eye fundus examination) with 20 nondiabetic control subjects. The patients had diabetes for $8.2 \pm 8.1$ years and their recent glycaemic control levels $\left(\mathrm{HbA}_{1 \mathrm{c}}\right)$ mean was $7 \pm 1.3 \%$. Other diabetic group's characteristics included non-insulin treatment, no neuropathy complaints, normal microalbumin urine tests, and $9(47 \%)$ hypertensive patients. No significant $(p<0.05)$ differences were found between the diabetic and control groups on any measure. The results suggest that type 2 diabetes is not directly related to significantly neuropsychological alterations. It is possible that cognitive decrements and mood alterations among type 2 diabetic patients described in previous studies are associated with the presence of complications such as retinopathy, hypoglicaemia, or even neuropathy with clinical signs. 


\section{LISTA DE FIGURAS}

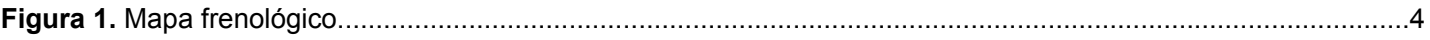

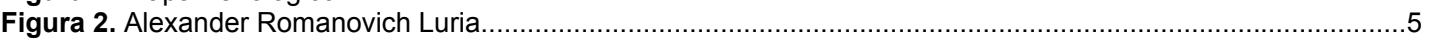

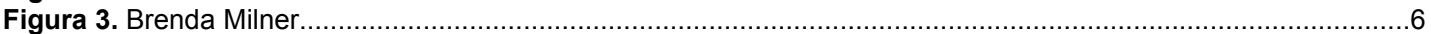

Figura 4. Imagem de Hermes por Giovanni Battista Tiepolo (1696-1770) .....................................................10

Figura 5. Boneco do personagem "chapeleiro" de Walt Disney, à direita …..................................................15

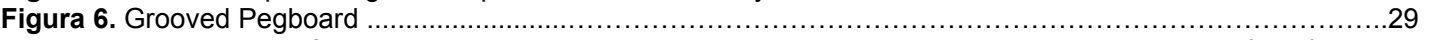

Figura 7. Modelo de gráfico mediante a apresentação da distribuição dos dados com a mediana, $1^{\circ}$ e $3^{\circ}$ quartil e

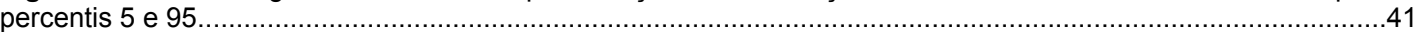

Figura 8. Mediana, $1^{\circ}$ e $3^{\circ}$ quartis, percentil 5 e 95 dos dados brutos obtidos pelo grupo exposto ao vapor de $\mathrm{Hg}^{0} \mathrm{e}$

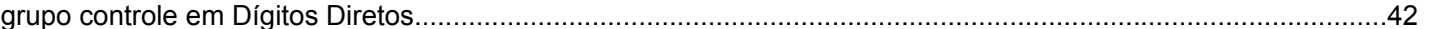
Figura 9. Mediana, $1^{\circ}$ e $3^{\circ}$ quartis, percentil 5 e 95 dos dados brutos obtidos pelo grupo exposto ao vapor de $\mathrm{Hg}^{0}$ e

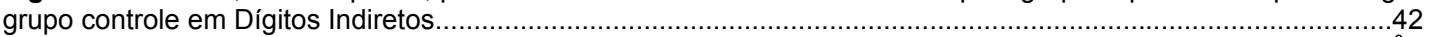
Figura 10. Mediana, $1^{\circ}$ e $3^{\circ}$ quartis, percentil 5 e 95 dos tempos obtidos pelo grupo exposto ao vapor de $\mathrm{Hg}^{0}$ e

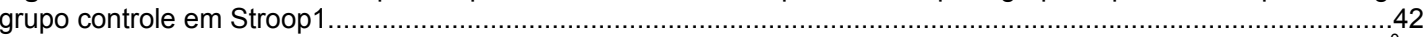
Figura 11. Mediana, $1^{\circ}$ e $3^{\circ}$ quartis, percentil 5 e 95 dos tempos obtidos pelo grupo exposto ao vapor de $\mathrm{Hg}^{0}$ e

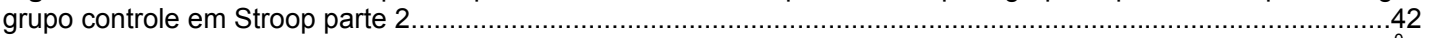
Figura 12. Mediana, $1^{\circ}$ e $3^{\circ}$ quartis, percentil 5 e 95 dos tempos obtidos pelo grupo exposto ao vapor de $\mathrm{Hg}^{0} \mathrm{e}$ grupo controle em Stroop parte 3............................................................................................4 Figura 13. Mediana, $1^{\circ}$ e $3^{\circ}$ quartis, percentil 5 e 95 dos dados brutos obtidos pelo grupo exposto ao vapor de $\mathrm{Hg}^{0}$ e grupo controle no Efeito Stroop....................................................................................................4 43 Figura 14. Mediana, $1^{\circ}$ e $3^{\circ}$ quartis, percentil 5 e 95 dos escores brutos obtidos pelo grupo exposto ao vapor de $\mathrm{Hg}^{0}$ e grupo controle no SRT para o Total de Recuperação............................................................................4 Figura 15. Mediana, $1^{\circ}$ e $3^{\circ}$ quartis, percentil 5 e 95 dos escores brutos obtidos pelo grupo exposto ao vapor de $\mathrm{Hg}^{0}$ e grupo controle no SRT para Recuperação de Longo Prazo...................................................................4 Figura 16. Mediana, $1^{\circ}$ e $3^{\circ}$ quartis, percentil 5 e 95 dos escores brutos obtidos pelo grupo exposto ao vapor de $\mathrm{Hg}^{0}$ e grupo controle no SRT em Armazenamento de Longo Prazo..............................................................4 Figura 17. Mediana, $1^{\circ}$ e $3^{\circ}$ quartis, percentil 5 e 95 dos escores brutos obtidos pelo grupo exposto ao vapor de $\mathrm{Hg}^{0}$ e grupo controle no SRT em Recuperação Consistente de Longo

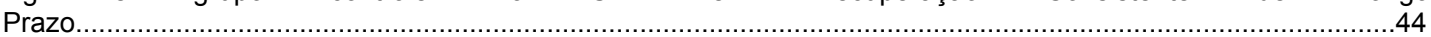
Figura 18. Mediana, $1^{\circ}$ e $3^{\circ}$ quartis, percentil 5 e 95 dos escores brutos obtidos pelo grupo exposto ao vapor de $\mathrm{Hg}^{\circ}$ e grupo controle no SRT em Recuperação Randômica de Longo

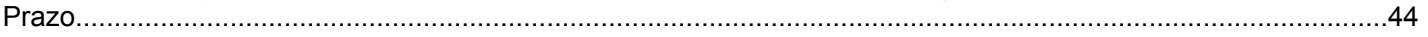

Figura 19. Mediana, $1^{\circ}$ e $3^{\circ}$ quartis, percentil 5 e 95 dos escores brutos obtidos pelo grupo exposto ao vapor de

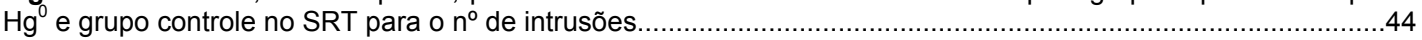
Figura 20. Mediana, $1^{\circ}$ e $3^{\circ}$ quartis, percentil 5 e 95 dos escores brutos obtidos pelo grupo exposto ao vapor de $\mathrm{Hg}^{0}$ e grupo controle no SRT em Recuperação Tardia............................................................................4 Figura 21. Mediana, $1^{\circ}$ e $3^{\circ}$ quartis, percentil 5 e 95 dos escores brutos obtidos pelo grupo exposto ao vapor de $\mathrm{Hg}^{0}$ e grupo controle no SRT para o Total de Reconhecimento...................................................................44 Figura 22. Mediana, $1^{\circ}$ e $3^{\circ}$ quartis, percentil 5 e 95 dos escores brutos obtidos pelo grupo exposto ao vapor de $\mathrm{Hg}^{0}$ e grupo controle em Reprodução Visual Imediata................................................................................. Figura 23. Mediana, $1^{\circ}$ e $3^{\circ}$ quartis, percentil 5 e 95 dos escores brutos obtidos pelo grupo exposto ao vapor de $\mathrm{Hg}^{0}$ e grupo controle em Reprodução Visual Tardia........................................................................................45 Figura 24. Mediana, $1^{\circ}$ e $3^{\circ}$ quartis, percentil 5 e 95 dos escores brutos obtidos pelo grupo exposto ao vapor de $\mathrm{Hg}^{\circ}$ e grupo controle em FAS para 0 total de palavras emitidas iniciadas com a letra

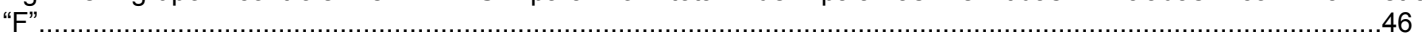

Figura 25. Mediana, $1^{\circ}$ e $3^{\circ}$ quartis, percentil 5 e 95 dos escores brutos obtidos pelo grupo exposto ao vapor de $\mathrm{Hg}^{0}$ e grupo controle em FAS para $\mathrm{O}$ total de palavras emitidas iniciadas com a letra

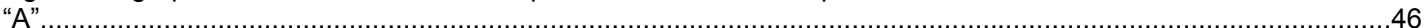
Figura 26. Mediana, $1^{\circ}$ e $3^{\circ}$ quartis, percentil 5 e 95 dos escores brutos obtidos pelo grupo exposto ao vapor de $\mathrm{Hg}^{0}$ e grupo controle em FAS para o total de palavras emitidas iniciadas com a letra

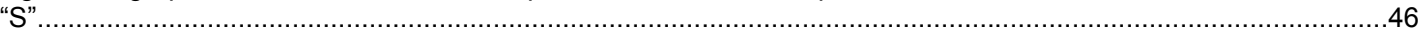
Figura 27. Mediana, $1^{\circ}$ e $3^{\circ}$ quartis, percentil 5 e 95 dos escores brutos obtidos pelo grupo exposto ao vapor de $\mathrm{Hg}^{0} \mathrm{e}$ grupo controle em FAS para $\mathrm{O}$ total de palavras emitidas no

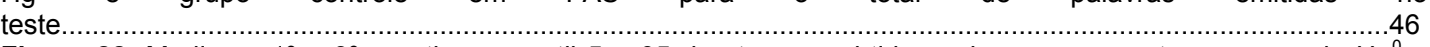
Figura 28. Mediana, $1^{\circ}$ e $3^{\circ}$ quartis, percentil 5 e 95 dos tempos obtidos pelo grupo exposto ao vapor de $\mathrm{Hg}^{0}$ e grupo controle em Grooved Pegboard para a mão dominante...................................................................47 Figura 29. Mediana, $1^{\circ}$ e $3^{\circ}$ quartis, percentil 5 e 95 dos tempos obtidos pelo grupo exposto ao vapor de $\mathrm{Hg}^{0} \mathrm{e}$ grupo controle em Grooved Pegboard para a mão não dominante................................................................47 Figura 30. Mediana, $1^{\circ}$ e $3^{\circ}$ quartis, percentil 5 e 95 dos escores brutos obtidos pelo grupo exposto ao vapor de $\mathrm{Hg}^{0}$ e grupo controle em Cubos Figura 31. Mediana, $1^{\circ}$ e $3^{\circ}$ quartis, percentil 5 e 95 dos escores brutos obtidos pelo grupo exposto ao vapor de $\mathrm{Hg}^{0}$ e grupo controle no teste de Wisconsin para o total de erros......................................................................48 Figura 32. Mediana, $1^{\circ}$ e $3^{\circ}$ quartis, percentil 5 e 95 dos escores brutos obtidos pelo grupo exposto ao vapor de $\mathrm{Hg}^{\circ}$ e grupo controle no teste de Wisconsin para $0 \mathrm{n}^{\circ}$ de respostas

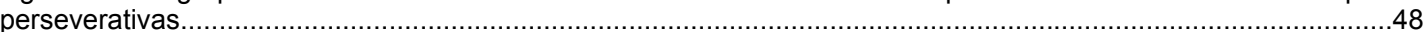
Figura 33. Mediana, $1^{\circ}$ e $3^{\circ}$ quartis, percentil 5 e 95 dos escores brutos obtidos pelo grupo exposto ao vapor de $\mathrm{Hg}^{0} \mathrm{e}$ grupo controle no teste de Wisconsin para erros

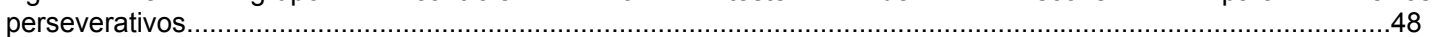


Figura 34. Mediana, $1^{\circ}$ e $3^{\circ}$ quartis, percentil 5 e 95 dos escores brutos obtidos pelo grupo exposto ao vapor de $\mathrm{Hg}^{\mathrm{O}} \mathrm{e}$ grupo controle no teste de Wisconsin para erros não

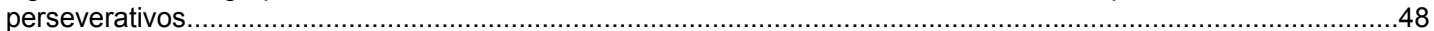

Figura 35. Mediana, $1^{\circ}$ e $3^{\circ}$ quartis, percentil 5 e 95 dos escores brutos obtidos pelo grupo exposto ao vapor de $\mathrm{Hg}^{0}$ e grupo controle no teste de Wisconsin para $0 \mathrm{n}^{\circ}$ de respostas de nível

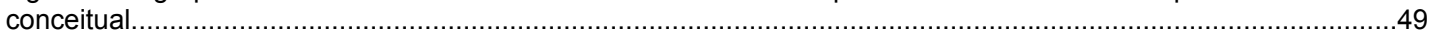

Figura 36. Mediana, $1^{\circ}$ e $3^{\circ}$ quartis, percentil 5 e 95 dos escores brutos obtidos pelo grupo exposto ao vapor de $\mathrm{Hg}^{0}$ e grupo controle no teste de Wisconsin para 0 n $n^{\circ}$ categorias

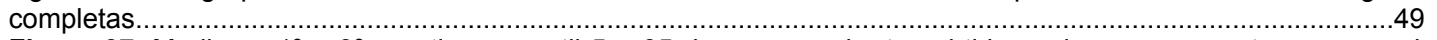
Figura 37. Mediana, $1^{\circ}$ e $3^{\circ}$ quartis, percentil 5 e 95 dos escores brutos obtidos pelo grupo exposto ao vapor de $\mathrm{Hg}^{0}$ e grupo controle no teste de Wisconsin para $0 \mathrm{n}^{\circ}$ de tentativas para completar a $1^{\circ}$

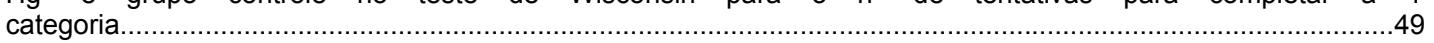
Figura 38. Mediana, $1^{\circ}$ e $3^{\circ}$ quartis, percentil 5 e 95 dos escores brutos obtidos pelo grupo exposto ao vapor de $\mathrm{Hg}^{0}$ e grupo controle no teste de Wisconsin para 0 n ${ }^{\circ}$ de perdas de

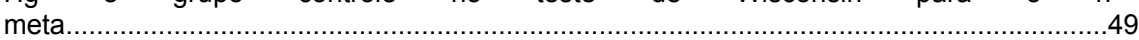

Figura 39. Mediana, $1^{\circ}$ e $3^{\circ}$ quartis, percentil 5 e 95 dos escores brutos obtidos pelo grupo exposto ao vapor de $\mathrm{Hg}^{0}$ e grupo controle em Vocabulário.

Figura 40. Mediana, $1^{\circ}$ e $3^{\circ}$ quartis, percentil 5 e 95 dos escores brutos obtidos pelo grupo exposto ao vapor de $\mathrm{Hg}^{0}$ e grupo controle no BDI.................................................51

Figura 41. Mediana, $1^{\circ}$ e $3^{\circ}$ quartis, percentil 5 e 95 dos escores brutos obtidos pelo grupo exposto ao vapor de $\mathrm{Hg}^{0}$ e grupo controle no IDATE para estado de ansiedade.................51

Figura 42. Mediana, $1^{\circ}$ e $3^{\circ}$ quartis, percentil 5 e 95 dos escores brutos obtidos pelo grupo exposto ao vapor de $\mathrm{Hg}^{0}$ e grupo controle no IDATE para traço de ansiedade....................51

Figura 43. Mediana, $1^{\circ}$ e $3^{\circ}$ quartis, percentil 5 e 95 dos tempos obtidos pelos grupos de pacientes expostos com e sem diagnóstico de tendinite no Grooved Pegboard para a mão Figura 44 . Mediana, $1^{\circ}$ e $3^{\circ}$ quartis, percentil 5 e 95 dos tempos obtidos pelos grupos de pacientes expostos com e sem diagnóstico de tendinite no Grooved Pegboard para a mão não

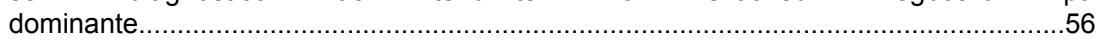

Figura 45. Mediana, $1^{\circ}$ e $3^{\circ}$ quartis, percentil 5 e 95 dos tempos obtidos pelos grupos de pacientes expostos com e sem diagnóstico de tendinite em Cubos..................................57

Figura 46. Mediana, $1^{\circ}$ e $3^{\circ}$ quartis, percentil 5 e 95 dos escores brutos obtidos pelo grupo de pacientes diabéticos $\begin{array}{llllllll}\text { do } & \text { tipo } & 2 & \mathrm{e} & 0 & \text { grupo } & \text { controle } & \mathrm{em}\end{array}$

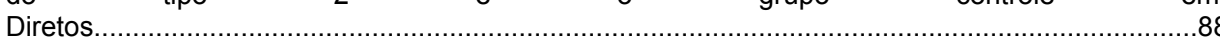

Figura 47. Mediana, $1^{\circ}$ e $3^{\circ}$ quartis, percentil 5 e 95 dos escores brutos obtidos pelo grupo de pacientes diabéticos $\begin{array}{llllllll}\text { do } & \text { tipo } & 2 & \mathrm{e} & 0 & \text { grupo } & \text { controle } & \mathrm{em}\end{array}$

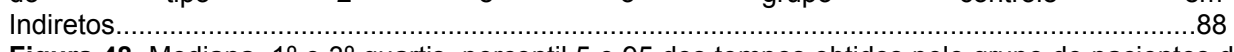

Figura 48. Mediana, $1^{\circ}$ e $3^{\circ}$ quartis, percentil 5 e 95 dos tempos obtidos pelo grupo de pacientes diabéticos do tipo 2 e $\quad 0 \quad$ grupo $\quad$ controle $\quad$ em $\quad$ Stroop

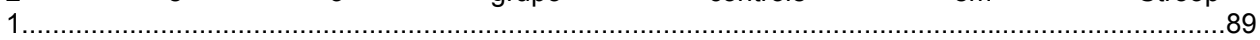

Figura 49. Mediana, $1^{\circ}$ e $3^{\circ}$ quartis, percentil 5 e 95 dos tempos obtidos pelo grupo de pacientes diabéticos do tipo 2 e $\quad$ o $\quad$ grupo $\quad$ controle em $\quad$ Stroop

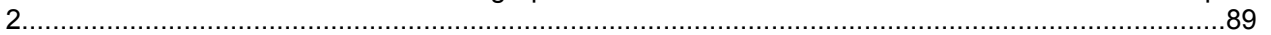

Figura 50. Mediana, $1^{\circ}$ e $3^{\circ}$ quartis, percentil 5 e 95 dos tempos obtidos pelo grupo de pacientes diabéticos do tipo 2 e $\quad$ o $\quad$ grupo $\quad$ controle $\quad$ em $\quad$ Stroop

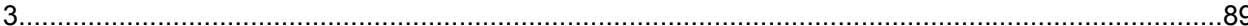

Figura 52. Mediana, $1^{\circ}$ e $3^{\circ}$ quartis, percentil 5 e 95 dos escores brutos obtidos pelo grupo de pacientes diabéticos $\begin{array}{llllllllll}\text { do } & \text { tipo } & 2 & \mathrm{e} & \mathrm{O} & \text { grupo } & \text { controle } & \text { no } & \text { SRT } & \text { em }\end{array}$

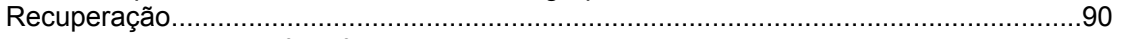

Figura 53. Mediana, $1^{\circ}$ e $3^{\circ}$ quartis, percentil 5 e 95 dos escores brutos obtidos pelo grupo de pacientes diabéticos do tipo 2 e o grupo controle no SRT em Total de Recuperação de Longo Prazo.....................................................................90

Figura 54. Mediana, $1^{\circ}$ e $3^{\circ}$ quartis, percentil 5 e 95 dos escores brutos obtidos pelo grupo de pacientes diabéticos do tipo 2 e o grupo controle no SRT em Armazenamento de Longo Prazo.......................................................................................90

Figura 55. Mediana, $1^{\circ}$ e $3^{\circ}$ quartis, percentil 5 e 95 dos escores brutos obtidos pelo grupo de pacientes diabéticos

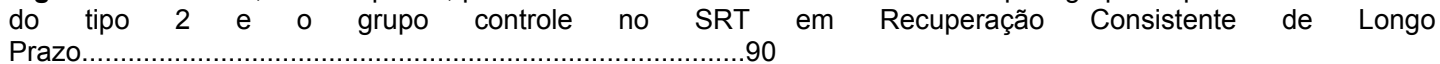

Figura 56. Mediana, $1^{\circ}$ e $3^{\circ}$ quartis, percentil 5 e 95 dos escores brutos obtidos pelo grupo de pacientes diabéticos do tipo 2 e o grupo controle no SRT em Recuperação Randômica de Longo Prazo...........................................................................91

Figura 57. Mediana, $1^{\circ}$ e $3^{\circ}$ quartis, percentil 5 e 95 dos escores brutos obtidos pelo grupo de pacientes diabéticos do tipo 2 e 0 grupo controle no $\quad$ SRT $\quad$ para $0 \quad n^{\circ}$ de intrusões......................................................................................... 91

Figura 58. Mediana, $1^{\circ}$ e $3^{\circ}$ quartis, percentil 5 e 95 dos escores brutos obtidos pelo grupo de pacientes diabéticos do tipo 2 e $\quad 0 \quad$ grupo $\quad$ controle no $\quad$ SRT em Tardia.............................................................................................. 91

Figura 59. Mediana, $1^{\circ}$ e $3^{\circ}$ quartis, percentil 5 e 95 dos escores brutos obtidos pelo grupo de pacientes diabéticos do tipo 2 e $\quad 0$ grupo controle no $\quad$ SRT em Reconhecimento...........................................................................................99

Figura 60. Mediana, $1^{\circ}$ e $3^{\circ}$ quartis, percentil 5 e 95 dos escores brutos obtidos pelo grupo de pacientes diabéticos

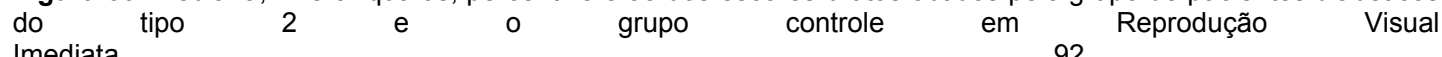


Figura 61. Mediana, $1^{\circ}$ e $3^{\circ}$ quartis, percentil 5 e 95 dos escores brutos obtidos pelo grupo de pacientes diabéticos do tipo 2 e 0 grupo controle em Reprodução Visual

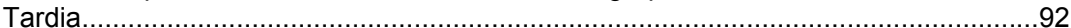

Figura 62. Mediana, $1^{\circ}$ e $3^{\circ}$ quartis, percentil 5 e 95 dos escores brutos obtidos pelo grupo de pacientes diabéticos do tipo 2 e o grupo controle em FAS para o total de palavras geradas com a letra "F"..........................................................................93

Figura 63. Mediana, $1^{\circ}$ e $3^{\circ}$ quartis, percentil 5 e 95 dos escores brutos obtidos pelo grupo de pacientes diabéticos do tipo 2 e o grupo controle em FAS para o total de palavras geradas com a letra "A"..........................................................................93

Figura 64. Mediana, $1^{\circ}$ e $3^{\circ}$ quartis, percentil 5 e 95 dos escores brutos obtidos pelo grupo de pacientes diabéticos do tipo 2 e 0 grupo controle em FAS para o total de palavras geradas com a letra "S".....................................................................93

Figura 65. Mediana, $1^{\circ}$ e $3^{\circ}$ quartis, percentil 5 e 95 dos escores brutos obtidos pelo grupo de pacientes diabéticos do tipo 2 e o grupo controle em FAS para o total de palavras geradas no teste.....................................................................................93

Figura 66. Mediana, $1^{\circ}$ e $3^{\circ}$ quartis, percentil 5 e 95 dos tempos obtidos pelo grupo de pacientes diabéticos e o grupo controle em Grooved Pegboard para a mão dominante......................................................................................................

Figura 67. Mediana, $1^{\circ}$ e $3^{\circ}$ quartis, percentil 5 e 95 dos tempos obtidos pelo grupo de pacientes diabéticos e o grupo controle em Grooved Pegboard para a mão não $\begin{array}{lcccccc}\text { Figura } 68 . & \text { Mediana, } & 1^{\circ} \text { e } & 3^{\circ} & \text { quartis, percentil } 5 \text { e } & 95 & \text { dos escores brutos obtidos pelo grupo de pacientes diabéticos } \\ \text { do } & \text { tipo } & 2 & \text { e } & 0 & \text { grupo } & \text { controle }\end{array}$

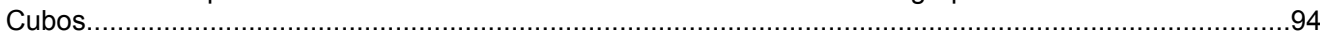

Figura 69. Mediana, $1^{\circ}$ e $3^{\circ}$ quartis, percentil 5 e 95 dos escores brutos obtidos pelo grupo de pacientes diabéticos do tipo 2 e 0 grupo controle no teste de Wisconsin para 0 total de erros.....................................................................................95

Figura 70. Mediana, $1^{\circ}$ e $3^{\circ}$ quartis, percentil 5 e 95 dos escores brutos obtidos pelo grupo de pacientes diabéticos do tipo 2 e o grupo controle no teste de Wisconsin para 0 total de respostas perseverativas.....................................................................95

Figura 71. Mediana, $1^{\circ}$ e $3^{\circ}$ quartis, percentil 5 e 95 dos escores brutos obtidos pelo grupo de pacientes diabéticos do tipo 2 e 0 grupo controle no teste de Wisconsin para erros Figura 72. Mediana, $1^{\circ}$ e $3^{\circ}$ quartis, percentil 5 e 95 dos escores brutos obtidos pelo grupo de pacientes diabéticos do tipo 2 e o grupo controle no teste de Wisconsin para erros não

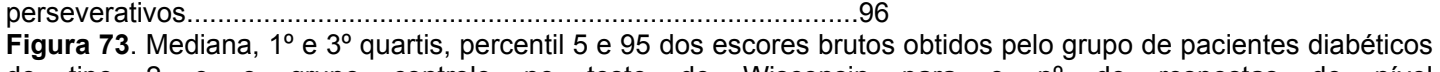
do tipo 2 e o grupo controle no teste de Wisconsin para $0 n^{\circ}$ de respostas de nível conceitual.................................................................96

Figura 74. Mediana, $1^{\circ}$ e $3^{\circ}$ quartis, percentil 5 e 95 dos escores brutos obtidos pelo grupo de pacientes diabéticos do tipo 2 e 0 grupo controle no teste de Wisconsin para $0 n^{\circ}$ de categorias

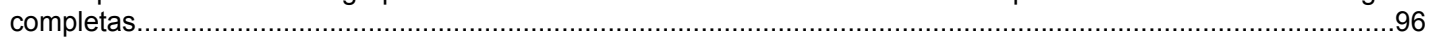
Figura 75. Mediana, $1^{\circ}$ e $3^{\circ}$ quartis, percentil 5 e 95 dos escores brutos obtidos pelo grupo de pacientes diabéticos do tipo 2 e o grupo controle no teste de Wisconsin para $0 \mathrm{n}^{\circ}$ de tentativas para completar a $1^{\circ}$

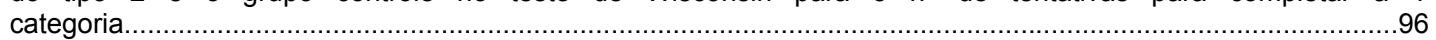
Figura 76. Mediana, $1^{\circ}$ e $3^{\circ}$ quartis, percentil 5 e 95 dos escores brutos obtidos pelo grupo de pacientes diabéticos do tipo 2 e o grupo controle no teste de Wisconsin para o $\mathrm{n}^{\circ}$ de tentativas para perdas de meta... . .96 


\section{LISTA DE TABELAS}

Tabela 1. Referências de publicações cujos resultados apontam para a existência ou ausência de rebaixamento no desempenho da função neuropsicológica examinada .......... 18

Tabela 2. Instrumentos utilizados previamente na literatura científica para a avaliação de pacientes com histórico de intoxicação por vapor de mercúrio ou diabetes e referência dos estudos em que foram utilizados

Tabela 3. Características gerais dos participantes expostos ao mercúrio e grupo

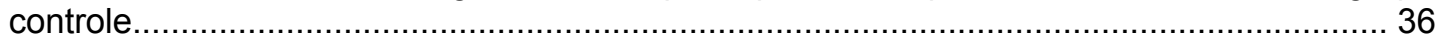

Tabela 4. Variáveis específicas do grupo exposto ao vapor de $\mathrm{Hg}^{0}$................................... 38

Tabela 5. Medianas, médias, desvios e valores de $p$ referentes aos dados brutos obtidos pelos grupos exposto e controle na avaliação neuropsicológica

Tabela 6. Variáveis intragrupos com correlação significativa, coeficiente de correlação de Spearman (rS) e valor d ep.

Tabela 7. Comparação dos dados gerais e escores obtidos nos testes e inventários dos subgrupos com maior e menor tempo de exposição ao vapor de mercúrio

Tabela 8. Comparação dos dados gerais e escores obtidos nos testes e inventários dos subgrupos com maior e menor tempo de afastamento do vapor de mercúrio......

Tabela 9. Comparação dos dados gerais e escores obtidos nos testes e inventários dos subgrupos com maior e menor concentração urinária de mercúrio

Tabela 10. Comparação dos dados gerais e escores obtidos nos testes Grooved Pegboard e Cubos entre pacientes expostos com e sem diagnóstico de tendinite.

Tabela 11. Comparação dos dados gerais e escores brutos obtidos nos testes e inventários dos subgrupos com maior e menor índice de depressão

Tabela 12. Comparação dos dados gerais e escores brutos obtidos nos testes e inventários dos subgrupos com maior e menor índice de estado de ansiedade

Tabela 13. Comparação dos dados gerais e escores brutos obtidos nos testes e inventários dos subgrupos com maior e menor índice de traço de ansiedade

Tabela 14. Comparação dos dados gerais e escores brutos obtidos nos testes e inventários dos subgrupos com ou sem uso de antidepressivo e/ou ansiolítico

Tabela 15. Características gerais dos participantes diabéticos do tipo 2 e grupo controle.. 82

Tabela 16. Variáveis específicas do grupo diabético

Tabela 17. Medianas, médias, desvios e valores de $p$ referentes aos dados brutos obtidos pelos grupos diabético e controle na avaliação neuropsicológica.

Tabela 18. Teste de correlação de Spearman com resultado significativo entre variáveis intragrupos, coeficiente de correlação (rS) e valor de $p$ 86 e 87

Tabela 19. Comparação dos dados gerais e escores obtidos nos testes e inventários de pacientes diabéticos com e sem diagnóstico de hipertensão.

Tabela 20. Comparação dos dados gerais e escores obtidos nos testes e inventários de pacientes diabéticos com e sem níveis indicativos de depressão. 100 


\section{LISTA DE ABREVIATURAS}

a.C. - Antes de Cristo

BDI - Escala Beck de Depressão (Beck Depression Scale)

$\mathrm{Cr}$ - Creatinina

DM - Diabetes Mellitus

DMPS - 2,3 dimercatopropane 1 sulfanato

DMSA - ácido 2,3 dimercaptosuccinato

DP - Desvio Padrão

FAS - Teste de Fluência Verbal Fonêmica

$\mathrm{HbA}^{1} \mathrm{C}$ - Hemoglobina Glicada ou Glicada

$\mathrm{Hg}^{0}$ - Mercúrio Metálico ou Elementar

$\mathrm{Hg}^{+1}-$ Mercúrio Monovalente

$\mathrm{Hg}^{+2}$ - Mercúrio Divalente

HgU - Concentração Urinária de Mercúrio

IDATE - Inventário de Ansiedade Traço-Estado

M - Média

Md - Mediana

PET - Tomografia por Emissão de Pósitrons

RM - Ressonância Magnética

SNA - Sistema Nervoso Autônomo

SNC - Sistema Nervoso Central

SNP - Sistema Nervoso Periférico

SPECT - Tomografia por Emissão de Fóton Único

SRT - Buschke Selective Reminding Test

TC - Tomografia Computadorizada

UFPA - Universidade Federal do Pará

USP - Universidade de São Paulo

WAIS-R - Escala Wechsler de Inteligência para Adultos Revisada (Wechsler Adult Intelligence Scale - Revised)

WMS-R - Escala Wechsler de Memória Revisada (Wechsler Memory Scale - Revised) 


\section{Considerações Gerais SOBRE $O$ ESTUDO}

Este estudo é parte de um projeto temático em andamento e desenvolvido em conjunto pela Universidade de São Paulo (USP) e a Universidade Federal do Pará (UFPA), visando à investigação de patologias e condições neurodegenerativas quanto aos efeitos sobre as funções neuropsicológicas, no sistema visual humano e em modelos animais.

Os subprojetos desenvolvidos incluem pesquisas sobre a possibilidade e caracterização de alterações neuropsicológicas (disfunções cognitivas, psicomotoras, de linguagem e distúrbios do humor) e perdas visuais (eletrofisiológicas, de visão de cores, contrastes e campo visual) associadas a intoxicação por mercúrio, diabetes, doença de Parkinson, distrofia muscular de Duchene, esclerose múltipla, doença de Leber e alcolismo. Os trabalhos com modelos animais envolvem o estudo da visão de tartarugas, cães e peixes, além de alterações de comportamento nestes últimos.

O presente estudo incluso no programa de mestrado constitui um dos subprojetos referidos e se restringiu à investigação dos perfis neuropsicológicos de dois grupos patológicos citados: indivíduos intoxicados com mercúrio e pacientes diabéticos do tipo 2 .

O mercúrio, apesar de conhecido como substância altamente tóxica, apresenta ampla aplicação nas áreas de garimpo para extração de ouro e no setor industrial, muitas vezes sem utilização de métodos de controle ou redução dos riscos de intoxicação. Além disso, o mercúrio inorgânico depositado no mar como resultado de processos industriais ou mesmo como parte de seu ciclo natural, após a biotransformação em metil mercúrio, ingressa na cadeia alimentar, atingindo o ser 
humano através da alimentação de peixes. Trata-se, portanto, de uma questão ambiental e de saúde publica, que necessita de investigação dos efeitos da intoxicação e meios de alerta para a população geral e autoridades responsáveis, a fim da redução ou eliminação dos problemas relacionados.

O diabetes tipo 2 corresponde a uma grave disfunção do metabolismo dos açúcares, freqüente em indivíduos a partir do 40 anos de idade e atinge milhões de pessoas no mundo. Características atuais como urbanização crescente, vida sedentária, má alimentação e ausência de exercícios físicos aliados aos fatores genéticos contribuem para o aumento da incidência desta doença crônica e da mortalidade decorrente desta, ou mesmo complicações graves. A prevalência do diabetes na população mundial e complicações relacionadas justifica a importância do conhecimento sobre seus efeitos e fisiopatologia subjacente. 


\section{INTRODUÇÃO}

\subsection{Neuropsicologia}

\subsection{Considerações Gerais}

A neuropsicologia pode ser definida como o ramo da neurociência que estuda a relação entre comportamento e o funcionamento cerebral em condições normais e patológicas, assim como os distúrbios cognitivos, emocionais e de personalidade decorrentes de lesões (Gil, 2002) ou disfunções cerebrais de natureza elétrica ou química.

A história da neuropsicologia remete ao estudo das funções cerebrais, cujos primeiros registros foram encontrados no Egito, com datas de 1700 a 1600 a.C. Os gregos foram os pioneiros na localização das atividades mentais complexas no cérebro, uma vez que Pitágoras, considerado por alguns autores o primeiro neurologista ou neuropsicológo, trouxe as observações mais remotas deste órgão como responsável pelo pensamento e pelas sensações, com áreas específicas relativas às diferentes modalidades (Feinberg \& Farah, 1997).

Posteriormente, o estudo do cérebro se estendeu ao longo dos séculos principalmente através de observações anatômicas. No século XIX, apoiada na hipótese de que as faculdades mentais e características de personalidade seriam localizadas em regiões cerebrais específicas, tornou-se popular a Frenologia, desenvolvida pelo neurologista Franz Joseph Gall (1758-1828). A Frenologia valorizou o estudo da forma do cérebro, considerando que áreas superficiais cerebrais salientes revelariam maior desenvolvimento da função mental ou maior propensão ao comportamento atribuído à região em questão. Os mapas frenológicos (figura 1) indicavam as regiões da superfície cerebral e respectiva função mental ou comportamento a que se acreditavam associados (Luria, 1973). 
Entretanto, o modelo foi amplamente questionado e abandonado por muitos pesquisadores devido à ausência de bases científicas ou observações clínicas.

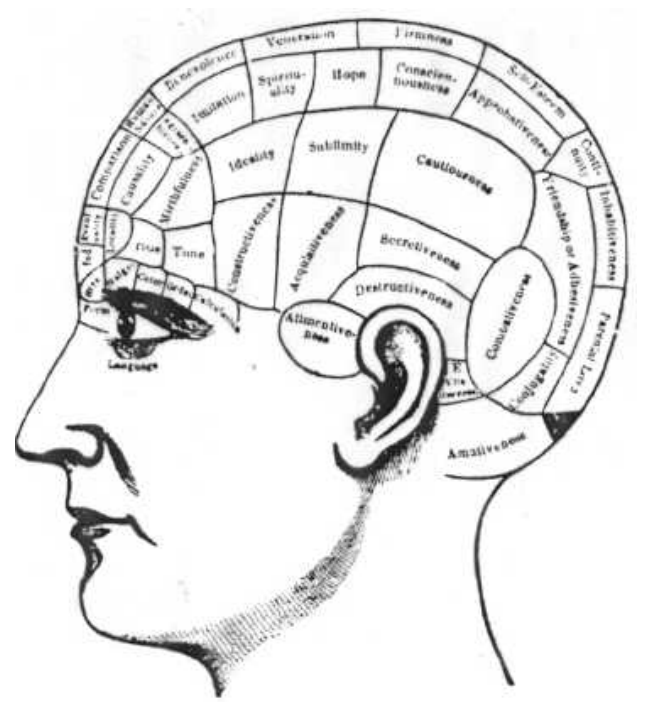

Figura 1. Mapa frenológico. (Fonte: Clarke e O’Malley, 1968)

Na segunda metade do século XIX, com tendência ainda localizacionista, porém caracterizada por pesquisas científicas e seguindo o modelo lesional, diversos estudos promoveram avanços na área da neurologia comportamental. Neste contexto, o anatomista Paul Broca (1824-1880) foi pioneiro na identificação da área cerebral envolvida na fala expressiva, ao descrever um paciente com severa dificuldade na expressão da fala, acompanhada da destruição do terço posterior do giro frontal inferior no hemisfério esquerdo, mas preservando os aspectos de compreensão da linguagem. Posteriormente em 1873, o psiquiatra Carl Wernicke (1848-1904) descreveu um caso de lesão no giro temporal superior esquerdo, em que o paciente apresentou perda da capacidade de compreensão da linguagem falada, permanecendo inalterada a habilidade de expressão da mesma (Luria, 1973).

Outro caso clássico ocorrido no século XIX e que contribuiu para o desenvolvimento da neuropsicologia corresponde ao relato do paciente Phineas 
Gage, que sobreviveu a uma lesão cerebral acidental provocada por perfuração com uma barra de ferro, lesionando a parte frontal do hemisfério esquerdo. $\mathrm{O}$ paciente demonstrou comprometimento nas habilidades de planejamento, de imaginar objetos, formas e cores, além de mudanças severas de personalidade, tornando-se um individuo agressivo, irresponsável e inadequado socialmente.

A partir do século $X X$, a tendência estritamente localizacionista da atividade mental foi questionada e a noção de "sistema funcional" foi difundida pelo neurologista soviético Alexander Romanovich Luria (1902-1978), considerado um marco para a neuropsicologia. Segundo Luria (figura 2), as atividades nervosas complexas não resultam da função de uma única região cerebral, mas envolvem a ativação dos "sistemas funcionais complexos", os quais são formados por estruturas nervosas com papéis específicos que atuam em concerto para a execução de determinada tarefa. Conforme este modelo, é fundamental a verificação de "zonas cerebrais operando em concerto na determinação de uma atividade mental complexa e respectivas contribuições de cada uma" e não a localização de áreas cerebrais específicas (Luria, 1973).

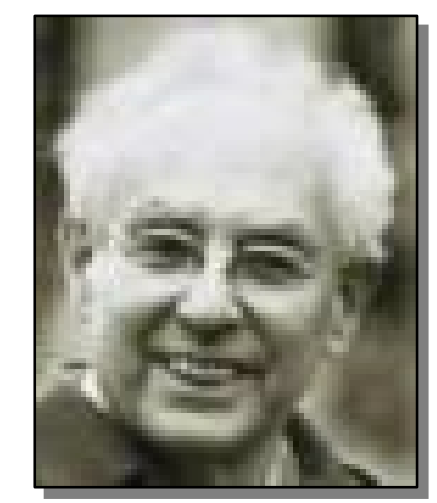

Figura 2. Alexander Romanovich Luria

Com a Segunda Guerra Mundial, intensificaram-se os estudos a partir de cérebros lesionados, com contribuições expressivas de Luria e Brenda Milner (1918-) (figura 3) pesquisadora que trouxe, na década de 60, grande perspectiva 
para a compreensão da memória e sua dissociação entre curta e longa duração, com a descrição do paciente H.M., que teve a remoção bilateral de parte do córtex temporal medial, amígdala e parte do hipocampo visando à extinção de crises epilépticas. Como seqüela, a paciente não era capaz de formar novos registros mnemônicos, não se lembrava de fatos e eventos ocorridos imediatamente antes da cirurgia, mas podia recuperar memórias anteriores (Magila \& Xavier, 2000).

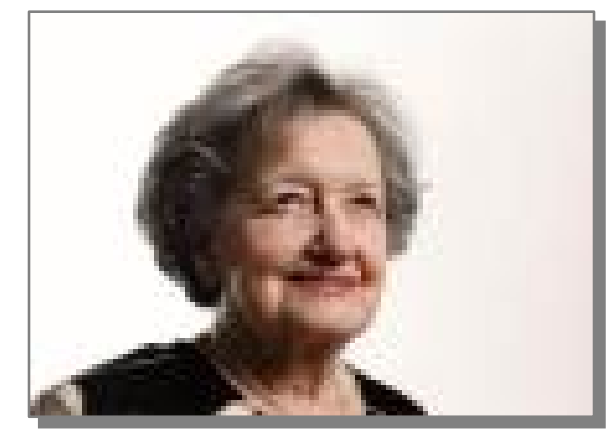

Figura 3. Brenda Milner

Verifica-se ao longo da história, que a neuropsicologia experimental resultou de avanços provenientes de estudos em pacientes únicos com distúrbios particulares (Feinberg \& Farah, 1997), importantes pela observação e descrição de alterações cerebrais e respectivas manifestações comportamentais. A verificação de que as funções mentais complexas se relacionam ao funcionamento de áreas cerebrais atuantes em concerto possibilitou a associação entre cérebro e comportamento, o que constitui a base da neuropsicologia.

O termo "neuropsicologia" foi apresentado e divulgado de maneira sistemática a partir de 1913 (Lezak, 1995). No século XX a neuropsicologia foi caracterizada por estudos do tecido cerebral quanto às diferenças morfológicas celulares entre as regiões, mapeamento através de neurocirurgias, desenvolvimento de medidas quantitativas de desempenho e de novas tecnologias como a tomografia computadorizada (TC), ressonância magnética (RM), tomografia por emissão de fóton único (SPECT) e tomografia por emissão de pósitrons (PET), que possibilitaram a observação do cérebro in vivo e em pleno funcionamento, o 
que têm contribuído para o avanço da neuropsicologia, assim como das demais neurociências.

No Brasil, a titulação de profissionais especializados em neuropsicologia foi reconhecida em 2004 através da resolução n 002/2004 do Conselho Federal de Psicologia, segundo a qual o neuropsicólogo "atua no diagnóstico, no tratamento e na pesquisa da cognição, emoções, comportamento e personalidade sob o enfoque da relação com o funcionamento cerebral".

\subsection{Avaliação Neuropsicológica}

A avaliação neuropsicológica é o instrumento que trata do exame das funções neuropsicológicas, que correspondem às habilidades mentais, mediadas pelo SNC e incluem processos perceptivos e motores, cognição e intelecto, linguagem, expressão emocional e comportamento social. É utilizada na identificação de alterações decorrentes de lesão ou disfunção cerebral e no diagnóstico de neuropatologias, em conjunto com os demais métodos da neurologia.

Uma vez que a manifestação das atividades mentais depende não somente de fatores biológicos, a avaliação neuropsicológica considera também fatores psicológicos, emocionais e sociais constituintes do ser humano e pode utilizar o método de comparação do desempenho neuropsicológico entre indivíduos de mesma faixa etária e em certos contextos, do mesmo sexo e/ou nível de educação formal.

As funções neuropsicológicas envolvem recepção, armazenamento e processamento de informações, além de respostas comportamentais. São freqüentemente interdependentes, trabalham em concerto e representam facetas 
de uma mesma atividade (Lezak, 1995), de modo que ás vezes se torna difícil a distinção entre as mesmas para apoio didático.

Alguns autores diferenciam as chamadas funções executivas, embora muitos as consideram como habilidades cognitivas. Incluem flexibilidade mental, capacidade de criação de novas estratégias, habilidade de julgamento e crítica de situações, além da atividade dirigida a metas, necessária para a execução de tarefas que exigem procedimentos distintos, permitindo a utilização adequada da retroalimentação enviada pelo meio, indispensável para regulação do comportamento. Mediadas principalmente pelo lobo frontal, são as funções de maior complexidade desenvolvidas no ser humano.

As finalidades da avaliação neuropsicológica incluem (Lezak, 1995):

- diagnóstico com o discernimento entre os sintomas psiquiátricos e neurológicos;

- $\quad$ avaliação do tratamento fornecido ao paciente;

- $\quad$ pesquisa para a compreensão da organização da atividade cerebral e sua transição para o comportamento, além da investigação de distúrbios específicos e alterações comportamentais

Este instrumento permite a verificação do modo como os prejuízos relacionados a estas alterações afetam o desempenho geral do indivíduo em atividades diversas e sua qualidade de vida.

Os resultados provenientes da avaliação não devem ser interpretados isoladamente, mas contemplados como um todo, uma vez que as funções cerebrais atuam em conjunto e os testes neuropsicológicos são incapazes de isolar as funções com precisão. O perfil neuropsicológico obtido através da avaliação integra informações quantitativas, isto, é, qual a esfera prejudicada e qualitativas, ou seja, como se manifesta a dificuldade e em que grau (Gouveia \& Fabrício, 2004). 
As funções neuropsicológicas são afetadas por traumas, distúrbios vasculares, metabólicos ou endócrinos, doenças degenerativas, processos infecciosos, neoplasias, privação de oxigênio e exposição a agentes tóxicos (Lezak, 1995). 


\section{Avaliação NeURopsicológica de PACIENTES EXPOSTOS AO VAPOR DE MERCÚRIO}

\subsection{Introdução}

\subsection{Considerações Gerais}

O mercúrio é um metal tóxico, prateado, apresenta-se em estado líquido na temperatura ambiente e foi utilizado em sua forma metálica por povos da Antigüidade com finalidade terapêutica e para a obtenção do ouro (Azevedo, 2003).

A denominação mercúrio decorre de uma homenagem ao planeta Mercúrio, que conforme a mitologia romana, é o mensageiro dos deuses, também o deus dos mercadores, filho de Júpiter e Maia, correspondente ao deus grego Hermes (figura 4). Os romanos o chamaram de hidrargiro (Azevedo, 2003), derivado do termo Hydrargyrum em latim, que significa prata líquida (hidro=elemento de composição que indica água e árgyros=prata) e originou a sigla $\mathrm{Hg}^{0}$ na tabela periódica dos elementos químicos (Faria, 2003).

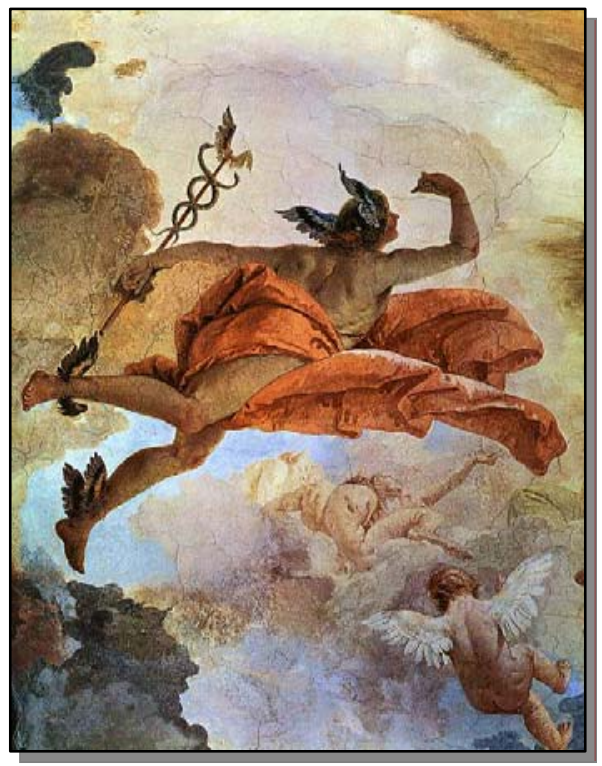

Figura 4. Imagem de Hermes por Giovanni Battista Tiepolo (1696-1770) 
$\mathrm{Na}$ Idade Média, o mercúrio foi amplamente utilizado na produção de amálgamas (ligas de metal) especialmente de prata e de ouro, mas a principal aplicação foi na alquimia, considerado o representante dos líquidos.

O uso do mercúrio e seus compostos para fins terapêuticos persistiu até o século $\mathrm{XVI}$ no tratamento de quase todas as doenças até então conhecidas. Em meados do século XVII, o mercúrio elementar foi o primeiro elemento químico a ter controle de sua utilização devido à incidência de sintomas apresentados por mineradores (Azevedo, 2003).

Na natureza, o mercúrio é encontrado em 3 formas: metálica ou elementar $\left(\mathrm{Hg}^{0}\right)$; formas iônicas ou inorgânicas, que correspondem aos sais de mercúrio derivados dos íons mercuroso e mercúrico $\left(\mathrm{Hg}^{+1}\right.$ e $\mathrm{Hg}^{+2}$, respectivamente) e os compostos orgânicos, resultantes da ação de microrganismos aquáticos sobre as modalidades metálica ou inorgânica (Satoh, 2000).

Nas formas elementar e inorgânica, o mercúrio tem ampla aplicação no setor industrial, como na metalurgia, petro-química, produção de lâmpadas, cloroálcalis, papel, amálgamas dentários, chapéus de feltro e equipamentos médicos, entre outros. O mercúrio elementar também é utilizado atualmente nas áreas de garimpo para extração de ouro, atividade que envolve alta concentração do metal no ambiente onde é realizada (Faria, 2003).

\subsection{Intoxicação por Mercúrio Metálico}

O caráter tóxico do mercúrio se deve às várias formas químicas próprias e à alta volatilidade e solubilidade em água e lipídeos, o que facilita a passagem pelos alvéolos pulmonares, pela barreira hemato-encefálica e placenta (Faria, 2003). 
A exposição ambiental, a alimentação marítima e a quantidade de amálgamas dentários constituem indicadores dos níveis de mercúrio na população geral e são de grande importância na determinação de limites de exposição que marcam os riscos para a saúde pública (Echeverria et al., 1995).

Deve-se distinguir a intoxicação pelos compostos orgânicos, mercúrio metálico e derivados inorgânicos, pois produzem sintomatologias distintas embora dados da literatura científica apontem para maior semelhança de sintomas entre as exposições aos dois últimos (Azevedo, 2003).

Após a introdução do vapor de mercúrio elementar ou inorgânico via pulmonar, a excreção se inicia quase imediatamente através dos rins. O mercúrio também é eliminado do organismo através do fígado (via bile), mucosa intestinal, glândulas sudoríparas e salivares (Agency for Toxic Substance and Disease Registry, 1992) e leite. As vias urinárias e fecal são as mais importantes para a eliminação. A maior parte do mercúrio é eliminada de 60 a 70 dias, mas os efeitos produzidos podem ser detectados por meses ou anos (Azevedo, 2003).

O sistema nervoso central é considerado o principal órgão afetado na intoxicação crônica pelo vapor de mercúrio elementar em humanos (Agency for Toxic Substance and Disease Registry, 1992; Kishi et al., 1994; Langworth, Almkvist, Söderman, \& Wikström, 1992; Vassallo et al., 1996). Além disso, a acumulação do mercúrio na célula nervosa parece persistir por toda a vida do individuo (Faria, 2003).

Conforme a legislação brasileira, as concentrações máximas de mercúrio indicadoras de normalidade são de $40 \mu \mathrm{g}$ de $\mathrm{Hg}^{0} / \mathrm{m}^{3}$ no ar e $5 \mu \mathrm{g}$ por grama de creatinina $(\mathrm{Cr})$ na urina $(\mathrm{HgU})$ para a população geral e $35 \mu \mathrm{g}$ de $\mathrm{Hg} / \mathrm{gCr}$ para trabalhadores expostos (Faria, 2003). A urina é o melhor marcador biológico quando se suspeita da intoxicação crônica (Agency for Toxic Substance and Disease Registry, 1992), uma vez que a toxicocinética do mercúrio na urina é mais 
lenta do que no sangue, com meia vida de 90 dias para exposição de longa duração (Satoh, 2000). Entretanto, com o cessar da exposição, as concentrações urinárias de mercúrio tornam-se normais, pois são apenas indicadores da excreção corrente (Faria, 2003).

O termo eretismo foi apresentado pela primeira vez em 1805 por John Pearson para identificar todos os efeitos da intoxicação por $\mathrm{Hg}^{0}$ identificados até então, mas no século $X X$, foi utilizado para designação exclusiva das alterações de comportamento, humor e personalidade como, irritabilidade, melancolia, depressão, timidez, ansiedade, dificuldade de concentração e de tomada de decisões, insônia, embotamento intelectual, perda de memória e nos casos mais graves, apatia completa, alucinações e delírios, ideações suicidas, psicose maníaco-depressiva, e alterações da fala com moleza na língua (Azevedo, 2003).

O mercurialismo crônico ocupacional ou hidrargirismo (Faria, 2003) corresponde a intoxicação pelo metal (Rodriguez \& Rodriguez, 1982) e caracterizase por um conjunto de sintomas apresentados pelo indivíduo após período de inalação dos vapores de mercúrio metálico ou sais derivados (Azevedo, 2003) no processo de trabalho. Trata-se de uma síndrome do sistema nervoso central (SNC) (Langolf, Chafffin, Henderson, \& Whittle, 1978) manifestada através dos distúrbios psíquicos (Hua, Huang, \& Yang, 1995) característicos do eretismo, acompanhados de dores musculares, inflamação da gengiva, tremor muscular, sendo também freqüentes hipertensão arterial, alergias e alterações renais (Faria, 2003). A intoxicação crônica pelo vapor de mercúrio pode ainda provocar polineuropatia, diminuição da acuidade visual, dificuldade na pronúncia da fala, distúrbio de equilíbrio, ataxia e nos casos mais graves, movimentos convulsivos involuntários (Azevedo, 2003).

A síndrome aparece conforme concentração contínua a partir de 0,004 $\mathrm{mg} / \mathrm{m}^{3}$ de mercúrio no ambiente e os sinais de toxicidade podem ser observados a 
partir de um ano de exposição ocupacional (Brown, 1954). O diagnóstico é determinado pela identificação de neurastenia e por 3 ou mais dos seguintes sintomas: hipertrofia da tireóide, aumento da captação de iodo radioativo pela tireóide, pulso fraco, taquicardia, dermografismo, gengivite, alterações hematoiéticas e aumento da eliminação urinária (Azevedo, 2003).

O mercurialismo também existe na modalidade aguda, porém com menor freqüência. Atualmente é rara a intoxicação aguda por mercúrio, pois os conhecimentos provenientes da pesquisa sobre este agente levaram à intensificação dos cuidados e precauções tomados pelos indivíduos em ocupações relacionadas (Azevedo, 2003). A intoxicação aguda envolve concentração a partir de $1,1 \mathrm{mg} / \mathrm{m}^{3}$ no ar e os principais efeitos imediatos consistem no aquecimento do organismo, provocando alterações os sistemas nervoso, digestivo e respiratório, além dos rins. Poucas horas depois, o indivíduo pode apresentar tremores, sabor metálico na boca, náuseas, diarréia, dispnéia, tosse, fraqueza muscular, reflexos lentos, sonolência, delírio, alucinação, perda de sensibilidade e da memória, além de instabilidade emocional manifestada através dos sintomas de irritabilidade e tendência suicida. Com a intensificação do quadro, pode haver bronquite, edema do pulmão, com risco de morte por insuficiência respiratória (Agency for Toxic Substance and Disease Registry, 1992).

O mercurialismo foi uma das primeiras doenças ocupacionais identificadas, conhecida na Índia desde 500 a.C. (Brown, 1954). Restringiu-se inicialmente aos mineradores (Azevedo, 2003) até a primeira metade do século XVII. Com a introdução do nitrato de mercúrio na manufatura de chapéus de feltro na França em 1865, a maioria dos casos de mercurialismo passou a ser observada nas indústrias de chapéus (Brown, 1954). Neste mesmo ano, C. L. Dogson, sob a pseudônimo Lewis Carrol escreveu "As aventuras de Alice no país das maravilhas", em que o personagem "chapeleiro louco" (figura 5) manifesta a intoxicação ocupacional por 
mercúrio, também conhecida como "doença do chapeleiro louco" (O'Carrol, et al., 1995; Satoh, 2000).

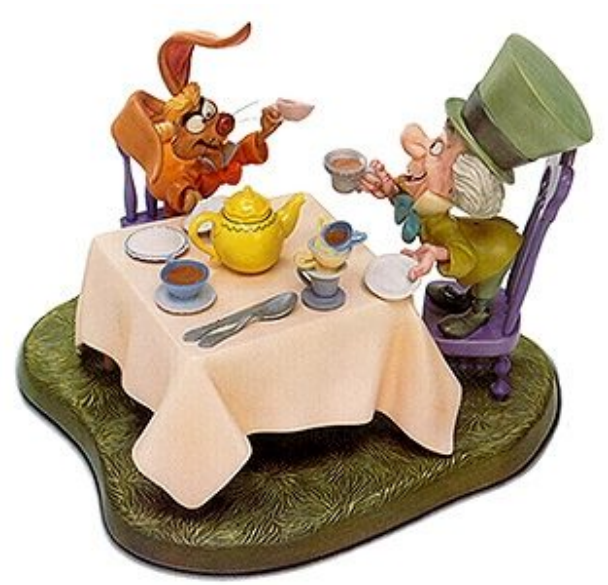

Figura 5. Boneco do personagem "Chapeleiro Louco", de Walt Disney, à direita.

Há evidências da persistência do mercurialismo mesmo depois de cessada a exposição ocupacional, apesar da redução dos sintomas como tremor e gengivite e da concentração normal de mercúrio urinário, pois conforme mencionado, esta corresponde a um indicador de exposição corrente (Satoh, 2000).

Antidepressivos, tranqüilizantes e analgésicos têm sido utilizados no tratamento para intoxicação mercurial crônica, embora a literatura não tenha revelado os resultados produzidos. Também são usados agentes quelantes, que capturam íons metais produzindo duas ou mais ligações, como o ácido 2,3 dimercaptosuccinato (DMSA) e o 2,3 dimercatopropane 1 sulfanato (DMPS) (Faria, 2003).

\subsection{Fisiopatologia da Intoxicação pelo Vapor de Mercúrio e o SNC}

A respiração é a principal via de introdução do vapor de $\mathrm{Hg}^{0}$ e dos sais de mercúrio no organismo. Os vapores inalados atravessam a membrana alvéolocapilar e alcançam a corrente sangüínea, com absorção de até $80 \%$ do montante. A introdução cutânea é pequena, mas pode provocar dermatite nos casos de sensibilidade ao mercúrio. Entretanto, a ingestão de mercúrio não produz efeitos adversos porque é muito pequena a absorção no trato intestinal (Azevedo, 2003). 
Uma pequena parte do $\mathrm{Hg}^{0}$ inalado é oxidado no sangue e grande parte chega no cérebro e outros órgãos sob a forma elementar. Devido à solubilidade em gorduras e a ausência de carga elétrica, o mercúrio elementar apresenta grande capacidade de difusão simples entre as células, o que lhe permite atravessar facilmente as barreiras hemato-encefálica e placentária. Ao deixar o sangue e penetrar nos tecidos, o mercúrio rapidamente oxida-se transformado em mercúrio divalente $\left(\mathrm{Hg}^{+2}\right)$, ligando-se a proteínas celulares e perdendo a propriedade da solubilidade o que provoca sua instalação no cérebro com grande dificuldade de ser liberado (Azevedo, 2003).

O mercúrio elementar e seus compostos inorgânicos agem pelo mesmo mecanismo em que o íon atua precipitando proteínas e inibindo enzimas sulfidrilas. A inibição destas enzimas é reversível com o cessar da exposição ao metal (Rodriguez \& Rodriguez, 1982).

Estudos sobre a concentração de mercúrio no cérebro não evidenciam a preferência do metal por uma região ou outra, mas variações específicas conforme cada caso. Houve três estudos com os seguintes resultados: distribuição do mercúrio no tecido cerebral partilhada entre o cerebelo, a protuberância anular e o pólo anterior do lobo frontal; alterações fisiopatológicas nos córtex frontal e occipital, gânglio basal, substância negra, córtex superior temporal, cerebelo e substância branca subcortical; lesões associadas à intoxicação por mercúrio no córtex occipital e substância negra (Azevedo, 2003).

As autópsias dos cérebros de dois ex-mineradores com histórico de exposição crônica prévia a concentrações altas do vapor de mercúrio (0,9 a 2,7 $\mathrm{mg} / \mathrm{m}^{3}$ ), 9,5 anos de trabalho em média e 10 anos de afastamento da função mostraram grande acumulação do metal no córtex, especialmente occipital e parietal e substância negra, apesar da conservação as características morfofisiológicas (Takahata, Hayashi, Watanabe, \& Anso, 1970). 
No estudo de caso de um indivíduo que sofreu exposição ocupacional aguda ao vapor de mercúrio inorgânico, a imagem funcional do SPECT mostrou hipermetabolismo do córtex cingulado posterior que, conforme exame realizado, associou-se a déficits de atenção/concentração, principalmente em tarefas que requerem rapidez, além de ansiedade e agitação. As neuroimagens anatômicas provenientes da RM não revelaram marcações (O'Carroll et al., 1995).

\subsection{Exposição Crônica ao Vapor de Mercúrio e a Avaliação Neuropsicológica}

Estudos referentes a trabalhadores expostos cronicamente ao vapor de mercúrio por período superior a um ano demonstram a relação entre a exposição e sintomas neuropsicológicos e neurológicos, não havendo, entretanto, consenso entre as funções mentais afetadas (Hua et al., 1995; Ellingsen, Bast-Pettersen, Efskind \& Thomassen, 2001; Meyer-Baron Schaeper, \& Seeber, 2002). Além disso, tais divergências não podem ser explicadas pelos diferentes níveis de exposição (Meyer-Baron et al., 2002). Entretanto, a disfunção motora parece constituir o sinal mais freqüentemente relatado da exposição excessiva ao mercúrio (Langolf et al., 1978; Meyer-Baron et al., 2002).

A discrepância entre os resultados descritos na literatura é ilustrada pela tabela 1, que lista os domínios examinados e respectivas referências cujos exames de indivíduos com histórico de exposição crônica ocupacional ao vapor de mercúrio (mineradores, trabalhadores industriais ou dentistas) mostram alterações com índice estatístico $(p<0,05)$ ou ausência destas quando comparados com controles. 
Tabela 1

Referências de publicações cujos resultados apontam para a existência ou ausência de rebaixamento no desempenho da função neuropsicológica examinada

\begin{tabular}{|c|c|c|}
\hline \multirow[b]{2}{*}{ Função examinada } & \multirow{2}{*}{$\begin{array}{l}\text { Referências } \\
\begin{array}{l}\text { Resultados mostram } \\
\text { alteração na função }\end{array}\end{array}$} & \multirow{2}{*}{$\begin{array}{l}\text { Referências } \\
\text { Resultados não mostram } \\
\text { alteração }\end{array}$} \\
\hline & & \\
\hline Atenção concentrada & Liang et al. (1993) & Ellingsen et al. (2001) \\
\hline \multirow[t]{3}{*}{ Memória de curto prazo } & Foo et al. $(1993)^{\mathrm{D}}$ & Tirado et al. $(2000)^{\mathrm{M}}$ \\
\hline & & Ellingsen et al. (2001)' \\
\hline & & Lucchini et al. (2003) \\
\hline \multirow[t]{2}{*}{ Tempo de reação } & Foo et al. $(1993)^{\mathrm{D}}$ & $\begin{array}{l}\text { Soleo, Urbano, Petrera, \& } \\
\text { Ambrosi, (1990) }\end{array}$ \\
\hline & Liang et al. (1993)' & Lucchini et al. (2003) \\
\hline \multirow[t]{2}{*}{ Memória visual } & Liang et al. (1993) & Piikivi et al. (1984)' \\
\hline & & Tirado et al. (2000) ${ }^{\mathrm{M}}$ \\
\hline \multirow[t]{2}{*}{ Velocidade psico-motora } & Liang et al. (1993) & Shapiro et al. (1982) \\
\hline & Lucchini et al. (2003) & Ellingsen et al. (2001)' \\
\hline \multirow[t]{2}{*}{ Destreza manual } & Piikivi et al. (1984)' & Shapiro et al. (1982) \\
\hline & Foo et al. $(1993)^{\mathrm{D}}$ & Ellingsen et al. (2001) \\
\hline Função viso-motora & Shapiro et al. $(1982)^{\mathrm{D}}$ & Soleo et al. (1990)' \\
\hline Percepção visual & Liang et al. )1993)' & Tirado et al. (2000) ${ }^{\mathrm{M}}$ \\
\hline
\end{tabular}

D estudo com dentistas

I estudo com trabalhadores industriais

${ }^{\mathrm{M}}$ estudo com mineradores

Em uma meta-análise que visou à procura de tendências gerais em alterações neuro-comportamentais resultantes da exposição ocupacional ao vapor de mercúrio, Meyer-Baron et al. (2002) investigaram 12 estudos que preencheram requisitos pré-estabelecidos, identificando a presença de déficits de atenção como componente da memória de curto prazo, mas não em testes que requerem velocidade, como tempo de reação e memória visual. Também foram descritos prejuízos em habilidades construtivas, associados à concentração média urinária de mercúrio entre 18 e $34 \mu \mathrm{g} / \mathrm{g}$ Cr. Para os autores, as divergências aparentes entre 
os resultados nestes apresentados podem decorrer de fatores de confusão, como a inteligência pré-mórbida dos indivíduos e a possibilidade de exposição a outras toxinas.

Encontra-se na literatura científica uma variedade de pesquisas sobre o desempenho neuropsicológico de trabalhadores industriais com exposição crônica e atual ao vapor de mercúrio.

Em um estudo longitudinal conduzido por 6 anos em uma fábrica de cloro-álcalis, identificou-se déficit de memória de curto prazo, mesmo nos indivíduos que mantiveram o nível urinário de mercúrio abaixo de $0,5 \mathrm{mg} / \mathrm{l}$, limite estabelecido como critério para afastamento do trabalhador de seu cargo (Langolf, Smith, Henderson, \& Whittle, 1981).

Smith, Langolf, \& Goldberg (1983) descrevem déficit de memória de curto prazo associado ao nível de exposição ao vapor de mercúrio em 26 funcionários (concentração média de $\mathrm{Hg}^{0}$ urinário=0,2 mg/l; variação de 0 a $0,51 \mathrm{mg} / \mathrm{l}$ ) de 2 fábricas de cloro-álcalis.

Em um estudo de caso referente aos danos ambientais e ocupacionais relativos a uma multinacional da produção de cloro-álcalis situada na Nicarágua, Hassan et al. (1981) citam a ocorrência de déficit de memória e/ou dificuldade de concentração e/ou tremor em 45 dos 52 trabalhadores examinados (nível de vapor de mercúrio no ar superior a $600 \mu \mathrm{g} / \mathrm{m}^{3}$ no local de serviço).

Em outra indústria do mesmo produto, embora a avaliação de 36 trabalhadores (nível de $\mathrm{Hg}^{0}$ urinário médio=290,6 \pm 145,6 nmol/l e sangüíneo médio=99,7 \pm 89,7 nmol/l; tempo de exposição mínimo de 10 anos) comparados com sujeitos controles, tenha apresentado alteração com significância estatística somente no teste de destreza manual, uma análise intragrupos mostrou déficits entre os indivíduos com maior índice de exposição nos testes de formação de conceitos e memória lógica (Piikivi et al., 1984). 
Vinte e oito funcionários (concentração de $\mathrm{Hg}^{0}$ urinário de 150 a 200 nmol/l) de indústria de lâmpadas fluorescentes revelaram baixo desempenho em memória verbal de curto prazo e maior índice de depressão, embora os testes de tempo de reação, retenção visual, velocidade psicomotora e personalidade não tenham demonstrado alterações (Soleo et al., 1990).

Em outra fábrica similar, 88 trabalhadores (concentração média de $\mathrm{Hg}^{0}$ urinário $=0,024 \mathrm{mg} / \mathrm{l} \pm$ 0,058; tempo de exposição mínima de 2 anos) comparados com controles obtiveram escores significantemente baixos nos teste de habilidade aritmética, atenção concentrada, tempo de reação para estímulos visuais, percepção visual e função psicomotora, enquanto que a memória visual se mostrou inalterada (Liang et al., 1993).

Ellingsen et al. (2001) testaram os efeitos do mercúrio metálico em trabalhadores (concentração urinária média de $\mathrm{Hg}^{0}=U 5,9 \mathrm{nmol} / \mathrm{mmol}$ de $\mathrm{Cr}$, variação de 1,1 a 16,8 nmol/mmol $\mathrm{Cr}$; tempo médio de exposição=13,3 anos, variação de 2,8 a 34,5 anos) de uma indústria de cloro-álcalis, não observando diferença estatística entre o grupo exposto $(n=47)$ e o grupo controle $(n=47)$ em nenhum dos testes aplicados, que corresponderam a medidas de funções intelectuais gerais, velocidade viso-motora, atenção, memória de curto prazo, funções motoras, atenção visual sustentada e tempo de reação. Entretanto, houve correlação entre maior índice de exposição e o desempenho prejudicado nos testes de velocidade viso-motora e psicomotora, atenção e memória visual imediata.

Um projeto multicêntrico que incluiu 6 universidades italianas promoveu o exame de 122 trabalhadores (nível de $\mathrm{Hg}^{0}$ urinário médio=10,4 $\pm 6,9 \mu \mathrm{g} / \mathrm{g} \mathrm{Cr}$ ) de indústrias de cloro-álcalis, termômetros e lâmpadas fluorescentes e 196 sujeitos controles (nível de $\mathrm{Hg}^{0}$ urinário médio=1,9 $\pm 2,8 \mu \mathrm{g} / \mathrm{g} \mathrm{Cr}$ ) revelou diferença significativa $(p<0,05)$ entre os grupos nos testes de velocidade e coordenação motora, embora os resultados referentes a tempo de reação, memória de curto 
prazo, velocidade viso-motora, capacidade de inibição de estímulos e escala de humor não tenham se mostrado discrepantes em relação ao grupo controle (Lucchini et al., 2003).

Os estudos com dentistas envolvem baixo nível de exposição ao mercúrio elementar. Verifica-se nestes, a ênfase no exame das habilidades motoras, fundamentais no exercício destes profissionais.

Shapiro et al. (1982) administraram testes neuropsicológicos em 26 dentistas e 17 indivíduos controles, tendo os profissionais expostos apresentado rebaixamento com significância estatística $(p<0,05)$ em habilidade viso-gráfica e na velocidade de condução sensorial nervosa. Não houve diferença entre os grupos nos testes de inteligência, velocidade psicomotora e destreza manual.

No estudo cujo objetivo principal consistiu na comparação dos efeitos neurocomportamentais provocados por três substâncias distintas: tolueno, solventes mistos e mercúrio, 98 dentistas $(7,4 \pm 5,4$ anos de exposição) apresentaram escores significantemente menores nos testes de memória de curtoprazo, velocidade viso-motora e destreza manual, em relação ao grupo controle não exposto a quaisquer agentes tóxicos (Foo et al., 1993).

No exame de 19 dentistas (concentração média urinária de $\mathrm{Hg}^{0}=36,4 \pm$ 20,0 $\mu \mathrm{g} / \mathrm{l})$, o nível de $\mathrm{Hg}^{0}$ urinário foi associado ao prejuízo em memória de curto prazo, tempo de reação, vocabulário, concentração, além dos sintomas de labilidade emocional e irritabilidade aumentados (Echeverria et al., 1995).

Bittner et al. (1998) administraram testes de velocidade e precisão motora; controle, tremor e destreza manuais e tempo de reação em dentistas (concentração urinária de $\left.\mathrm{Hg}^{0} \leq 55 \mu \mathrm{g} / \mathrm{l}\right)$, demonstrando associação entre o desempenho prejudicado em destreza manual e a concentração urinária de mercúrio.

Em contraste à exposição ocupacional a baixos níveis de vapor de mercúrio, o trabalho de mineração constitui a situação de maior concentração aérea do metal. 
Tirado et al. (2000) identificaram déficits de função executiva e praxias construcionais; maior ocorrência de sintomas de depressão e ansiedade e alterações neurológicas representadas por amnésia, insônia e tremor na língua em 22 mineradores que atuavam na extração do ouro (tempo de exposição superior a 3 anos; índice de exposição não especificado) comparados com controles ( $n=22)$. Os testes de estado mental geral, memória de curto-prazo, verbal e visual, linguagem e percepção visual se demonstraram inalterados.

Pesquisas referentes às alterações neuropsicológicas associadas ao vapor de mercúrio, porém com cessação da exposição crônica anterior à avaliação, são escassas, mas importantes por promover a aquisição de informações relevantes quanto à possibilidade de seqüelas ocasionadas pelo contato com o metal. Portanto, tais fatos justificam a necessidade de maior investigação neste âmbito.

Em um estudo que incluiu o exame neuropsicológico de 75 ex-trabalhadores de fábricas de cloro-álcalis com tempo de exposição médio ao vapor de mercúrio de 7,9 anos (DP=6,8), 12,7 anos de afastamento ( $\mathrm{DP}=11,7)$, concentração de mercúrio urinário de $1,8 \mathrm{nmol} / \mathrm{mmol} \mathrm{Cr}(\mathrm{DP}=1,3)$ e 52 controles, os indivíduos expostos indicaram alteração atencional e da função motora (Mathiesen, Ellingsen, \& Kjuus, 1999).

Kishi et al. (1994) administraram testes neuropsicológicos em 76 exmineradores (concentração de vapor de mercúrio na ar $>1 \mathrm{mg} / \mathrm{m}^{3}$ ) e 76 sujeitos controles, 18 anos após a cessação da exposição crônica. Os resultados mostraram que, apesar da diminuição de sintomas como tremor nos pés e dedos, irritabilidade e depressão, outros sintomas como presbiopia, tremor nas mãos, dor de cabeça e diminuição da libido foram significantemente $(p<0,05)$ maiores nos exmineradores, além do desempenho prejudicado nos testes de capacidade sensóriomotora, tempo de reação, coordenação motora e viso-motora, destreza manual, controle inibitório, função viso-espacial e memória de curto prazo, indicando a 
existência de alterações neuropsicológicas de longo prazo. A duração da exposição se correlacionou com desempenho prejudicado em coordenação viso-motora, tempo de reação e no controle inibitório. O tempo de afastamento teve correlação com melhor desempenho em tempo de reação e memória de curto prazo. Os autores sugerem que há um efeito de longo prazo leve na coordenação motora, mesmo anos após cessada a exposição. Setenta por cento da amostra teve internação para tratamento, mas nada foi especificado sobre a utilização de agentes quelantes.

Frumkin, Letz, Williams, Gerr \& Pierce et al. (1988) investigaram a possibilidade de alterações neuropsicológicas relacionadas à exposição ao vapor de mercúrio em ex-trabalhadores $(n=147)$ de uma indústria de produção cloroálcalis com média de 5,7 anos (DP=6,5) de afastamento da função (mínimo de 1 ano de trabalho prévio; concentração média de mercúrio urinário $=2,76 \pm 2,04$ $\mu \mathrm{g} / \mathrm{gmCr})$, comparados com controles $(n=132)$, tendo os ex-trabalhadores apresentado desempenho pior nos testes de tempo de reação, destreza manual e memória verbal. Os grupos não mostraram diferenças significativas nos testes de memória de curto prazo, atenção dividida, inteligência geral e vocabulário. 


\subsection{Objetivos}

\subsection{Geral}

- Examinar a possibilidade da ocorrência de disfunções neuropsicológicas em pacientes com diagnóstico de mercurialismo crônico, anos após a interrupção da exposição ocupacional ao vapor de mercúrio elementar.

\subsection{Específicos}

- $\quad$ Testar a hipótese de associação entre maior tempo de exposição ao vapor de mercúrio e pior desempenho neuropsicológico.

- Examinar a possibilidade de melhor resultado na bateria neuropsicológica conforme maior o tempo de afastamento da fonte de exposição ao metal.

- Verificar se existe associação entre desempenho neuropsicológico prejudicado e maior concentração atual de mercúrio urinário.

- Estudar a relação entre fatores de confusão (idade, escolaridade, tendinite, depressão, ansiedade e uso de medicamentos psicotrópicos) e os resultados nos testes neuropsicológicos. 


\subsection{Materiais e Métodos}

\subsection{Procedimentos}

Cada participante foi submetido a uma sessão de avaliação neuropsicológica, com duração média de 1,5 horas, composta pelas seguintes etapas:

a) anamnese $^{1}$ (anexo 1) para coleta de dados pessoais, clínicos e comportamentais dos participantes;

b) aplicação dos testes para exame das funções neuropsicológicas;

c) avaliação dos sintomas de depressão e ansiedade através da administração de inventários

As sessões de avaliação neuropsicológica foram conduzidas nas dependências do Departamento de Psicologia Experimental, Bloco D, sala 206, do Instituto de Psicologia da USP. O estudo foi aprovado pelos comitês de ética em pesquisa do mesmo instituto (processo 0403/CEPH/190803/IP) e do Hospital Universitário da USP (processo 379/03). Os voluntários foram informados sobre os objetivos e procedimentos da pesquisa e assinaram termo de consentimento ${ }^{2}$ informado após leitura (anexo 2), previamente à execução das etapas da avaliação neuropsicológica.

Com base em pesquisas publicadas que apresentam a avaliação das funções neuropsicológicas em associação à intoxicação mercurial ou ao diabetes, que também constitui foco de estudo nesta dissertação de mestrado, foi elaborado

\footnotetext{
${ }^{1}$ Utilizou-se um protocolo único de anamnese para ambos os estudos que compõem esta dissertação de mestrado e, portanto, inclui tanto questões referentes à intoxicação mercurial quanto ao diabetes.

${ }^{2} \mathrm{O}$ termo de consentimento também foi comum aos dois estudos e, portanto, contempla informações sobre o estudo de indivíduos intoxicados com mercúrio e pacientes diabéticos.
} 
um protocolo de avaliação neuropsicológica, com testes descritos a seguir. A tabela

2 lista os instrumentos revisados e respectivas referências.

Tabela 2

Instrumentos utilizados previamente na literatura científica para a avaliação de pacientes com histórico de intoxicação por vapor de mercúrio ou diabetes e referência dos estudos em que foram utilizados

\begin{tabular}{|c|c|}
\hline Testes & Referências \\
\hline Dígitos & $\begin{array}{l}\text { Austin e Deary (1999) }{ }^{\mathrm{D}} \text {; Cosway, Strachan, Dougall, Frier, e } \\
\text { Deary (2001) }{ }^{\mathrm{D}} \text {; Drasch, Bose-O’Reilly, Beinhoff, Roider, e } \\
\text { Maydl }(2000)^{\mathrm{M}} \text {; Ellingsen et al. (2001) }{ }^{\mathrm{M}} \text {; Lindeman et al. } \\
(2001)^{\mathrm{D}} \text {; Lowe, Tranel, Wallace, e Welty }(1994)^{\mathrm{D}} \text {; Northam et } \\
\text { al. (1998) })^{\mathrm{D}} \text {; O'Carroll, Masterton, Dougall, Ebmeier, e } \\
\text { Goodwin }(1995)^{\mathrm{M}} ; \text { Strachan, Deary, Ewing, e Frier }(2000)^{\mathrm{D}} \text {; } \\
\text { Tirado et al. }(2000)^{\mathrm{M}} ; \text {; Zaslavsky, Gross, Chaves e Machado } \\
(1995)^{\mathrm{D}}\end{array}$ \\
\hline Teste de Stroop & $\begin{array}{l}\text { O'Carroll et al. }(1995)^{\mathrm{M}} \text {; Ryan e Geckle }(2000)^{\mathrm{D}} \text {; Strachan et al. } \\
(2000)^{\mathrm{D}}\end{array}$ \\
\hline Teste de Buschke & Vanhanen et al. $(1999)^{\mathrm{D}}$ \\
\hline Reprodução Visual & $\begin{array}{l}\text { Austin e Deary }(1999)^{\mathrm{D}} \text {; Cosway et al. }(2001)^{\mathrm{D}} \text {; O'Carroll et al. } \\
(1995)^{\mathrm{M}} \text {; Piikivi, Hanninen, Martelin, e Mantere }(1984)^{\mathrm{M}} \text {; } \\
\text { Tirado et al. }(2000)^{\mathrm{M}}\end{array}$ \\
\hline FAS & $\begin{array}{l}\left.\text { Austin e Deary }(1999)^{\mathrm{D}}\right) \text {; Lowe et al. }(1994)^{\mathrm{D}} \text {; Northam et al. } \\
(1998)^{\mathrm{D}} \text {; O'Carroll et al. }(1995)^{\mathrm{M}}\end{array}$ \\
\hline Grooved Pegboard & $\begin{array}{l}\text { Ellingsen et al. }(2001)^{\mathrm{M}} \text {; Foo, Ngim, Salleh, Jeyaratnam, e } \\
\text { Boey }(1993)^{\mathrm{M}} \text {; Shapiro et al. }(1982)^{\mathrm{M}}\end{array}$ \\
\hline Cubos & $\begin{array}{l}\left.\text { Austin e Deary }(1999)^{\mathrm{D}}\right) \text {; Lowe et al. }(1994)^{\mathrm{D}} \text {; O'Carroll et al. } \\
(1995)^{\mathrm{M}} \text {; Ryan e Geckle }(2000)^{\mathrm{D}} \text {; Strachan et al. }(2000)^{\mathrm{D}}\end{array}$ \\
\hline Teste de Wisconsin & O'Carroll et al. $(1995)^{\mathrm{M}}$; Tirado et al. $(2000)^{\mathrm{M}}$ \\
\hline Vocabulario & Shapiro et al. $(1982)^{\mathrm{M}}$ \\
\hline
\end{tabular}

D estudos com pacientes diabéticos

M estudos com pacientes expostos ao vapor mercúrio

Uma vez que alterações de humor se associam aos efeitos da intoxicação mercurial (Satoh, 2000; Meyer-Baron et al., 2002; Faria, 2003) e do diabetes (Moreira et al., 2003; Papealbaum et al., 2005), foram incluídos inventários de depressão e ansiedade no protocolo de avaliação.

Estudos mostram alterações neuropsicológicas em pacientes com depressão, incluindo prejuízos memória de curto prazo (Antikainen et al., 2001), memória episódica (Fossati, Coyette, Ergis \& Allilaire, 2002) funções executivas (Grant, Thase \& Sweeney, 2001; Fossati et al., 2002), além de lentificação psicomotora (Antikainen et al., 2001; Fossati et al., 
2002). Por outro lado, indivíduos com níveis altos de ansiedade mostraram déficits de funções executivas (Browndyke et al., 2002), função viso-espacial (Buckelew \& Hannay, 1986), fluência verbal (Buckelew \& Hannay, 1986) e dificuldade no controle psicomotor (Browndyke et al., 2002). Portanto, as avaliações de depressão e ansiedade nos pacientes são fundamentais para a verificação da possibilidade de correlação entre os possíveis resultados prejudicados nos testes e alterações de humor.

\subsection{Instrumentos de Avaliação Neuropsicológica}

\subsection{Testes para exame das funções neuropsicológicas}

\subsection{Dígitos}

Subteste da Escala Wechsler de Memória-Revisada (WMS-R) (Wechsler, 1987), Dígitos é dividido em duas etapas em que são lidas séries de números (com intervalo de um segundo entre um e o seguinte) e solicitada a repetição das mesmas na ordem direta (Dígitos-Diretos) ou inversa (Dígitos-Inversos) em que foram apresentadas, tornando-se mais longas gradativamente até 8 dígitos. DígitosDiretos fornece a amplitude atencional, isto é, a quantidade de informação que se consegue armazenar de uma só vez; Dígitos-Inversos corresponde a uma avaliação de memória operacional, ou seja, da capacidade de reter certo número de informações em curto período de tempo, além do controle mental para operacionalização de informações.

\subsection{Teste de Stroop (Stroop Interference Test)}

O teste de Stroop avalia a capacidade de manter a meta em uma atividade e inibir a tendência de fornecer respostas impulsivas, além da velocidade no processamento de informações. Utilizou-se neste estudo, uma modificação da 
versão desenvolvida na Universidade de Victoria, Canadá, citada por Spreen e Strauss (1991), que inclui três etapas, com grau crescente de dificuldade.

A tarefa consiste em verbalizar nomes de cores impressas (apresentadas através de estímulos diferentes em cada etapa do teste) em cartões, seguindo uma ordem definida pelo aplicador. Na primeira etapa os estímulos são retângulos coloridos (quatro cores diferentes); na segunda fase, o cartão apresenta palavras "neutras", isto é, não correspondentes a nomes de cores e na terceira parte, apresentam-se nomes de cores impressos em outra cor (por exemplo, a palavra "vermelho" é impressa na cor verde). Assim, o examinando deve verbalizar o nome de cada cor impressa, inibindo a tendência para a leitura da palavra. O dado bruto corresponde ao tempo (em segundos) utilizado para a realização de cada etapa. $\mathrm{O}$ efeito stroop é obtido através do quociente entre os tempos referentes à terceira e primeira etapas e indica a capacidade de controle inibitório.

\subsection{Teste de Buschke (Buschke Selective RemindingTest-SRT)}

O teste de Buschke (SRT) avalia memória verbal, com a diferenciação entre retenção imediata, armazenamento e recuperação tardia de informações (após 30 minutos). O procedimento consiste na memorização e repetição de uma lista de 12 palavras apresentadas verbalmente. A lista em sua totalidade é apresentada por uma única vez e nas tentativas de aprendizagem subseqüentes, são relidas somente as palavras não evocadas na tentativa imediatamente anterior. Utilizou-se a versão proposta por Hannay e Lewin (1985) citados por Spreen e Strauss (1991) em que são administradas 12 tentativas, sendo o teste finalizado anteriormente, caso o examinando evoque todas as palavras em três tentativas consecutivas. Também foram registrados o número de intrusões, isto é, palavras não pertencentes à lista, mas emitidas pelo examinando como se tivesse sido evocada 
e o total de reconhecimento, correspondente à fase em que as palavras referentes ao teste deveriam ser identificadas dentro de uma lista composta por 36 palavras.

\subsection{Reprodução Visual}

Corresponde a um subteste da WMS-R (Wechsler, 1987), subdividido em duas etapas. Avalia as habilidades de memorização e reprodução de estímulos visuais, além da coordenação motora. São apresentados quatro modelos de figuras geométricas, um por vez, durante o intervalo de cinco segundos. Imediatamente após cada exposição, solicita-se o desenho do modelo (Reprodução Visual Imediata) em uma folha de papel. Após 30 minutos, é requerida novamente a reprodução dos modelos, mas sem a apresentação prévia dos mesmos (Reprodução Visual Tardia).

\subsection{Grooved Pegboard}

Grooved Pegboard é um teste de destreza manual (Lafayette Instrument Corporation, 1979) que consiste em um tabuleiro perfurado com 25 orifícios de mesma forma (semelhante a uma fechadura) e tamanho, porém posicionados com orientação randômica, além de pequenos bastões de mesma forma e tamanho que se encaixam nas aberturas. A tarefa consiste em encaixar os bastões nos orifícios seguindo uma ordem pré-determinada, com a utilização de apenas uma das mãos. O dado bruto corresponde ao tempo de execução da tarefa, em segundos. Administra-se inicialmente a mão dominante e em seguida a mão não dominante.

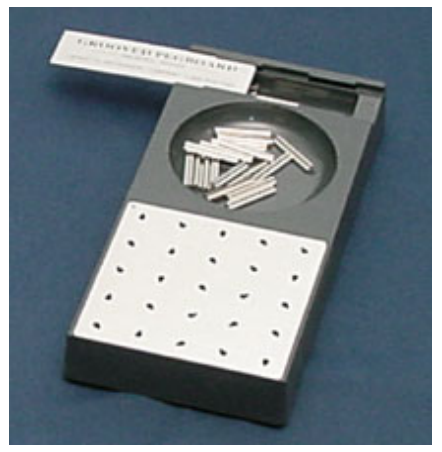

Figura 6. Gooved Pegboard 


\subsection{Fluência Verbal Categoria Fonêmica (FAS)}

A versão utilizada se inclui no Neurosensory Center Comprehensive Examination for Aphasia de Spreen e Benton (1977), citados por Spreen e Strauss (1991). Avalia a capacidade de evocar palavras iniciadas por uma letra prédeterminada, com fluência, durante o intervalo de um minuto. São administradas, respectivamente, as letras "F", "A" e "S", e por este motivo o teste também é conhecido como "FAS".

\subsection{Cubos}

Subteste da Escala Wechsler de Inteligência para Adultos - Revisada (WAIS-R) (Wechsler, 1981), avalia organização viso-espacial e habilidades de planejamento e resolução de problemas. São requisitadas as reproduções de modelos de figuras bidimensionais que se tornam complexas gradativamente, com a utilização de cubos contendo faces de cores vermelhas e brancas. Os modelos são apresentados um por vez e permanecem à mostra durante cada reprodução. $\mathrm{O}$ escore bruto de cada item acompanha o acréscimo caso haja execução da tarefa em menor tempo.

\subsection{Teste de Wisconsin (Wisconsin Card Sorting Test)}

O teste de Wisconsin (apêndice 1) é um teste de funções executivas. Utilizou-se neste estudo a versão proposta por Heaton, Chelune, Talley, Kay e Curtis (1993). Inclui 132 cartões (quatro são modelos), cada um contendo figuras que podem variar quanto à forma (triângulo, estrela, cruz ou círculo), cor (vermelho, verde, amarelo ou azul) e quantidades (uma, duas, três ou quatro figuras). A tarefa consiste em combinar os cartões a um dos quatro modelos apresentados, conforme 
critérios pré-estabelecidos (mesma cor, forma ou quantidade) que deverão ser deduzidos pelo examinando. Em cada protocolo, foram examinados os números de erros totais e perseverativos; respostas perseverativas e de nível conceitual (respostas corretas em blocos de pelo menos três acertos consecutivos); categorias completas e perdas de meta (cinco ou mais acertos consecutivos até nove, seguidos de um erro).

\subsection{Vocabulário}

Vocabulário é um subteste da WAIS-R (Wechsler, 1981), correspondente a uma medida de conhecimento semântico, em que são solicitados os significados de 35 palavras definidas.

\subsection{Inventários de Humor}

\subsection{Inventário Beck de Depressão (Beck Depression Inventory $-B D I)$}

Corresponde a um complemento ao diagnóstico prévio de depressão, realizado pelo ponto de vista do paciente (Gorenstein, Andrade \& Zuardi, 2000), avaliando a profundidade da depressão. Neste estudo foi utilizada a versão padronizada a adaptada para a população brasileira (Cunha, 2001). O inventário inclui 21 itens, cada qual contendo quatro afirmativas das quais o examinando seleciona aquela que lhe é mais apropriada. 


\subsection{Inventário de Ansiedade Traço-Estado (IDATE)}

O IDATE é um instrumento de avaliação da ansiedade em indivíduos adultos como medida objetiva do estado transitório de ansiedade e do traço de ansiedade, característica relativamente estável do indivíduo, como parte da sua personalidade (Cunha, Freitas \& Raymundo, 1993). Utilizou-se neste estudo a versão traduzida para o português e adaptada para a população brasileira (Biaggio \& Natalício, 1979). As escalas de traço e de estado de ansiedade consistem em 20 afirmações cada, às quais que o examinando atribui notas de zero a três, indicando como geralmente se sente ou demonstrando o seu estado de ansiedade em um determinado momento, respectivamente.

\subsection{Análise Estatística dos Resultados}

As variáveis dependentes corresponderam aos dados brutos obtidos pelo grupo de ex-trabalhadores e o controle nos testes e inventários aplicados, enquanto idade, escolaridade, tempo de exposição e de afastamento ao vapor de mercúrio e a concentração urinária do metal constituíram variáveis independentes.

As análises referentes às diferenças entre os grupos quanto aos resultados dos testes neuropsicológicos e à escolaridade foram realizadas utilizando-se o teste de Mann-Whitney, adequado para conjuntos de dados não paramétricos. Para comparação de idade e os escores totais dos inventários de depressão e ansiedade, foi aplicado o teste t de Student para amostras independentes, uma vez que a distribuição dos dados brutos destas variáveis mostrou-se conforme curva normal e com mesma variância entre o grupo exposto e controle.

Verificou-se a possibilidade de correlação estatística entre os escores brutos nos testes neuropsicológicos e variáveis contínuas intragrupos (idade, escolaridade, 
tempo de exposição e de afastamento ao vapor de $\mathrm{Hg}^{0}$, concentração urinária de mercúrio e escores de depressão e ansiedade) através do Teste de Correlação de Spearman

Fatores de confusão como diagnóstico de tendinite, escores altos de depressão e ansiedade, depressão e uso de medicamentos foram analisados subdividindo-se o grupo exposto segundo critérios pré-estabelecidos (vide item 3.62) e aplicando-se o teste $t$ de Student ou de Mann-Whitney conforme as características de distribuição e comparação de variâncias dos dados.

O grupo exposto também subdividido em subgrupos segundo critérios de tempo de exposição e afastamento ao vapor de mercúrio e de concentração urinária do metal (vide item 3.62) para determinação de possíveis diferenças de resultados em função desses fatores. Foram utilizados os mesmos métodos e estatísticos e critérios descritos acima.

Utilizou-se o programa estatístico Jandel Sigma-Stat Software 2.0 (Jandel Corporation, 1992) para os cálculos de comparações entre os dados brutos e adotou-se $p<0,05$ como limiar de significância. 


\subsection{Casuística}

Foram examinados 34 ex-trabalhadores de fábricas de lâmpadas fluorescentes com histórico de exposição ao vapor de mercúrio por tempo mínimo de 4 anos, dos quais 8 apresentaram fatores dos critérios de exclusão e, portanto, não participaram do estudo. Constituíram critérios de exclusão deste grupo, os históricos de tratamento com agentes quelantes, distúrbios endócrinos ou metabólicos, lesão ou cirurgia cerebral, problema vascular, abuso de álcool ou uso de drogas.

Vinte e seis ex-trabalhadores (20 homens e 6 mulheres) formaram a amostra. São pacientes com diagnóstico de mercurialismo crônico ocupacional, encaminhados pelo Departamento de Medicina Legal e Saúde Ocupacional do Instituto Oscar Freire da Universidade de São Paulo, onde vêm sendo acompanhados em tratamento ambulatorial. São indivíduos destros, com idade média de 41,5 \pm 6,1 anos e 9,8 \pm 1,8 anos de educação formal (tabela 3).

Os cargos exercidos pelos pacientes durante o tempo de trabalho se distribuíram pela linha de montagem de lâmpadas de mercúrio entre as funções de confecção de lâmpadas, embalagem e controle de qualidade. O vapor de mercúrio era constante durante o processo de produção, com maior ou menor concentração no ar conforme o cargo. Atitudes inadequadas como a quebra de lâmpadas defeituosas para análise, a falta de uso de equipamentos de proteção e aquecimento de refeições diretamente no vapor do mercúrio exalado pela máquina contribuíram para o agravamento da situação de exposição tóxica.

O grupo controle ${ }^{3}$ foi composto a partir do exame de 36 indivíduos sem queixas, dos quais 20 (18 homens e 2 mulheres) participaram do estudo por melhor

\footnotetext{
${ }^{3} \mathrm{O}$ mesmo integrante do grupo controle referente ao estudo do mercúrio pode ou não ter sido incluído entre os controles para o estudo de pacientes diabéticos, conforme melhor pareamento de idade e escolaridade.
} 
parear quanto à idade e escolaridade ao grupo exposto e por não apresentar características dos critérios de exclusão, representados pelos históricos de distúrbios psiquiátricos, neurológicos, endócrinos ou metabólicos, problemas vasculares, exposição crônica a substâncias tóxicas, lesão ou cirurgia cerebral, abuso de álcool ou uso de drogas. São funcionários da USP, destros, com idade média de 42,7 $\pm 8,2$ anos e 9,7 $\pm 2,2$ anos de educação formal. 


\subsection{Resultados}

A tabela 3 mostra as características gerais dos grupos, correspondentes ao sexo, idade, escolaridade e prevalência do tabagismo, incluindo média (M), desvio padrão (DP), mediana (Md) e valor de $p$ para as variáveis pertinentes. Não houve diferença significativa entre os grupos quanto à idade $(p=0,65)$ e escolaridade $(p=0,10)$.

Tabela 3

Características gerais dos participantes expostos ao mercúrio e grupo controle

\begin{tabular}{|c|c|c|c|c|c|c|c|c|c|}
\hline & \multicolumn{4}{|c|}{ Grupo Exposto } & \multicolumn{4}{|c|}{ Grupo Controle } & \multirow[b]{2}{*}{$P$} \\
\hline & $\mathbf{n}$ & $M_{ \pm} \mathrm{DP}$ & Md & $\%$ & $\mathbf{n}$ & $\mathbf{M} \pm \mathrm{DP}$ & Md & $\%$ & \\
\hline Sexo & 26 & & & 100 & 20 & & & 100 & \\
\hline Masculino & 20 & & & 77 & 18 & & & 90 & \\
\hline Feminino & 6 & & & 23 & 2 & & & 10 & \\
\hline Idade (anos) & & $41,5 \pm 6,1$ & 41,5 & & & $42,7 \pm 8,2$ & 42 & & 0,65 \\
\hline Escolaridade (anos) & & $9,8 \pm 1,8$ & 10 & & & $9,7 \pm 2,2$ & 11 & & 0,10 \\
\hline \multicolumn{10}{|l|}{ Tabagismo } \\
\hline Tabagistas & 2 & & & 7 & 4 & & & 20 & \\
\hline Ex-tabagistas & 2 & & & 7 & 0 & & & 0 & \\
\hline Não tabagistas & 22 & & & 86 & 16 & & & 80 & \\
\hline
\end{tabular}

A tabela 4 apresenta dados específicos do grupo exposto. Os tempos de exposição (10,2 \pm 3,8 anos) e afastamento (6 \pm 4,7 anos) ao vapor de mercúrio consideram a freqüência no trabalho de 5 dias por semana e jornada de 8 horas diárias. Conforme dados colhidos nos prontuários desses pacientes, as concentrações urinárias de mercúrio medidas 1 ano após o afastamento da sua função já se encontravam dentro dos limites normais, com média de 1,8 $\pm 0,9 \mu \mathrm{g} / \mathrm{g}$ Cr. 
Treze indivíduos (50\% da amostra) apresentaram diagnóstico de tendinite. Atualmente, 15 pacientes ( $58 \%$ da amostra) encontram-se afastados do cargo devido a problemas de saúde decorrentes da exposição ao mercúrio e/ou do trabalho repetitivo na linha de produção, 4 (15\%) foram demitidos e estão desempregados, 5 (19\%) foram aposentados por invalidez e apenas 2 (8\%) exercem atividades laborais autônomas, que não envolvem a exposição ao metal. Para o tratamento de depressão e/ou ansiedade, 5 indivíduos (19\%) fazem uso de antidepressivo, 5 (19\%) utilizam ansiolítico, 6 (23\%) são tratados com a combinação de ambos, em todos os casos, por período superior a um ano e 10 (39\%) não realizam acompanhamento medicamentoso desta natureza. No tratamento da depressão, os psicofármacos utilizados pertencem ao grupo antidepressivos tricíclicos (Amitril, Triptanol e Tofranil). Os tranqüilizantes são benzodiazepínicos (Diazepan e Rivotril).

A tabela 5 contém os resultados obtidos pelos grupos exposto e controle nos testes e inventários da avaliação neuropsicológica, representados pela mediana, média, desvio padrão, e valor de $p$ correspondente. 
Tabela 4

Variáveis específicas do grupo exposto ao vapor de $\mathrm{Hg}^{0}$

\begin{tabular}{|c|c|c|c|c|}
\hline & $\mathbf{N}$ & Md & $M \pm D P$ & $\%$ \\
\hline Tempo de exposição ao vapor de $\mathrm{Hg}^{0}$ (anos) & 26 & 9 & $10,2 \pm 3,8$ & \\
\hline Tempo de afastamento do vapor de $\mathrm{Hg}^{0}$ (anos) & 26 & 4,5 & $6 \pm 4,7$ & \\
\hline Concentração urinária de $\mathrm{Hg}^{0 *}(\mu \mathrm{g} / \mathrm{g}$ de $\mathrm{Cr})$ & 26 & 1,5 & $1,8 \pm 0,9$ & \\
\hline \multicolumn{5}{|l|}{ Tendinite } \\
\hline Sim & 13 & & & 50 \\
\hline Não & 13 & & & 50 \\
\hline \multicolumn{5}{|l|}{ Situação Ocupacional } \\
\hline Afastados por problemas de saúde & 15 & & & 58 \\
\hline Desempregados & 4 & & & 15 \\
\hline Aposentados por invalidez & 19 & & & 19 \\
\hline Profissionalmente ativos & 2 & & & 8 \\
\hline Tratamento Medicamentoso & 16 & & & 61 \\
\hline Antidepressivo & 5 & & & 19 \\
\hline Amitril & 2 & & & 7,5 \\
\hline Triptanol & 2 & & & 7,5 \\
\hline Tofranil & 1 & & & 4 \\
\hline Ansiolítico & 5 & & & 19 \\
\hline Rivotril & 5 & & & 19 \\
\hline Combinados (antidepressivo e ansiolítico) & 6 & & & 23 \\
\hline Amitril e Rivotril & 1 & & & 4 \\
\hline Amitril e Diazepan & 1 & & & 4 \\
\hline Triptanol e Rivotril & 3 & & & 11 \\
\hline Triptanol e Diazepan & 1 & & & 4 \\
\hline Nenhum & 10 & & & 39 \\
\hline
\end{tabular}

* medida 1 ano após cessada a exposição

A tabela 6 mostra as análises de correlação intragrupos em que foram encontradas significâncias estatísticas entre variáveis independentes (idade, escolaridade, escore bruto no BDI e no IDATE, HgU, tempos de exposição e de afastamento ao mercúrio) quando comparadas com os dados brutos referentes aos testes e inventários administrados. São apresentados o coeficiente de correlação de Spearman (rS) e o nível de significância (valor de p).

A descrição detalhada dos resultados apresentados nas tabelas 5 e 6 encontra-se a seguir (vide item 3.71) 
Tabela 5

Medianas, médias, desvios e valor de $p$ referentes aos dados brutos obtidos pelos grupos exposto e controle na avaliação neuropsicológica

\begin{tabular}{|c|c|c|c|c|c|}
\hline \multirow[b]{2}{*}{ Testes e Inventários } & \multicolumn{2}{|c|}{ Grupo Exposto } & \multicolumn{2}{|c|}{ Grupo Controle } & \multirow[b]{2}{*}{$\boldsymbol{P}$} \\
\hline & Md & $M \pm D P$ & Md & $M \pm D P$ & \\
\hline \multicolumn{6}{|l|}{ Dígitos } \\
\hline Diretos & 5 & $5,1 \pm 2,0$ & 6 & $6,1 \pm 1,9$ & $0,094^{*}$ \\
\hline Indiretos & 4 & $3,8 \pm 1,8$ & 4 & $3,9 \pm 1,4$ & $0,842^{*}$ \\
\hline \multicolumn{6}{|l|}{ Stroop } \\
\hline Parte 1 & 17 & $19,8 \pm 8,8$ & 14 & $15,0 \pm 4,6$ & $0,004^{*}$ \\
\hline Parte 2 & 22,5 & $26,5 \pm 13,8$ & 17 & $19,2 \pm 7,4$ & $0,010^{*}$ \\
\hline Parte 3 & 32,5 & $47,0 \pm 56,0$ & 29 & $30,8 \pm 10,1$ & $0,132^{*}$ \\
\hline Efeito Stroop & 1,8 & $2,1 \pm 0,9$ & 1,9 & $2,1 \pm 0,7$ & $0,731^{*}$ \\
\hline \multicolumn{6}{|l|}{ SRT } \\
\hline Total de Recuperação & 88 & $87,9 \pm 22,6$ & 107 & $102,1 \pm 20,3$ & $0,021^{*}$ \\
\hline Recuperação de Longo Prazo & 63 & $66,1 \pm 30,7$ & 89,5 & $87,1 \pm 24,4$ & $0,028^{*}$ \\
\hline Armazenamento de Longo Prazo & 86 & $78,0 \pm 31,4$ & 103 & $98,7 \pm 26,7$ & $0,021^{*}$ \\
\hline Recuperação Consistente de Longo Prazo & 34 & $36,9 \pm 25,6$ & 64 & $64,1 \pm 30,8$ & $0,006^{*}$ \\
\hline Recuperação Randômica de Longo Prazo & 30 & $29,0 \pm 13,5$ & 25,5 & $29,6 \pm 14,6$ & $0,907^{*}$ \\
\hline Intrusões & 2 & $3,5 \pm 3,9$ & 0,5 & $1,7 \pm 2,4$ & $0,108^{*}$ \\
\hline Recuperação Tardia (após 30 min.) & 8 & $6,8 \pm 3,2$ & 9 & $9,5 \pm 1,8$ & $0,008^{*}$ \\
\hline Total de Reconhecimento & 11 & $9,5 \pm 2,8$ & 12 & $11,2 \pm 1,1$ & $0,078^{*}$ \\
\hline \multicolumn{6}{|l|}{ Reprodução Visual } \\
\hline Imediata & 29,5 & $28,7 \pm 7,5$ & 30,5 & $29,0 \pm 7,3$ & $0,877^{*}$ \\
\hline Tardia (após 30 min.) & 20 & $21,2 \pm 11,3$ & 26 & $23,7 \pm 9,9$ & $0,528^{*}$ \\
\hline \multicolumn{6}{|l|}{ FAS } \\
\hline Letra F & 10 & $9,8 \pm 4,4$ & 11 & $11,9 \pm 3,1$ & $0,073^{*}$ \\
\hline Letra A & 7,5 & $8,2 \pm 3,4$ & 11 & $10,7 \pm 2,9$ & $0,006^{*}$ \\
\hline Letra S & 7 & $7,4 \pm 3,6$ & 9 & $9,5 \pm 3,2$ & $0,035^{*}$ \\
\hline Total & 25 & $24,7 \pm 10,6$ & 32,5 & $32,1 \pm 7,7$ & $0,010^{*}$ \\
\hline \multicolumn{6}{|l|}{ Grooved Pegboard } \\
\hline Mão Dominante & 79 & $89,9 \pm 20,7$ & 75,5 & $77,4 \pm 11,7$ & $0,019^{*}$ \\
\hline Mão Não Dominante & 95 & $104,1 \pm 30$ & 82,5 & $85,4 \pm 15,4$ & $0,008^{*}$ \\
\hline Cubos & 20 & $19,1 \pm 8,8$ & 22 & $23,4 \pm 11,0$ & $0,288^{*}$ \\
\hline \multicolumn{6}{|l|}{ Wisconsin } \\
\hline Total de Erros & 66 & $63,3 \pm 23,8$ & 52,5 & $53,1 \pm 26,0$ & $0,163^{*}$ \\
\hline Respostas Perseverativas & 41 & $48,1 \pm 31,5$ & 27 & $36,8 \pm 30,7$ & $0,124^{*}$ \\
\hline Erros Perseverativos & 36 & $39,0 \pm 23,8$ & 23 & $29,1 \pm 22,8$ & $0,076^{*}$ \\
\hline Erros Não Perseverativos & 28 & $28,0 \pm 21,0$ & 16,5 & $20,7 \pm 17,4$ & $0,171^{*}$ \\
\hline Respostas de Nível Conceitual & 42 & $41,6 \pm 21,3$ & 58 & $50,3 \pm 20,4$ & $0,167^{*}$ \\
\hline Categorias Completas & 2 & $2,8 \pm 2,2$ & 4 & $3,5 \pm 2,1$ & $0,251^{*}$ \\
\hline Tentativas para Completar a $1^{\circ}$ Categoria & 12 & $18,1 \pm 22,7$ & 11 & $20,8 \pm 25,9$ & $0,759^{*}$ \\
\hline Perdas de Meta & 0 & $0,5 \pm 0,7$ & 1 & $0,8 \pm 0,8$ & $0,166^{*}$ \\
\hline Vocabulário & 28 & $29,8 \pm 6,2$ & 33 & $32 \pm 12,3$ & $0,673^{*}$ \\
\hline BDI & 24 & $26,0 \pm 13,3$ & 6 & $7,1 \pm 5,7$ & $<0,001^{* *}$ \\
\hline \multicolumn{6}{|l|}{ IDATE } \\
\hline Estado & 58 & $56,6 \pm 11,0$ & 37 & $38,1 \pm 7,5$ & $<0,001^{* *}$ \\
\hline Traço & 55 & $56,7 \pm 11,8$ & 37 & $38,3 \pm 9,6$ & $<0,001^{* *}$ \\
\hline
\end{tabular}

* teste de Mann-Whitney

** teste $t$ de Student 
Tabela 6

Variáveis intragrupos com correlação significativa, coeficiente de correlação de Spearman (rS) e valor de p

\begin{tabular}{|c|c|c|c|c|c|}
\hline \multirow[b]{2}{*}{ Variáveis } & \multirow[b]{2}{*}{ Variáveis } & \multicolumn{2}{|c|}{ Grupo Exposto } & \multicolumn{2}{|c|}{ Grupo Controle } \\
\hline & & rS & $P$ & rS & $P$ \\
\hline \multirow[t]{8}{*}{ Idade } & Stroop & & & & \\
\hline & Parte 2 & - & - & 0,535 & 0,015 \\
\hline & Parte 3 & - & - & 0,637 & 0,002 \\
\hline & FA S & & & & \\
\hline & Letra A & - & - & $-0,583$ & 0,006 \\
\hline & Cubos & - & - & $-0,605$ & 0,004 \\
\hline & Wisconsin & & & & \\
\hline & Perdas de Meta & 0,499 & 0,021 & - & - \\
\hline \multirow[t]{13}{*}{ Escolaridade } & Dígitos Diretos & - & - & 0,735 & 0,000 \\
\hline & Stroop & & & & \\
\hline & Parte 3 & - & - & $-0,643$ & 0,018 \\
\hline & SRT & & & & \\
\hline & Reconhecimento & 0,438 & 0,046 & 0,502 & 0,033 \\
\hline & FAS & & & & \\
\hline & Letra A & 0,627 & 0,000 & - & - \\
\hline & Total & 0,392 & 0,047 & - & - \\
\hline & Cubos & 0,479 & 0,013 & - & - \\
\hline & Reprodução Visual & & & & \\
\hline & Imediata & - & - & 0,536 & 0,021 \\
\hline & Tardia & - & - & 0,526 & 0,024 \\
\hline & Vocabulário & - & - & 0,643 & 0,005 \\
\hline \multirow[t]{11}{*}{ BDI (escore bruto) } & - & - & - & - & - \\
\hline & Dígitos Indiretos & $-0,503$ & 0,010 & $-0,465$ & 0,044 \\
\hline & Stroop & & & & \\
\hline & Parte 3 & 0,483 & 0,014 & - & - \\
\hline & SRT & & & & \\
\hline & Rec. Consistente de Longo Prazo & $-0,433$ & 0,049 & - & - \\
\hline & Wisconsin & & & & \\
\hline & Erros & - & - & 0,642 & 0,002 \\
\hline & Respostas Perseverativas & - & - & 0,678 & 0,001 \\
\hline & Erros Perseverativos & - & - & 0,733 & 0,000 \\
\hline & Categorias Completas & $-0,442$ & 0,044 & $-0,575$ & 0,009 \\
\hline IDATE - Estado (escore bruto) & - & - & - & - & - \\
\hline IDATE - Traço (escore bruto) & Dígitos Indiretos & - & - & $-0,483$ & 0,030 \\
\hline $\mathrm{HgU}$ & IDATE - Traço & 0,755 & 0,021 & * & * \\
\hline Tempo de Exposição ao $\mathrm{Hg}^{0}$ & - & - & - & * & * \\
\hline Tempo de Afastamento do $\mathrm{Hg}^{0}$ & - & - & - & * & * \\
\hline
\end{tabular}

* não se aplica 


\subsection{Apresentação dos Resultados Conforme os Domínios Examinados}

As distribuições dos dados brutos resultantes de cada teste e inventário aplicados serão apresentados através de gráficos do tipo boxplot, que contém a mediana, o $1^{\circ}$ e $3^{\circ}$ quartil e os percentis 5 e 95 , conforme representa a figura 7 . A presença de asterisco indica diferença significante $(p<0,05)$ entre os desempenhos dos grupos para a variável em análise.

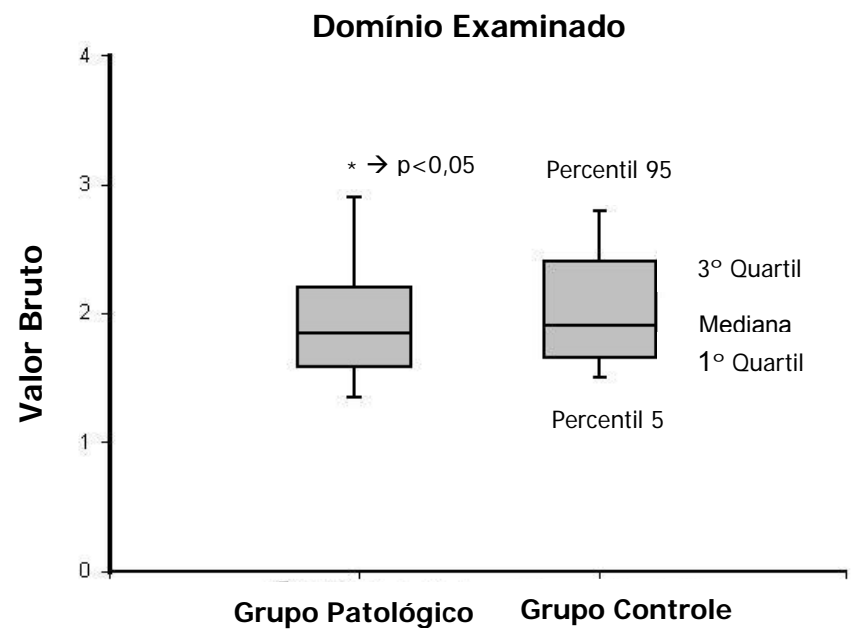

Figura 7. Modelo de gráfico mediante a apresentação da distribuição dos dados com a mediana, $1^{\circ}$ e $3^{\circ}$ quartil e percentis 5 e 95 .

\subsection{Atenção}

No teste Dígitos, o teste de Mann-Whitney não revelou diferença significante entre os grupos tanto na ordem direta $(p=0,094)$ (figura 8$)$, quanto na inversa $(p=0,842)$ (figura 9). Conforme a tabela 6, o grupo controle apresenta correlação positiva $(r S=0,735)$ entre a variável "escolaridade" e o escore bruto em Dígitos Diretos $(p=0)$. 


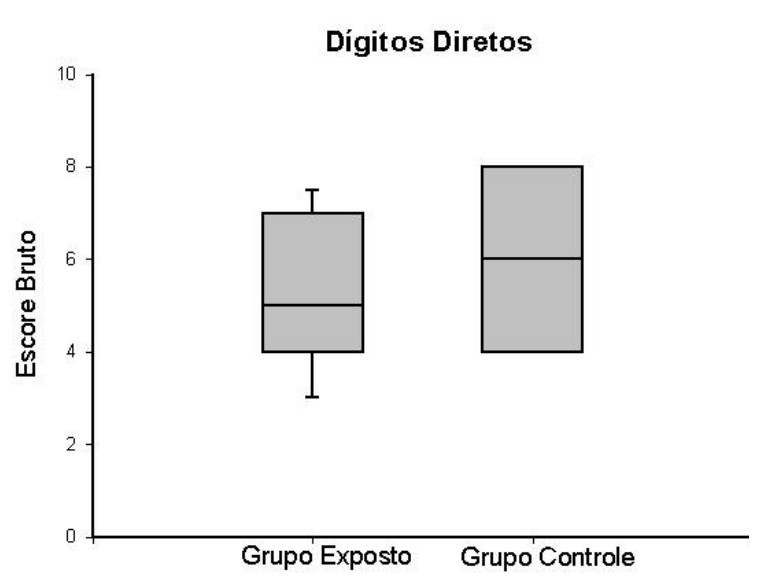

Figura 8. Mediana, $1^{\circ}$ e $3^{\circ}$ quartis, percentil 5 e 95 dos dados brutos obtidos pelo grupo exposto ao vapor de $\mathrm{Hg}^{\prime}$ e grupo controle em Dígitos Diretos.

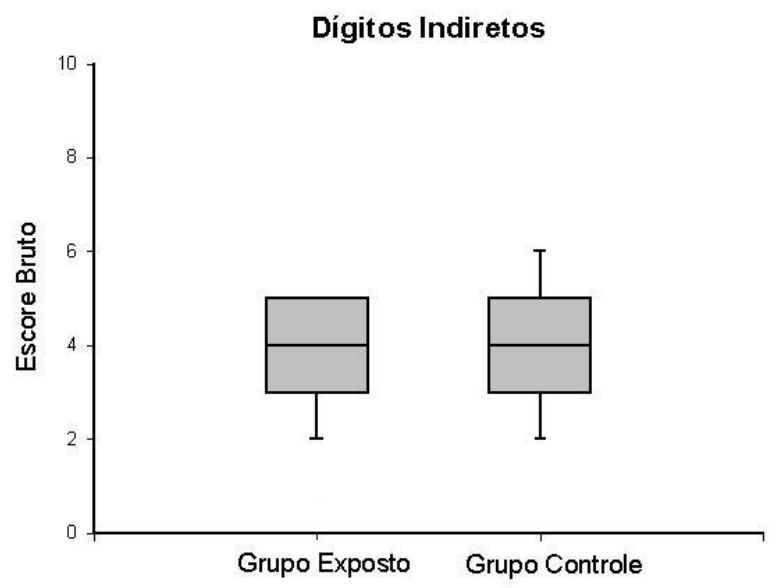

Figura 9. Mediana, $1^{\circ}$ e $3^{\circ}$ quartis, percentil 5 e 95 dos dados brutos obtidos pelo grupo exposto ao vapor de $\mathrm{Hg}^{0}$ e grupo controle em Dígitos Indiretos.

No teste de Stroop, os ex-trabalhadores demonstraram desempenho inferior ao grupo controle nas partes $1(p=0,004)$ (figura 10) e $2(p=0,010)$ (figura 11), mas não nos itens referentes à inibição de resposta impulsiva, representados pela parte $3(p=0,132)$ (figura 12) e o efeito stroop $(p=0,731)$ (figura 13). A variável "escolaridade" teve correlação negativa com o teste de Stroop na parte 3 para o grupo controle $(r S=-0,643 ; p=0,018)$, indicando menor tempo para a execução da tarefa conforme maior o nível de educação formal; enquanto "idade" manteve coeficiente de correlação positivo nas partes $2(r S=0,535 ; p=0,015)$ e $3(r S=0,637$; $p=0,002)$, conforme consta na tabela 6 .

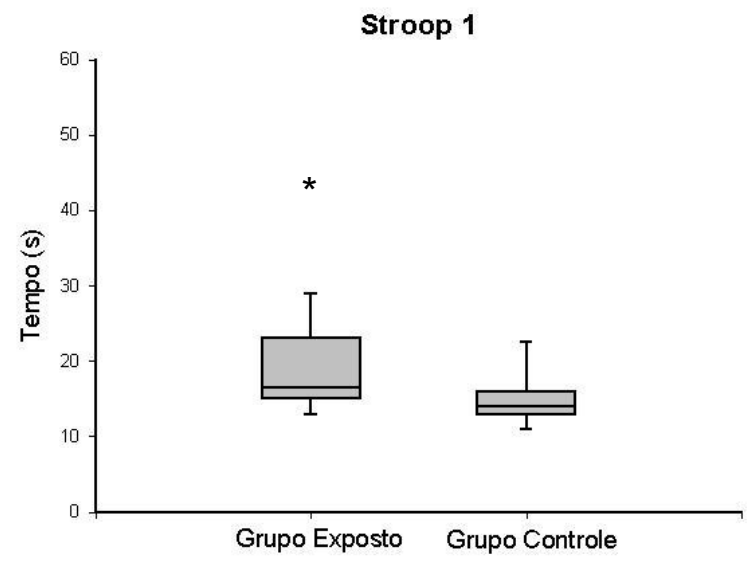

Figura 10. Mediana, $1^{\circ}$ e $3^{\circ}$ quartis, percentil 5 e 95 dos tempos obtidos pelo grupo exposto ao vapor $\mathrm{de}^{\mathrm{Hg}} \mathrm{e}$ grupo controle em Stroop parte 1.

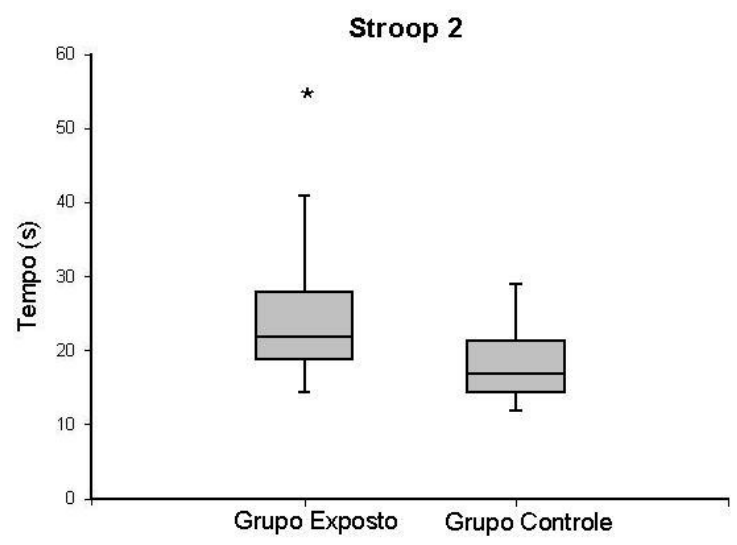

Figura 11. Mediana, $1^{\circ}$ e $3^{\circ}$ quartis, percentil 5 e 95 dos tempos obtidos pelo grupo exposto ao vapor $\mathrm{de}^{\mathrm{H}} \mathrm{e}$ grupo controle em Stroop parte 2. 


\section{Stroop 3}

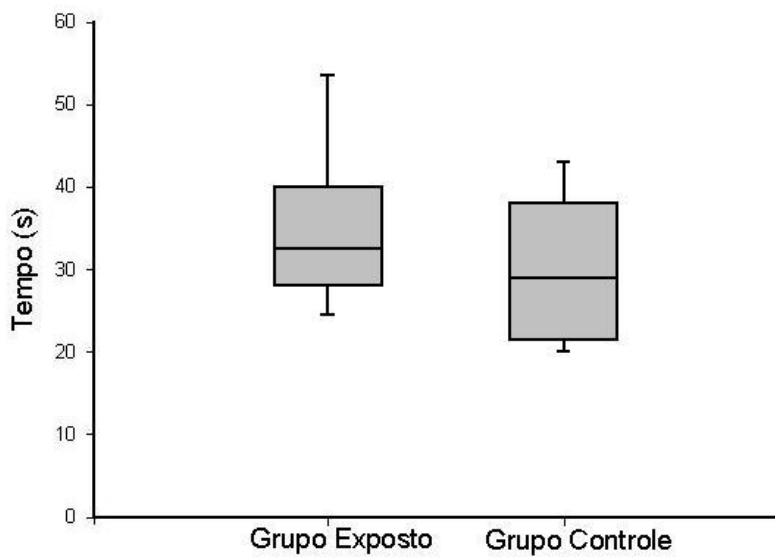

Figura 12. Mediana, $1^{\circ}$ e $3^{\circ}$ quartis, percentil 5 e 95 dos tempos obtidos pelo grupo exposto ao vapor de $\mathrm{Hg}^{0}$ e grupo controle em Stroop parte 3 .

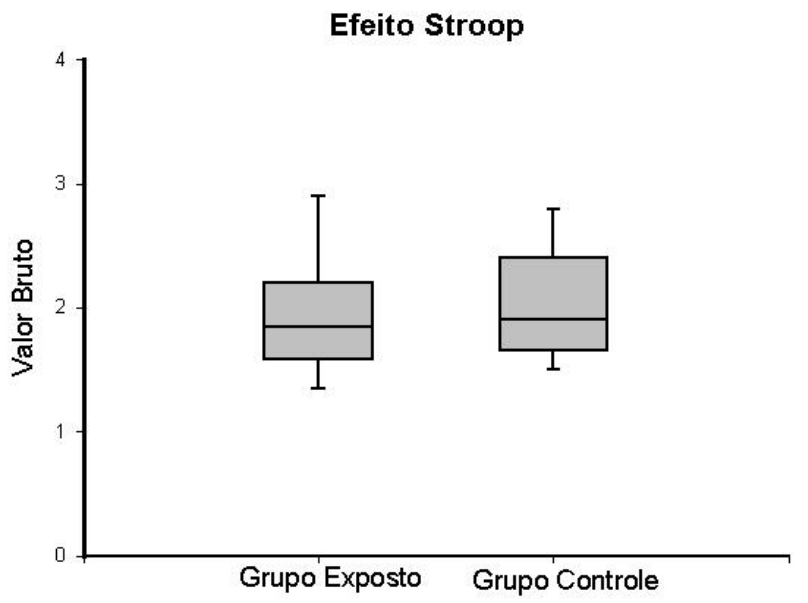

Figura 13. Mediana, $1^{\circ}$ e $3^{\circ}$ quartis, percentil 5 e 95 dos dados brutos obtidos pelo grupo exposto ao vapor de $\mathrm{Hg}^{0}$ e grupo controle no Efeito Stroop.

\subsection{Memória}

Em memória verbal, os dados do SRT mostraram diferença estatística no total de palavras recuperadas $(p=0,021)$ (figura 14$)$, recuperação $(p=0,028)$ (figura 15) e armazenamento $(p=0,021)$ (figura 16) de longo prazo, recuperação consistente de longo prazo $(p=0,006)$ (figura 17) e tardia $(p=0,008)$ (figura 20), mas não para recuperação randômica de longo prazo $(p=0,756)$ (figura 18), intrusões $(p=0,108)$ (figura 19) e reconhecimento $(p=0,078)$ (figura 21). Houve correlação de melhor reconhecimento das palavras conforme maior "escolaridade" tanto no grupo exposto ( $r S=0,438 ; p=0,046)$ quanto no controle ( $r S=0,502 ; p=0,033)$ (tabela 6).

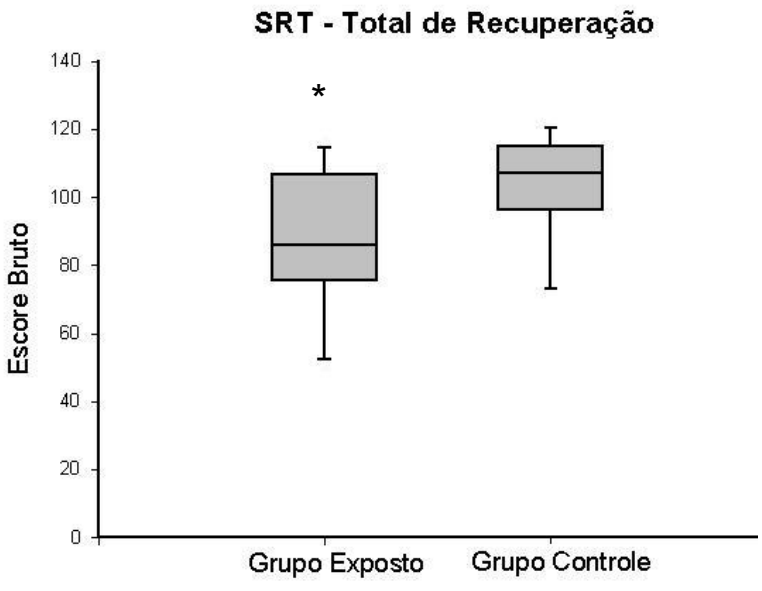

Figura 14. Mediana, $1^{\circ}$ e $3^{\circ}$ quartis, percentil 5 e 95 dos escores brutos obtidos pelo grupo exposto ao vapor de $\mathrm{Hg}^{0}$ e grupo controle no SRT para o Total de Recuperação.

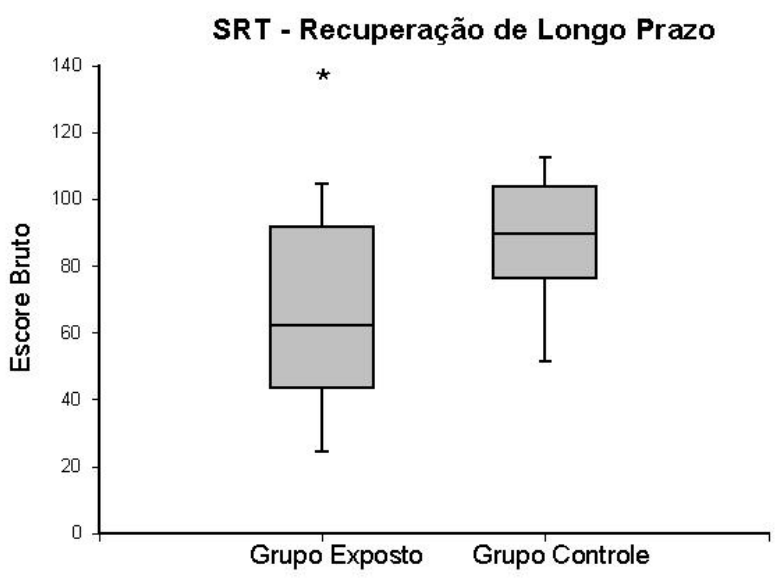

Figura 15. Mediana, $1^{\circ}$ e $3^{\circ}$ quartis, percentil 5 e 95 dos escores brutos obtidos pelo grupo exposto ao vapor de $\mathrm{Hg}^{0}$ e grupo controle no SRT para Recuperação de Longo Prazo. 


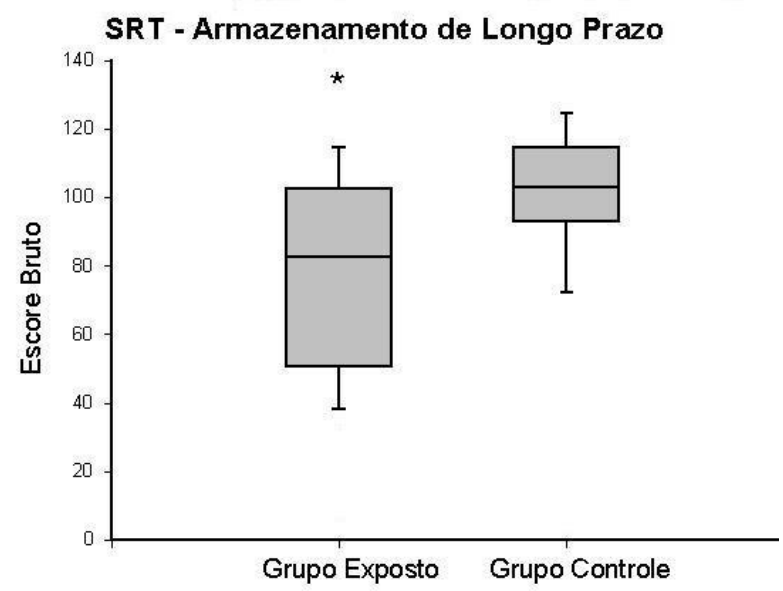

Figura 16. Mediana, $1^{\circ}$ e $3^{\circ}$ quartis, percentil 5 e 95 dos escores brutos obtidos pelo grupo exposto ao vapor de $\mathrm{Hg}^{0}$ e grupo controle no SRT em Armazenamento de Longo Prazo.

SRT -Recuperação Randômica de Longo Prazo

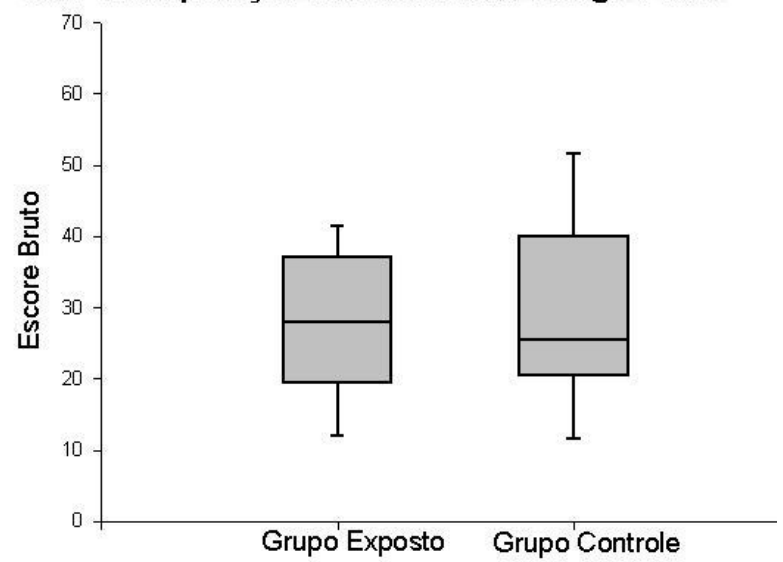

Figura 18. Mediana, $1^{\circ}$ e $3^{\circ}$ quartis, percentil 5 e 95 dos escores brutos obtidos pelo grupo exposto ao vapor de $\mathrm{Hg}^{0}$ e grupo controle no SRT em Recuperação Randômica de Longo Prazo.

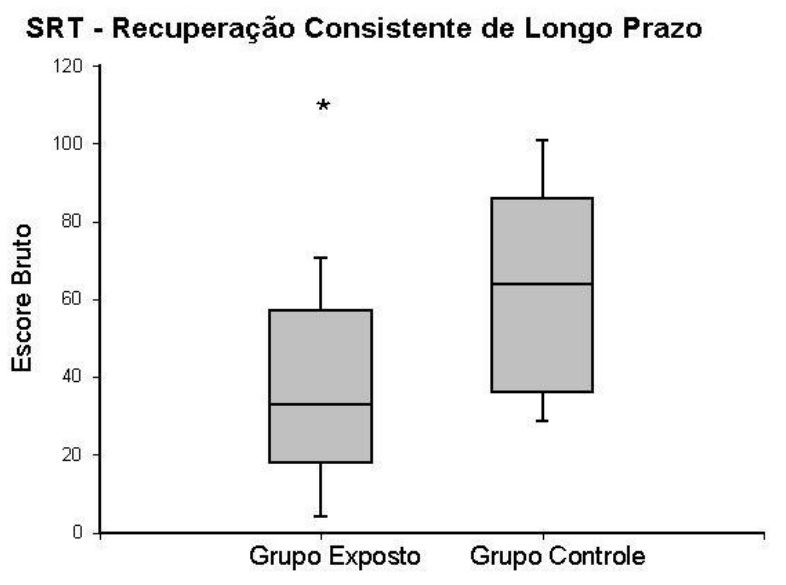

Figura 17. Mediana, $1^{\circ}$ e $3^{\circ}$ quartis, percentil 5 e 95 dos escores brutos obtidos pelo grupo exposto ao vapor de $\mathrm{Hg}^{0}$ e grupo controle no SRT em Recuperação Consistente de Longo Prazo.

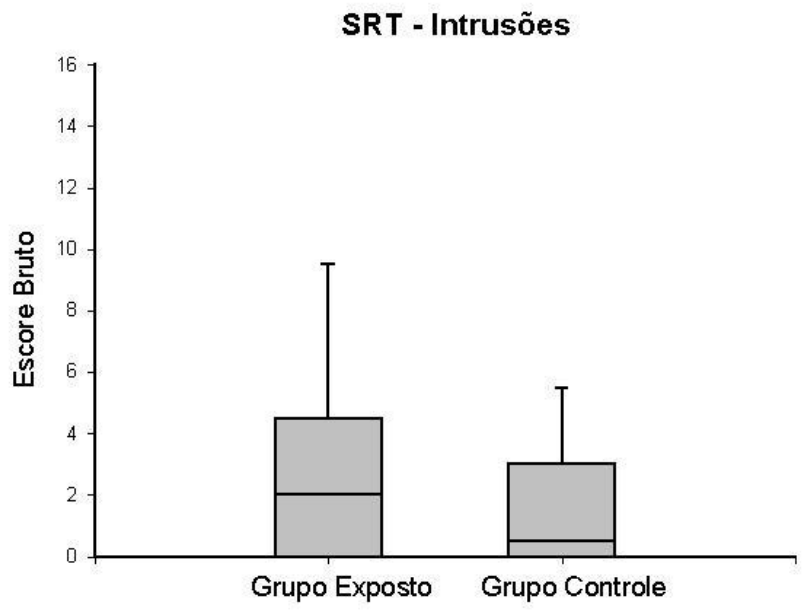

Figura 19. Mediana, $1^{\circ}$ e $3^{\circ}$ quartis, percentil 5 e 95 dos escores brutos obtidos pelo grupo exposto ao vapor de $\mathrm{Hg}^{0}$ e grupo controle no SRT para o $n^{\circ}$ de intrusões.

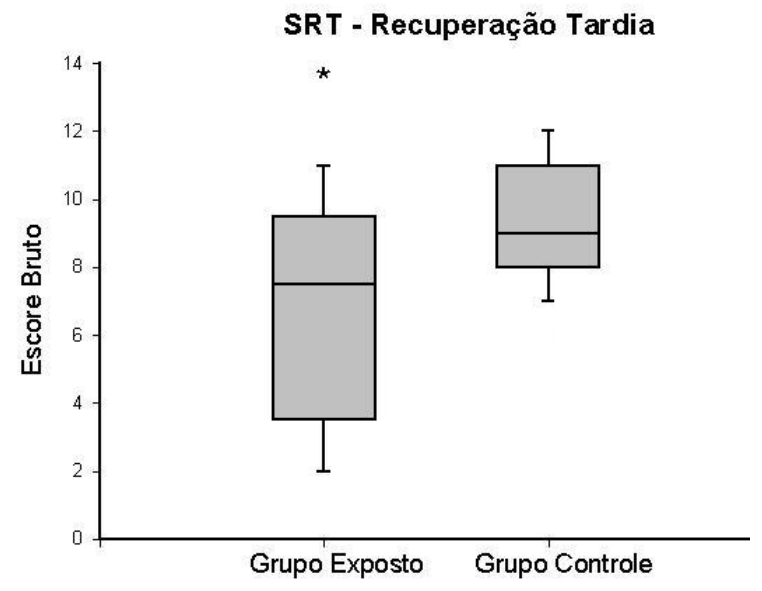

Figura 20. Mediana, $1^{\circ}$ e $3^{\circ}$ quartis, percentil 5 e 95 dos escores brutos obtidos pelo grupo exposto ao vapor de $\mathrm{Hg}^{0} \mathrm{e}$ grupo controle no SRT em Recuperação Tardia.

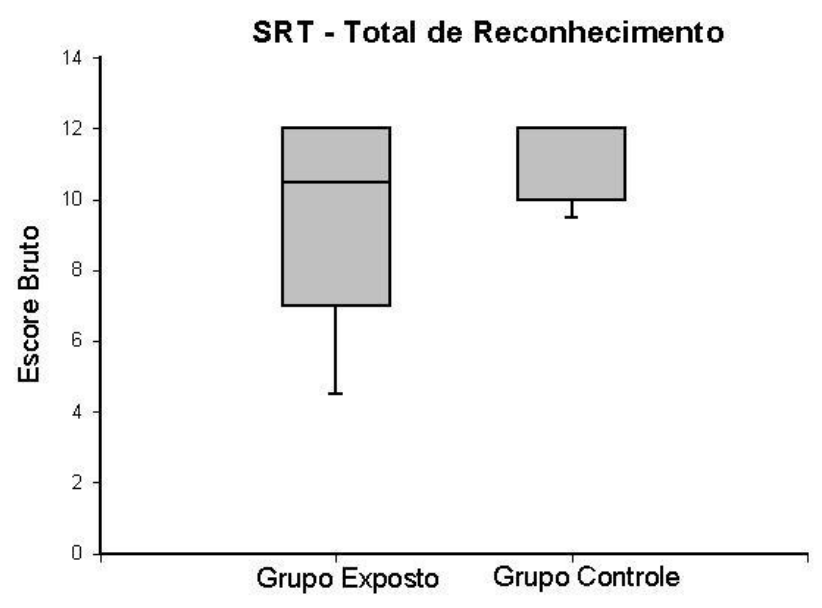

Figura 21. Mediana, $1^{\circ}$ e $3^{\circ}$ quartis, percentil 5 e 95 dos escores brutos obtidos pelo grupo exposto ao vapor de $\mathrm{Hg}^{0} \mathrm{e}$ grupo controle no SRT para o Total de Reconhecimento. 
Em memória visual, os resultados de Reprodução Visual do grupo exposto comparados ao grupo controle não demonstraram alterações em quaisquer fases do teste: reprodução imediata $(p=0,877)$ (figura 22) e tardia $(p=0,528)$ (figura 23$)$. A variável "escolaridade" relativa ao grupo controle apresentou correlação positiva com os escores brutos obtidos em ambas fases, imediata ( $r S=0,536 ; p=0,021)$ e tardia $(r S=0,536 ; p=0,024)$ (tabela 6$)$.

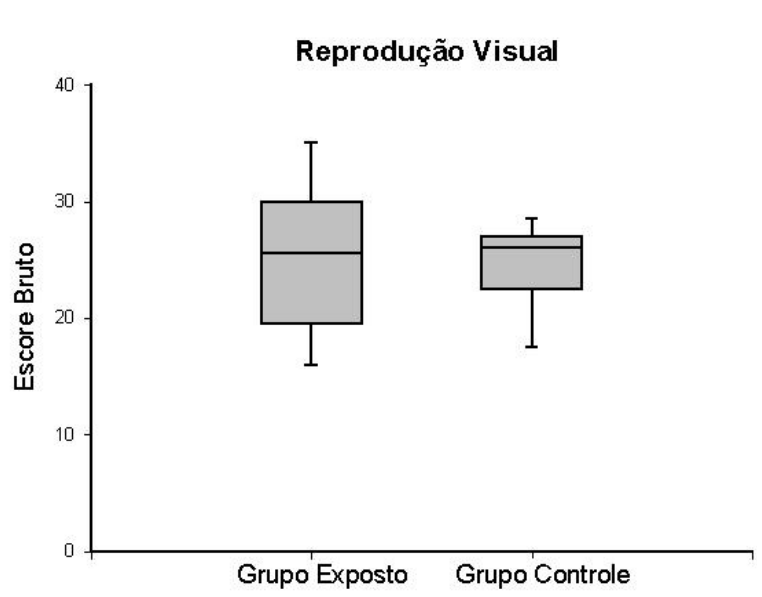

Figura 22. Mediana, $1^{\circ}$ e $3^{\circ}$ quartis, percentil 5 e 95 dos escores brutos obtidos pelo grupo exposto ao vapor de $\mathrm{Hg}^{0}$ e grupo controle em Reprodução Visual Imediata.

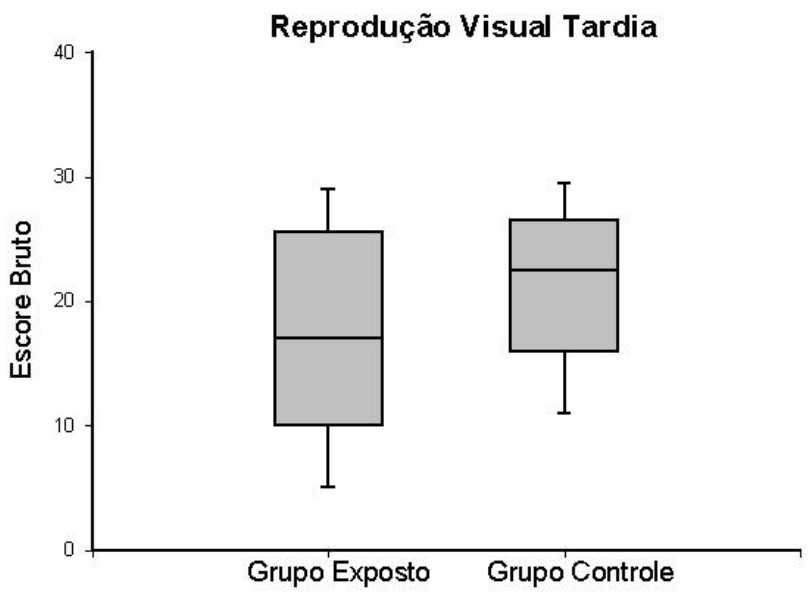

Figura 23. Mediana, $1^{\circ}$ e $3^{\circ}$ quartis, percentil 5 e 95 dos escores brutos obtidos pelo grupo exposto ao vapor de $\mathrm{Hg}^{0}$ e grupo controle em Reprodução Visual Tardia.

\subsection{Fluência Verbal}

No teste FAS, de fluência verbal, houve diferença estatística entre grupos no total de palavras emitidas $(p=0,010)$ (figura 27) e palavras iniciadas com as letras "A" $(p=0,006)$ (figura 25) e " $S$ " $(p=0,035)$ (figura 26), mas não para os escores relativos à letra "F" $(p=0,073)$ (figura 24). Entre os indivíduos expostos, o nível de "escolaridade" teve correlação com maior número de palavras com a inicial "A" $(r S=0,627 ; p=0)$ e o total de palavras geradas no teste $(r S=0,392 ; p=0,047)$; enquanto no grupo controle, o teste de correlação mostrou menor quantidade de palavras iniciadas com "A" conforme maior a "idade" $(r S=-0,583 ; p=0,006)$ (tabela $6)$. 


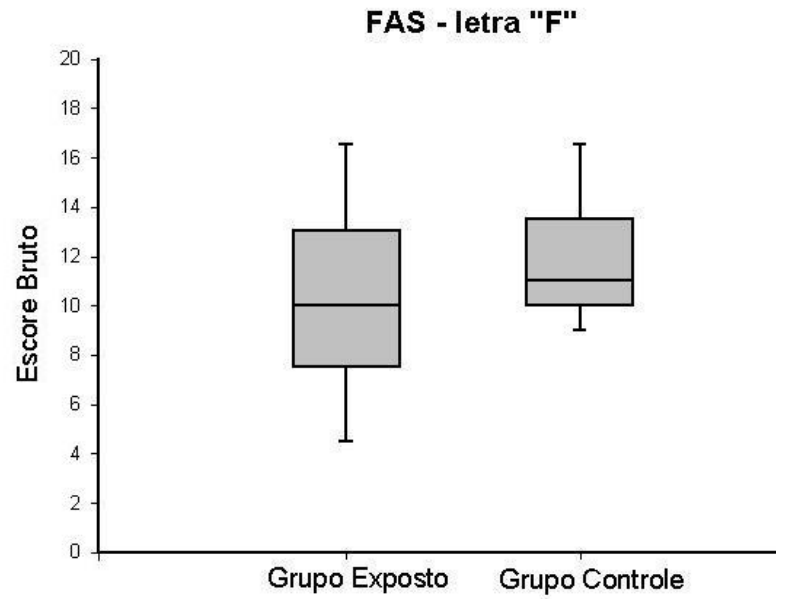

Figura 24. Mediana, $1^{\circ}$ e $3^{\circ}$ quartis, percentil 5 e 95 dos escores brutos obtidos pelo grupo exposto ao vapor de $\mathrm{Hg}^{0}$ e grupo controle em FAS para o total de palavras emitidas iniciadas com a letra " $F$ ".

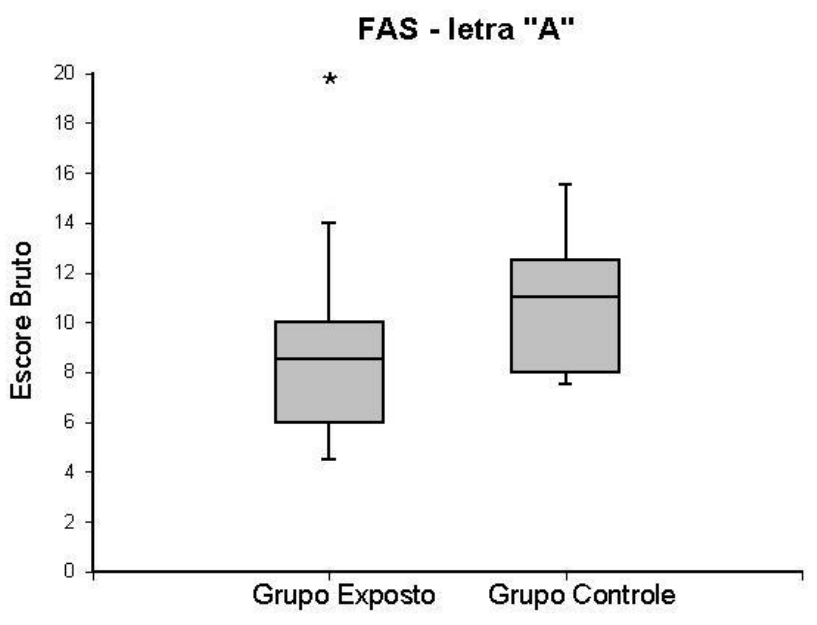

Figura 25. Mediana, $1^{\circ}$ e $3^{\circ}$ quartis, percentil 5 e 95 dos escores brutos obtidos pelo grupo exposto ao vapor de $\mathrm{Hg}^{0}$ e grupo controle em FAS para o total de palavras emitidas iniciadas com a letra "A".

\section{FAS - letra "S"}

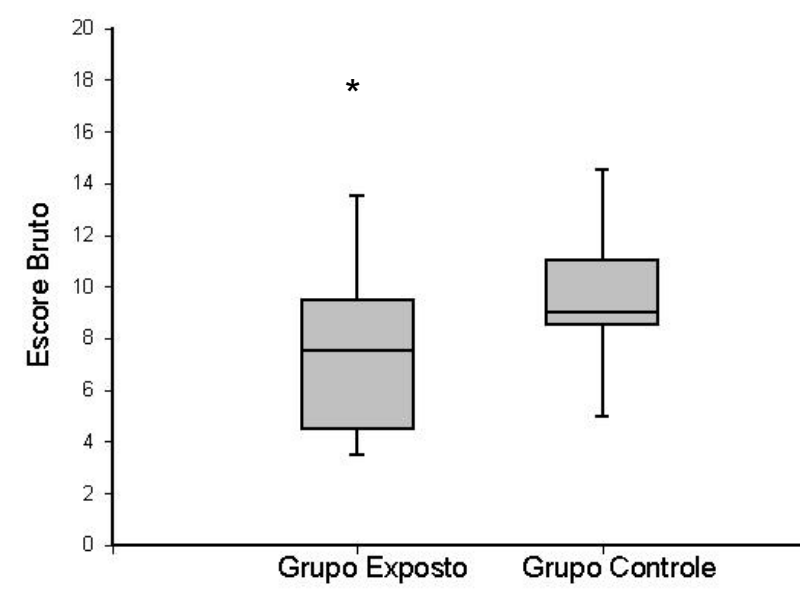

Figura 26. Mediana, $1^{\circ}$ e $3^{\circ}$ quartis, percentil 5 e 95 dos escores brutos obtidos pelo grupo exposto ao vapor de $\mathrm{Hg}^{0}$ e grupo controle em FAS para o total de palavras emitidas iniciadas com a letra " $S$ ".
FAS Total

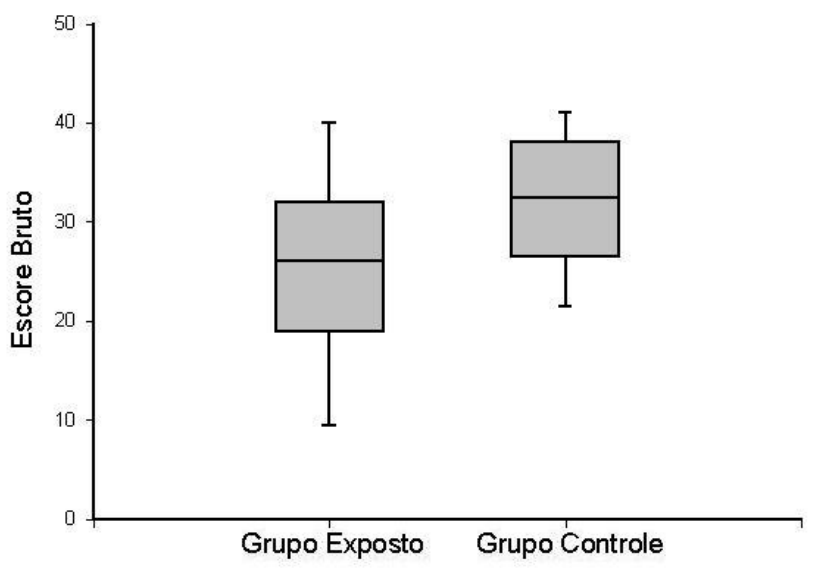

Figura 27. Mediana, $1^{\circ}$ e $3^{\circ}$ quartis, percentil 5 e 95 dos escores brutos obtidos pelo grupo exposto ao vapor de $\mathrm{Hg}^{0}$ e grupo controle em FAS para o total de palavras emitidas no teste.

\subsection{Destreza Manual}

No Grooved Pegboard, os ex-trabalhadores obtiveram tempos significantemente maiores em relação aos controles, tanto para a execução da tarefa utilizando a mão dominante $(p=0,019)$, quanto a mão não dominante $(p=0,008)$, assim como mostram as figuras 28 e 29 , respectivamente. 


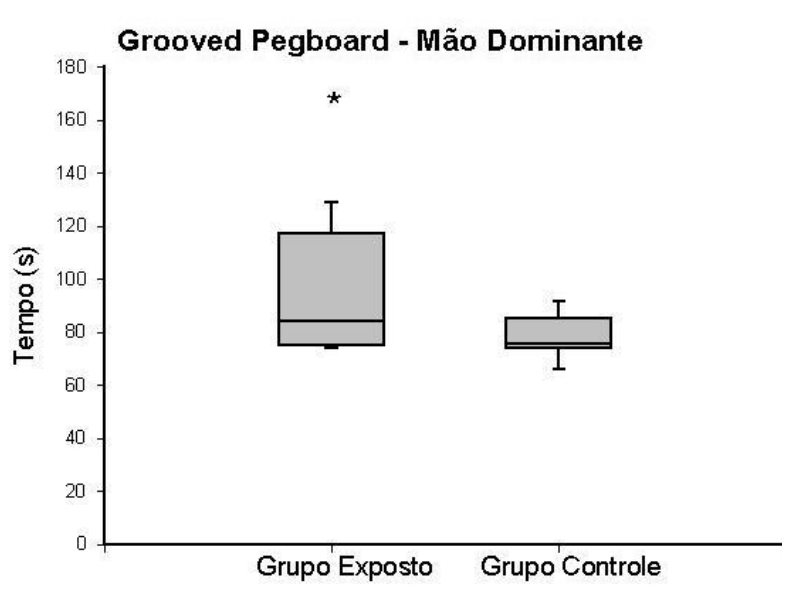

Figura 28. Mediana, $1^{\circ}$ e $3^{\circ}$ quartis, percentil 5 e 95 dos tempos obtidos pelo grupo exposto ao vapor de $\mathrm{Hg}^{0}$ e grupo controle em Grooved Pegboard para a mão dominante.

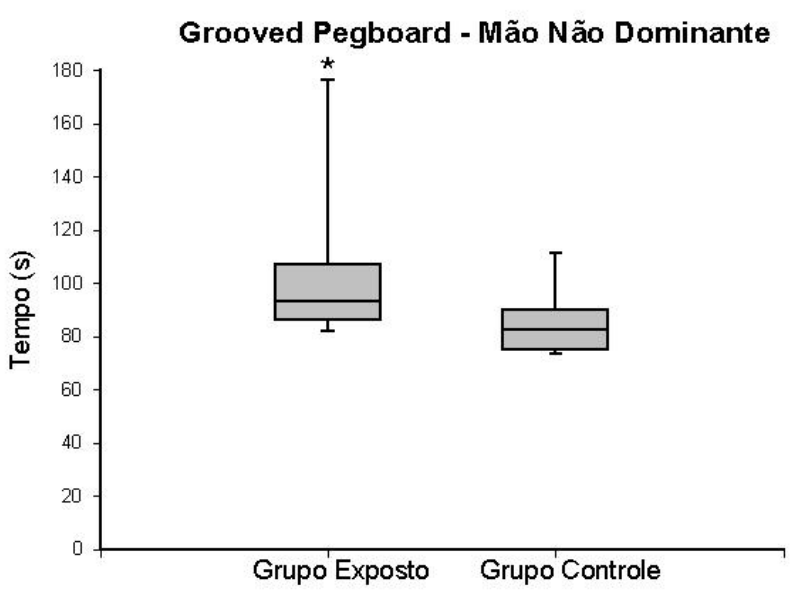

Figura 29. Mediana, $1^{\circ}$ e $3^{\circ}$ quartis, percentil 5 e 95 dos tempos obtidos pelo grupo exposto ao vapor de $\mathrm{Hg}^{0}$ e grupo controle em Grooved Pegboard para a mão não dominante.

\subsection{Função Viso-motora}

No teste Cubos, o desempenho do grupo exposto mostrou-se inalterado em relação ao grupo controle $(p=0,288)$ (figura 30$)$. O teste de correlação de Spearman mostrou significância indicativa de melhor desempenho no teste, de acordo com menor "idade" $(r S=-0,605, p=0,004)$ no grupo controle e conforme o aumento da "escolaridade" ( $r S=0,479 ; p=0,013)$ entre os ex-trabalhadores.

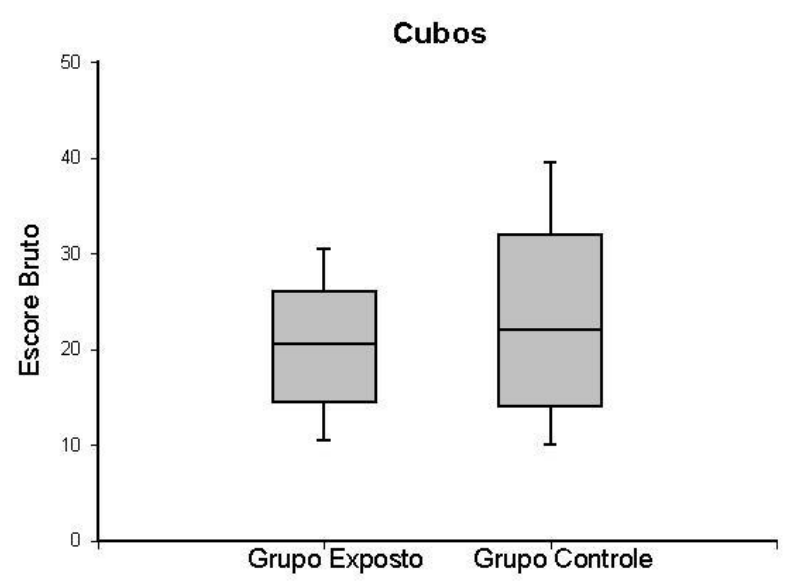

Figura 30. Mediana, $1^{\circ}$ e $3^{\circ}$ quartis, percentil 5 e 95 dos escores brutos obtidos pelo grupo exposto ao vapor de $\mathrm{Hg}^{0} \mathrm{e}$ grupo controle em Cubos.

\subsection{Funções Executivas}

No teste de Wisconsin, os grupos demonstraram desempenhos sem diferenças estatísticas em todos os itens avaliados: total de erros $(p=0,163)$ (figura 
$31)$, respostas perseverativas $(p=0,124)$ (figura 32), erros perseverativos $(p=0,076)$

(figura 33), erros não perseverativos $(p=0,171)$ (figura 34), respostas de nível conceitual $(p=0,167)$ (figura 35$)$, categorias completas $(p=0,251)$ (figura 36$)$, tentativas para completar a $1^{\circ}$ categoria $(p=0,759)$ (figura 37 ) e perdas de meta $(p=0,166)$ (figura 38). No grupo exposto, a variável "idade" apresentou correlação positiva com o número de perdas de meta $(r S=0,499 ; p=0,021)$, conforme mostra a tabela 6.

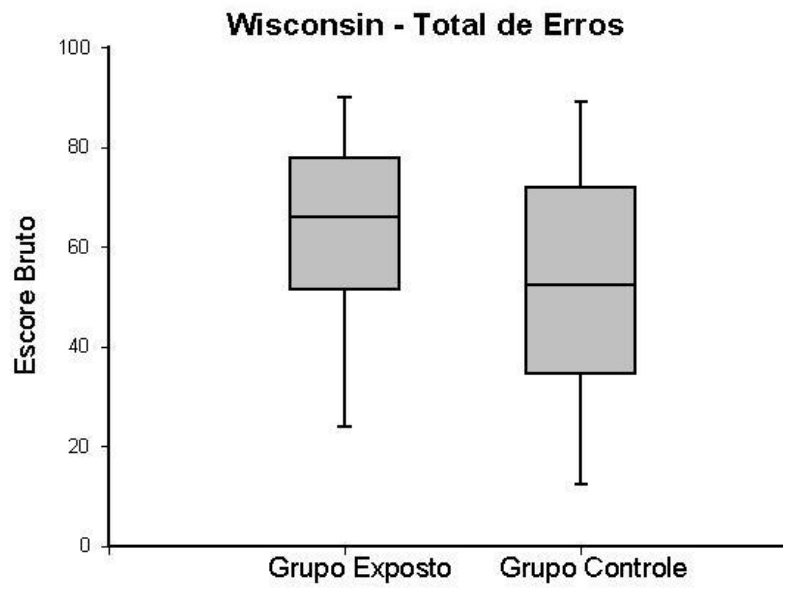

Figura 31. Mediana, $1^{\circ}$ e $3^{\circ}$ quartis, percentil 5 e 95 dos escores brutos obtidos pelo grupo exposto ao vapor de $\mathrm{Hg}^{0} \mathrm{e}$ grupo controle no teste de Wisconsin para o total de erros.

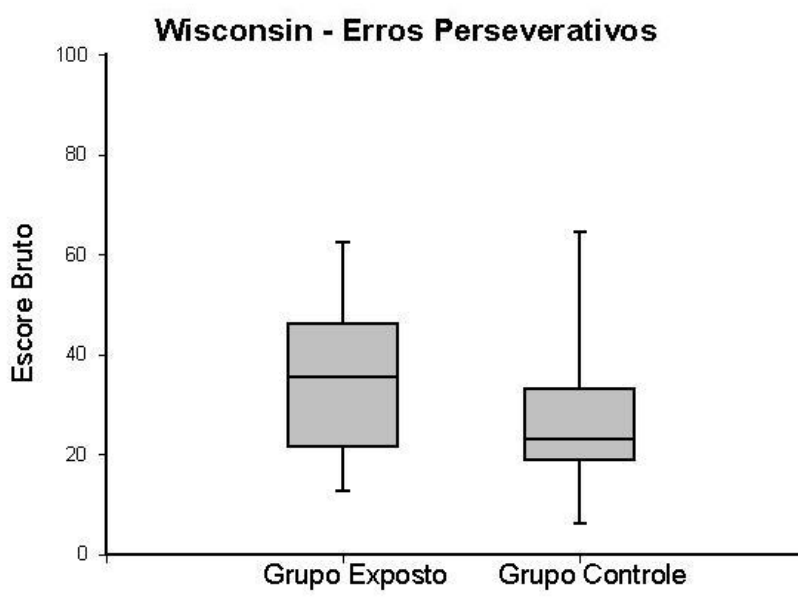

Figura 33. Mediana, $1^{\circ}$ e $3^{\circ}$ quartis, percentil 5 e 95 dos escores brutos obtidos pelo grupo exposto ao vapor de $\mathrm{Hg}^{0} \mathrm{e}$ grupo controle no teste de Wisconsin para erros perseverativos.

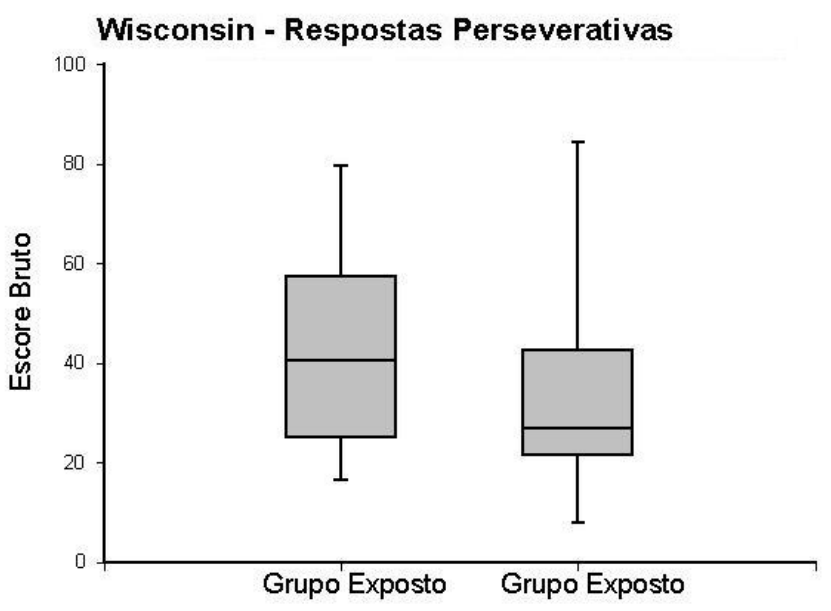

Figura 32. Mediana, $1^{\circ}$ e $3^{\circ}$ quartis, percentil 5 e 95 dos escores brutos obtidos pelo grupo exposto ao vapor de $\mathrm{Hg}^{0}$ e grupo controle no teste de Wisconsin para o $\mathrm{n}^{\circ}$ de respostas perseverativas.

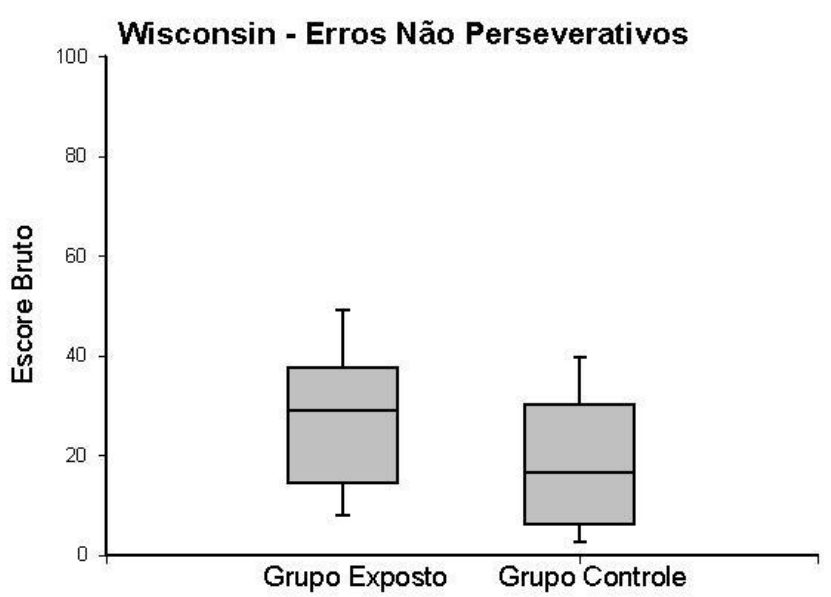

Figura 34. Mediana, $1^{\circ}$ e $3^{\circ}$ quartis, percentil 5 e 95 dos escores brutos obtidos pelo grupo exposto ao vapor de $\mathrm{Hg}^{0}$ e grupo controle no teste de Wisconsin para erros não perseverativos. 


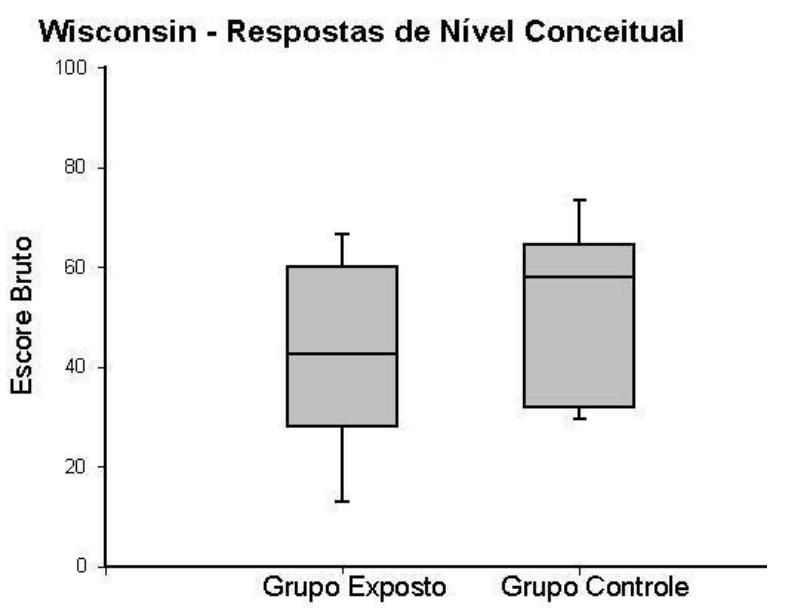

Figura 35. Mediana, $1^{\circ}$ e $3^{\circ}$ quartis, percentil 5 e 95 dos escores brutos obtidos pelo grupo exposto ao vapor de $\mathrm{Hg}^{0}$ e grupo controle no teste de Wisconsin para o $n^{\circ}$ de respostas de nível conceitual.

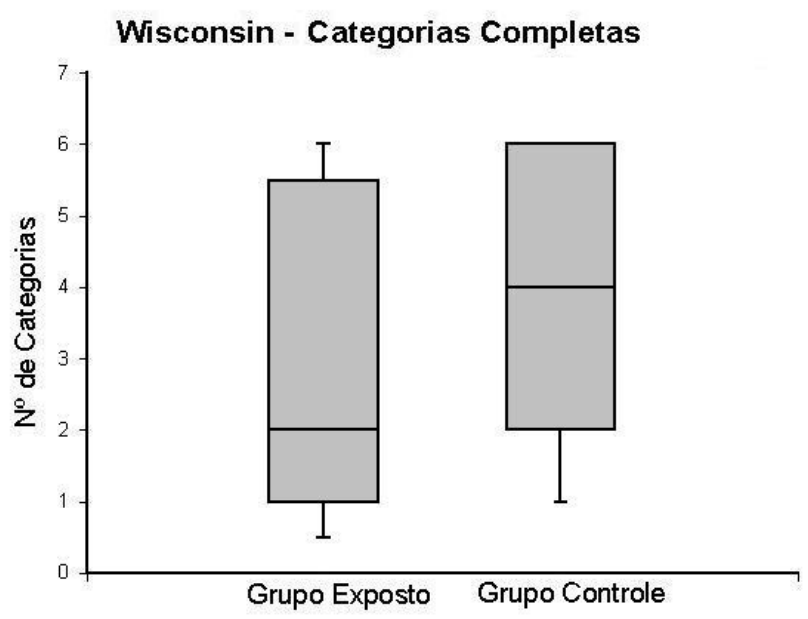

Figura 36. Mediana, $1^{\circ}$ e $3^{\circ}$ quartis, percentil 5 e 95 dos escores brutos obtidos pelo grupo exposto ao vapor de $\mathrm{Hg}^{0} \mathrm{e}$ grupo controle no teste de Wisconsin para o $n^{\circ}$ categorias completas.

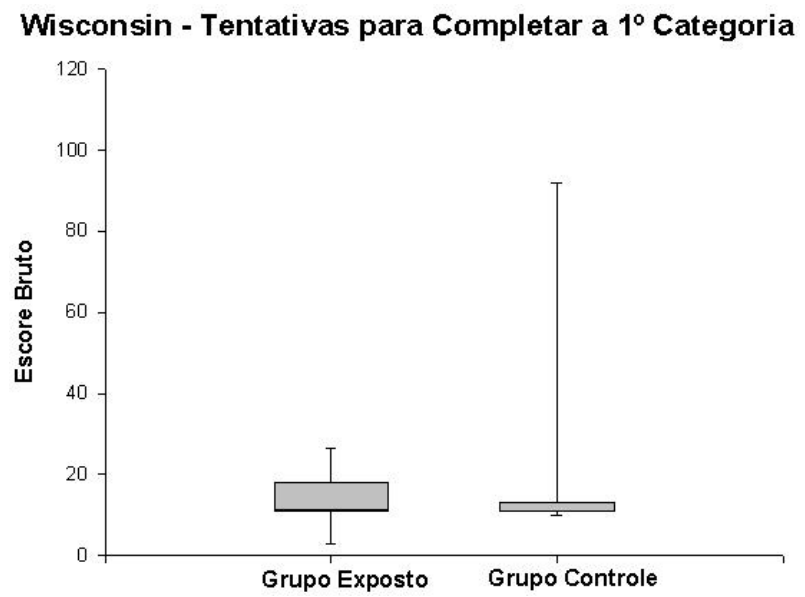

Figura 37. Mediana, $1^{\circ}$ e $3^{\circ}$ quartis, percentil 5 e 95 dos escores brutos obtidos pelo grupo exposto ao vapor de $\mathrm{Hg}^{0}$ e grupo controle no teste de Wisconsin para o $n^{\circ}$ de tentativas para completar a $1^{\circ}$ categoria.

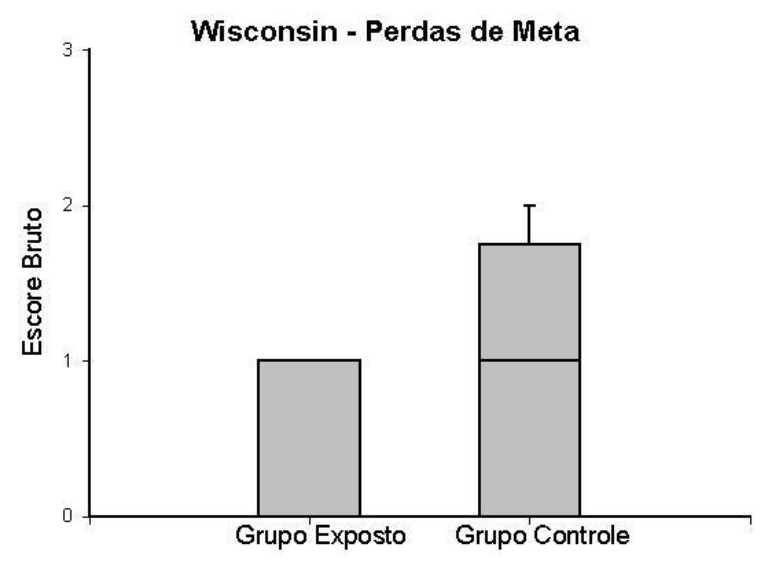

Figura 38. Mediana, $1^{\circ}$ e $3^{\circ}$ quartis, percentil 5 e 95 dos escores brutos obtidos pelo grupo exposto ao vapor de $\mathrm{Hg}^{0}$ e grupo controle no teste de Wisconsin para o $n^{\circ}$ de perdas de meta.

\subsection{Conhecimento Semântico}

Não houve diferença estatística entre os resultados obtidos pelos grupos no teste de Vocabulário ( $p=0,673$ ) (figura 39). Entre os participantes do grupo controle, o teste de correlação de Spearman demonstrou a associação entre o melhor desempenho conforme maior a "escolaridade" ( $r S=0,643 ; p=0,005)$ (tabela 6). 


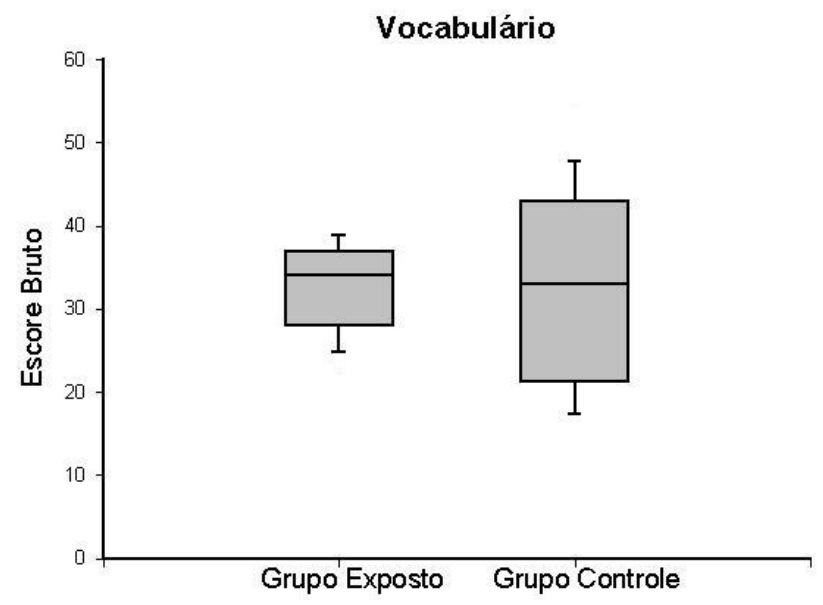

Figura 39. Mediana, $1^{\circ}$ e $3^{\circ}$ quartis, percentil 5 e 95 dos escores brutos obtidos pelo grupo exposto ao vapor de $\mathrm{Hg}^{0} \mathrm{e}$ grupo controle em Vocabulário.

\subsection{Depressão}

Os resultados do inventário de depressão (BDI) foram significantemente diferentes $(p<0,001)$ entre os grupos (figura 40 ). Conforme mostra a tabela 6 , o aumento dos escores totais de depressão se correlacionou com pior desempenho em Dígitos Indiretos $(r S=-0,503 ; p=0,010)$, Stroop parte $3(r S=0,483 ; p=0,014)$, Recuperação Consistente de Longo Prazo no teste de memória verbal ( $r S=-0,433$; $p=0,049)$ e para o Número de Categorias Completas no teste de Wisconsin ( $r S=-$ $0,442 ; p=0,044)$ dentre os indivíduos expostos. No grupo controle, houve correlação compatível com o aumento dos escores totais de depressão em associação a resultados prejudicados em Dígitos Indiretos $(r S=-0,465 ; p=0,044)$ e quanto ao total de erros $(r S=0,642 ; p=0,002)$, respostas perseverativas $(r S=0,678 ; p=0,001)$, erros perseverativos ( $r S=0,733 ; p=0$ ) e o número de categorias completas $(r S=-0,575$; $p=0,009$ ) referentes ao teste de Wisconsin (tabela 6). 


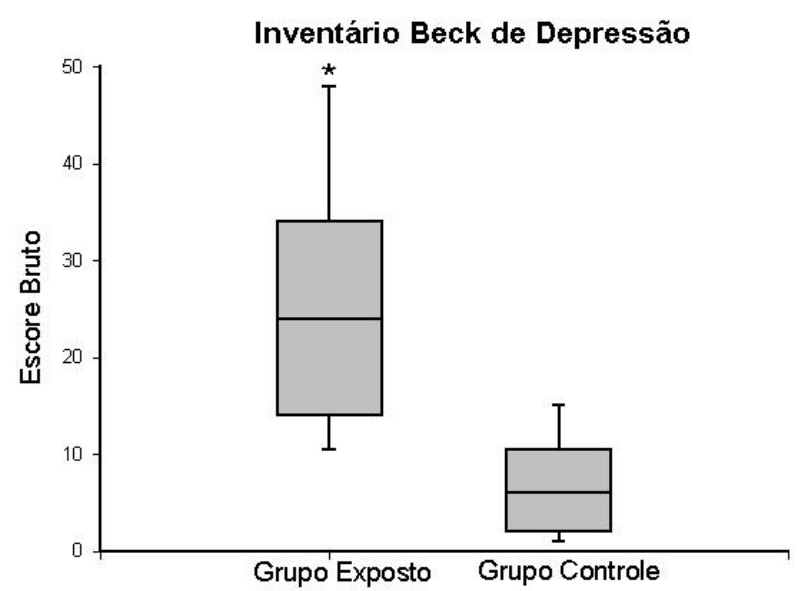

Figura 40. Mediana, $1^{\circ}$ e $3^{\circ}$ quartis, percentil 5 e 95 dos escores brutos obtidos pelo grupo exposto ao vapor de $\mathrm{Hg}^{0}$ e grupo controle no BDI.

\subsection{Ansiedade}

No IDATE, os ex-trabalhadores tiveram escores superiores correspondentes à alteração caracterizada por humor ansioso, tanto no inventário de "estado" (figura 41) quanto no de "traço" (figura 42) de ansiedade, ambos com $p<0,001$. O aumento dos escores do traço de ansiedade mostrou associação com o desempenho prejudicado em Dígitos Indiretos $(p=-0,483 ; p=0,030)$ entre os controles e com maiores concentrações urinárias de mercúrio no grupo exposto $(p=0,755 ; p=0,021)$ (tabela 6).

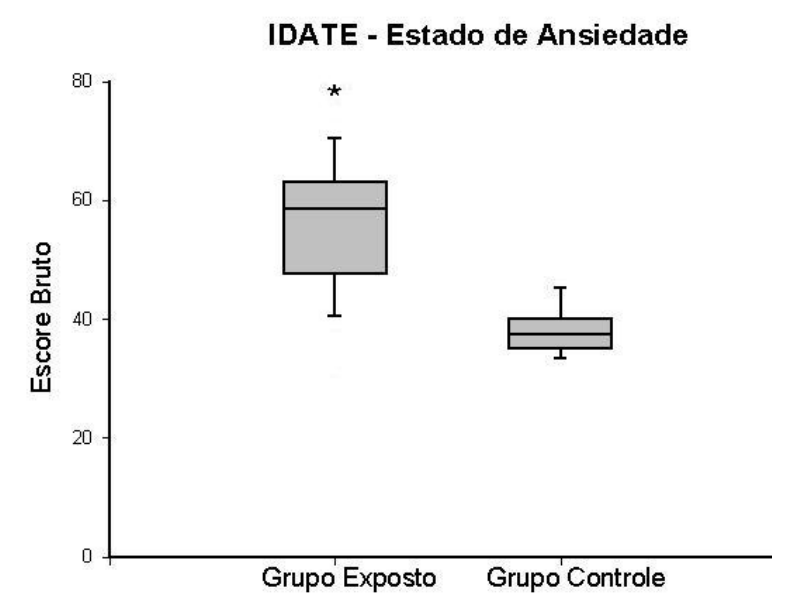

Figura 41. Mediana, $1^{\circ}$ e $3^{\circ}$ quartis, percentil 5 e 95 dos escores brutos obtidos pelo grupo exposto ao vapor de $\mathrm{Hg}^{0}$ e grupo controle no IDATE para estado de ansiedade.

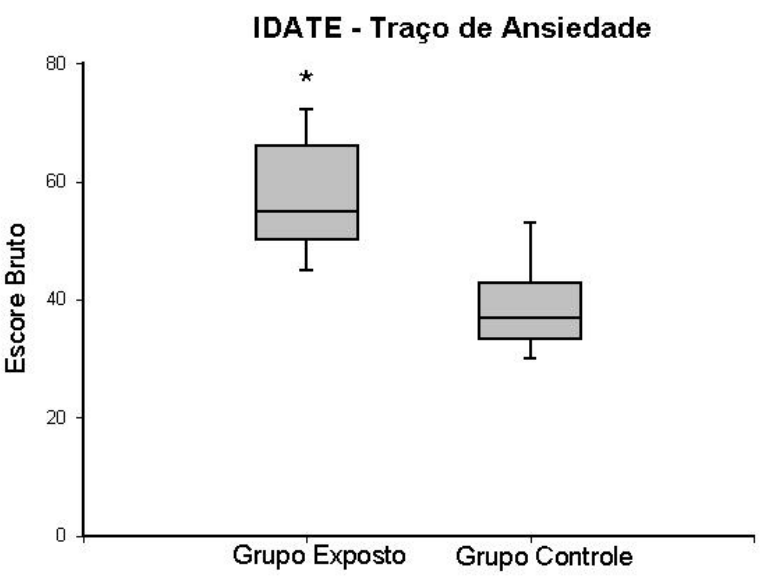

Figura 42. Mediana, $1^{\circ}$ e $3^{\circ}$ quartis, percentil 5 e 95 dos escores brutos obtidos pelo grupo exposto ao vapor de $\mathrm{Hg}^{0}$ e grupo controle no IDATE para traço de ansiedade. 
Conforme a tabela 6, os tempos de exposição e de afastamento do vapor de mercúrio não mostraram correlação com quaisquer variáveis referentes ao grupo exposto. 


\subsection{Resultados Relativos ao Grupo Exposto}

\subsection{1 Índices de Exposição}

Para testar a hipótese de associação entre o maior tempo de exposição ao vapor de mercúrio e disfunções neuropsicológicas, os ex-trabalhadores foram subdivididos em dois grupos com maior e menor tempo de trabalho nas fábricas de lâmpadas, utilizando-se a mediana ( $\mathrm{Md}=9$ anos) como ponto de corte.

Conforme mostra a tabela 7 , os indivíduos com mais tempo de trabalho em contato com mercúrio apresentam idades significantemente maiores $(p=0,013)$ em relação ao grupo menos exposto e, conforme esperado, maior tempo de exposição ao metal $(p<0,001)$. Entretanto, os subgrupos não mostram diferenças quanto aos resultados dos testes neuropsicológicos e inventários de humor.

Tabela 7

Comparação dos dados gerais e escores obtidos nos testes e inventários dos subgrupos com maior e menor tempo de exposição ao vapor de mercúrio.

\section{Tempo de Exposição}

\begin{tabular}{|c|c|c|c|c|c|}
\hline \multirow[b]{2}{*}{ Variáveis } & \multicolumn{2}{|c|}{$>9$ anos $(n=14)$} & \multicolumn{2}{|c|}{$<9$ anos $(n=12)$} & \multirow[b]{2}{*}{$P$} \\
\hline & Md & $M \pm D P$ & Md & $M \pm D P$ & \\
\hline Idade & 42 & $44,1 \pm 6,1$ & 37,5 & $38,3 \pm 4,5$ & 0,013 \\
\hline Escolaridade & 8 & $8,6 \pm 1,9$ & 8,5 & $9,2 \pm 1,6$ & 0,303 \\
\hline Tempo de exposição ao vapor de $\mathrm{Hg}^{0}$ (anos) & 13 & $14,4 \pm 5,9$ & 7 & $6,7 \pm 1,5$ & $<0,001$ \\
\hline Tempo de afastamento ao vapor de $\mathrm{Hg}^{0}$ (anos) & 4 & $6,3 \pm 5,9$ & 5,5 & $6,6 \pm 3,5$ & 0,520 \\
\hline $\mathrm{HgU}(\mu \mathrm{g} / \mathrm{g} \mathrm{Cr})$ & 1,3 & $1,5 \pm 0,8$ & 2,4 & $2,1 \pm 0,9$ & 0,324 \\
\hline Escores nos testes neuropsicológicos & - & - & - & - & n.s. ${ }^{*}$ \\
\hline Escores nos inventários de depressão e ansiedade & - & - & - & - & n.s. ${ }^{*}$ \\
\hline
\end{tabular}

*não significante

Para verificar a possibilidade de alterações neuropsicológicas relacionadas ao menor tempo de afastamento ao vapor de mercúrio, o grupo exposto foi subdividido entre indivíduos com maior ou menor intervalo até os dias atuais após o cessar do trabalho na indústria, tomando-se a mediana ( $\mathrm{Md}=4,5$ anos) como ponto 
de corte. A tabela 8 mostra a comparação dos dados gerais (idade, escolaridade, tempo de exposição e de afastamento ao vapor de mercúrio e concentração urinária), indicando diferença com significância estatística somente para o tempo de afastamento $(p<0,001)$ do contato com o metal. As análises referentes aos testes e inventários aplicados não revelaram diferenças significantes (tabela 8).

\section{Tabela 8}

Comparação dos dados gerais e escores obtidos nos testes e inventários dos subgrupos com maior e menor tempo de afastamento do vapor de mercúrio.

Tempo de Afastamento

\begin{tabular}{|c|c|c|c|c|c|}
\hline \multirow[b]{2}{*}{ Variáveis } & \multicolumn{2}{|c|}{$>4,5$ anos $(n=14)$} & \multicolumn{2}{|c|}{$<4,5$ anos $(n=12)$} & \multirow[b]{2}{*}{$\boldsymbol{P}$} \\
\hline & Md & $M \pm D P$ & Md & $M \pm D P$ & \\
\hline Idade & 41,5 & $42,3 \pm 7,1$ & 41,5 & $40,5 \pm 4,9$ & 0,470 \\
\hline Escolaridade & 9,5 & $9,4 \pm 1,6$ & 8 & $8,3 \pm 1,8$ & 0,110 \\
\hline Tempo de exposição ao vapor de $\mathrm{Hg}^{0}$ (anos) & 8 & $9 \pm 3,7$ & 11 & $13 \pm 7,4$ & 0,086 \\
\hline Tempo de afastamento ao vapor de $\mathrm{Hg}^{0}$ (anos) & 10 & $9,8 \pm 4,1$ & 3 & $2,5 \pm 1,2$ & $<0,001$ \\
\hline $\mathrm{HgU}(\mu \mathrm{g} / \mathrm{g} \mathrm{Cr})$ & 0,9 & $1,3 \pm 0,8$ & 2,4 & $2,3 \pm 0,7$ & 0,088 \\
\hline Escores nos testes neuropsicológicos & - & - & - & - & n.s. ${ }^{*}$ \\
\hline Escores nos inventários de depressão e ansiedade & - & - & - & - & n.s. ${ }^{*}$ \\
\hline
\end{tabular}

Os ex-trabalhadores também foram subdivididos entre aqueles com maior ou menor concentração urinária de mercúrio, conforme a mediana $(\mathrm{Md}=1,5 \mu \mathrm{g} / \mathrm{g}$ Cr), adotada como ponto de corte. A tabela 9 mostra os resultados da comparação entre os subgrupos quanto aos dados gerais e escores obtidos nos testes e inventários, indicando diferença significativa somente para o nível de mercúrio urinário $(p=0,005)$. 
Tabela 9

Comparação dos dados gerais e escores obtidos nos testes e inventários dos subgrupos com maior e menor concentração urinária de mercúrio.

Concentração Urinária de $\mathrm{Hg}^{0}$

\begin{tabular}{|c|c|c|c|c|c|}
\hline \multirow[b]{2}{*}{ Variáveis } & \multicolumn{2}{|c|}{$>1,5 \mu \mathrm{g} / \mathrm{gCr}(\mathrm{n}=16)$} & \multicolumn{2}{|c|}{$<1,5 \mu \mathrm{g} / \mathrm{gCr}(\mathrm{n}=10)$} & \multirow[b]{2}{*}{$P$} \\
\hline & Md & $M \pm D P$ & Md & $M \pm D P$ & \\
\hline Idade & 42 & $41,2 \pm 7,6$ & 43 & $43,3 \pm 10,5$ & 0,747 \\
\hline Escolaridade & 8 & $9,2 \pm 2,2$ & 11 & $9,7 \pm 2,3$ & 0,783 \\
\hline Tempo de exposição ao vapor de $\mathrm{Hg}^{0}$ (anos) & 8 & $9,4 \pm 3,4$ & 12 & $11,3 \pm 4$ & 0,495 \\
\hline Tempo de afastamento ao vapor de $\mathrm{Hg}^{0}$ (anos) & 3 & $5,2 \pm 4,4$ & 8 & $10,3 \pm 6,8$ & 0,143 \\
\hline $\mathrm{HgU}(\mu \mathrm{g} / \mathrm{g} \mathrm{Cr})$ & 2,5 & $2,4 \pm 0,6$ & 0,8 & $0,9 \pm 0,1$ & 0,005 \\
\hline Escores nos testes neuropsicológicos & - & - & - & - & n.s. ${ }^{*}$ \\
\hline Escores nos inventários de depressão e ansiedade & - & - & - & - & n.s. ${ }^{*}$ \\
\hline
\end{tabular}

*não significante

\subsection{Tendinite}

Para exame da hipótese de que os participantes com diagnóstico de tendinite apresentam desempenho inferior em testes que requerem precisão e rapidez motora devido a esta doença, os pacientes expostos foram subdivididos em 2 subgrupos, com e sem diagnóstico de tendinite, para uma análise dos resultados brutos referentes aos testes que requerem habilidade motora, Grooved Pegboard e Cubos, medidas de destreza manual e função viso-motora, respectivamente.

Os dados gerais (idade, escolaridade, tempo de exposição e de afastamento ao vapor de $\mathrm{Hg}^{0}$, concentração urinária de $\mathrm{Hg}^{0}$ ), as medianas, médias e desvios correspondentes aos dados brutos obtidos por ambos os grupos nos testes referidos estão dispostos na tabela 10. Os valores correspondentes a idade $(p=0,450)$, escolaridade $(0,794)$, tempo de exposição $(p=0,088)$ e de afastamento ao vapor de $\mathrm{Hg}^{0}(p=0,321)$, além da concentração urinária de mercúrio $(p=0,684)$ não tiveram diferenças significantes. Ao contrário do resultado esperado, no teste Grooved Pegboard, os pacientes com tendinite demonstraram melhor desempenho através do menor tempo para a execução da tarefa, porém sem significância estatística, tanto para a mão dominante $(p=0,621)$ (figura 43), quanto para a não 
dominante $(p=0,792)$ (figura 44). No teste Cubos, os escores brutos também não revelaram diferenças estatísticas entre os grupos $(p=0,966)$ (figura 45).

Tabela 10

Comparação dos dados gerais e escores obtidos nos testes Grooved Pegboard e Cubos entre pacientes expostos com e sem diagnóstico de tendinite.

\section{Tendinite}

\begin{tabular}{|c|c|c|c|c|c|}
\hline \multirow[b]{2}{*}{ Variável } & \multicolumn{2}{|c|}{$\operatorname{Sim}(n=13)$} & \multicolumn{2}{|c|}{ Não $(n=13)$} & \multirow[b]{2}{*}{$P$} \\
\hline & Md & $M \pm D P$ & Md & $M \pm D P$ & \\
\hline Idade & 39,0 & $41,5 \pm 7,5$ & 42,0 & $41,4 \pm 4,6$ & 0,450 \\
\hline Escolaridade & 8,0 & $9,0 \pm 1,6$ & 8,0 & $8,8 \pm 2,0$ & 0,794 \\
\hline Tempo de exposição ao vapor de $\mathrm{Hg}^{0}$ (anos) & 8,0 & $11,3 \pm 7,3$ & 10,0 & $10,4 \pm 4,8$ & 0,088 \\
\hline Tempo de afastamento ao vapor de $\mathrm{Hg}^{0}$ (anos) & 4,5 & $5,4 \pm 3,8$ & 7,0 & $7,5 \pm 5,6$ & 0,321 \\
\hline $\mathrm{HgU}(\mu \mathrm{g} / \mathrm{gCr})$ & 2,0 & $1,9 \pm 1,0$ & 1,6 & $1,6 \pm 0,8$ & 0,684 \\
\hline \multicolumn{6}{|l|}{ Grooved Pegboard } \\
\hline Mão dominante (segundos) & 74,5 & $83,4 \pm 18,4$ & 93,0 & $95,7 \pm 22,0$ & 0,621 \\
\hline Mão não dominante (segundos) & 90,5 & $100,5 \pm 31,7$ & 99,0 & $107,3 \pm 29,9$ & 0,792 \\
\hline Cubos & 19,0 & $18,5 \pm 9,8$ & 20 & $24,4 \pm 11,4$ & 0,966 \\
\hline
\end{tabular}

\section{Grooved Pegboard - Mão Dominante}

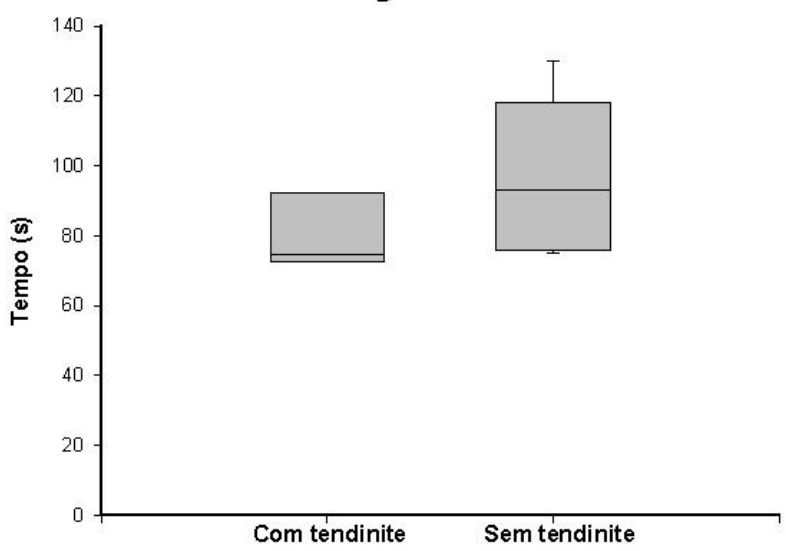

Figura 43. Mediana, $1^{\circ}$ e $3^{\circ}$ quartis, percentil 5 e 95 dos tempos obtidos pelos grupos de pacientes expostos com e sem diagnóstico de tendinite no Grooved Pegboard para a mão dominante.

\section{Grooved Pegboard - Mão Não Dominante}

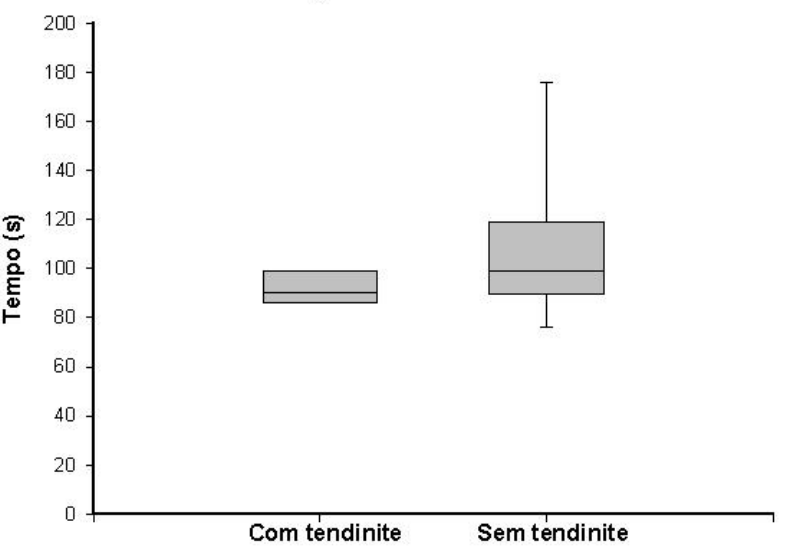

Figura 44. Mediana, $1^{\circ}$ e $3^{\circ}$ quartis, percentil 5 e 95 dos tempos obtidos pelos grupos de pacientes expostos com e sem diagnóstico de tendinite no Grooved Pegboard para a mão não dominante. 


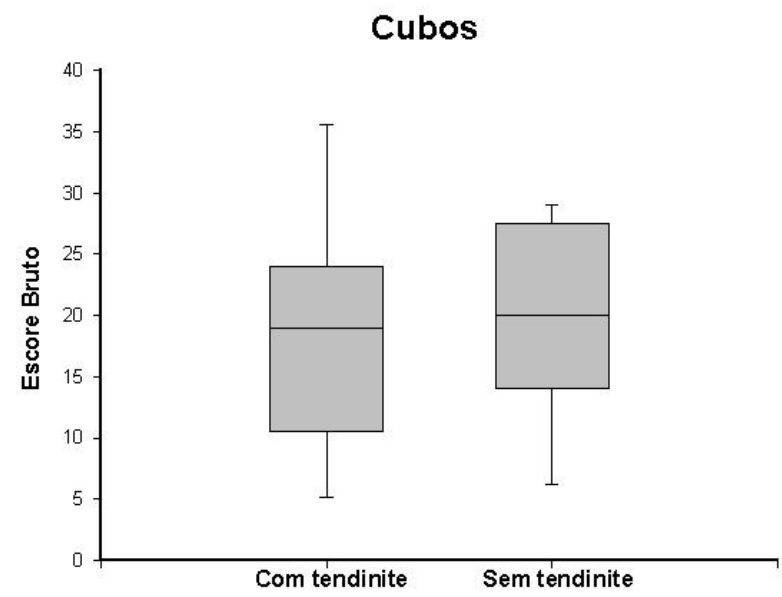

Figura 45. Mediana, $1^{\circ}$ e $3^{\circ}$ quartis, percentil 5 e 95 dos tempos obtidos pelos grupos de pacientes expostos com e sem diagnóstico de tendinite em Cubos.

\subsection{Depressão}

Conforme mostrou a tabela 5, o grupo exposto ao vapor de mercúrio obteve escores significantemente mais altos no Inventário Beck de Depressão. Apesar deste inventário não constituir um instrumento diagnóstico para depressão, podemos inferir a prevalência da doença no grupo estudado, estabelecendo-se escore total 20 como ponto de corte indicativo de depressão, recomendado por estudos prévios (Gorenstein, Vieira, Tung \& Artes, 1999). Para exame da hipótese de que as alterações neuropsicológicas encontradas no grupo exposto se associam aos indivíduos deprimidos, os ex-trabalhadores foram divididos entre grupos "com" e "sem" depressão, conforme o ponto de corte estabelecido. A tabela 11 mostra as medianas, médias, desvios padrões, valores de $p$ referentes aos dados gerais e resultados nos testes e inventários. Os pacientes expostos que atingiram o ponto de corte para depressão obtiveram escores significantemente mais altos no Inventário Beck de Depressão $(p<0,001)$ conforme o esperado, além de desempenho prejudicado em Dígitos Indiretos $(p=0,029)$. Os demais escores não mostraram alterações (tabela 11). 
Tabela 11

Comparação dos dados gerais e escores brutos obtidos nos testes e inventários dos subgrupos com maior e menor índice de depressão.

Escore Total de Depressão

\begin{tabular}{|c|c|c|c|c|c|}
\hline \multirow[b]{2}{*}{ Variáveis } & \multicolumn{2}{|c|}{$>20(n=16)$} & \multicolumn{2}{|c|}{$<20(n=10)$} & \multirow[b]{2}{*}{$P$} \\
\hline & Md & $M \pm D P$ & Md & $M \pm D P$ & \\
\hline Idade & 41 & $41,2 \pm 6,2$ & 42 & $41,8 \pm 6,3$ & 0,813 \\
\hline Escolaridade & 8 & $8,7 \pm 1,6$ & 8 & $9,2 \pm 2,1$ & 0,772 \\
\hline Tempo de exposição ao vapor de $\mathrm{Hg}^{0}$ (anos) & 9 & $9,8 \pm 4,1$ & 11 & $12,5 \pm 8$ & 0,339 \\
\hline Tempo de afastamento ao vapor de $\mathrm{Hg}^{0}$ (anos) & 5 & $7 \pm 5,6$ & 4,5 & $5,6 \pm 6,3$ & 0,812 \\
\hline $\mathrm{HgU}(\mu \mathrm{g} / \mathrm{g} \mathrm{Cr})$ & 2 & $1,8 \pm 1$ & 1,6 & $1,8 \pm 0,9$ & 1 \\
\hline \multicolumn{6}{|l|}{ Dígitos } \\
\hline Indiretos & 3 & $3,2 \pm 1,4$ & 4,5 & $4,9 \pm 1,8$ & 0,029 \\
\hline BDI & 31 & $33,2 \pm 10,9$ & 13 & $13,1 \pm 4,2$ & $<0,001$ \\
\hline Escores nos Demais Testes e Inventários & - & - & - & - & n.s. ${ }^{*}$ \\
\hline
\end{tabular}

\subsection{Ansiedade}

Para examinar possíveis associações entre desempenho prejudicado em testes neuropsicológicos e índices de ansiedade, os indivíduos expostos foram subdivididos conforme ponto de corte 49 indicativo de ansiedade em nível patológico, apresentado por estudo prévio (Gorenstein, Pompéia e Andrade, 1995), tanto para o inventário de estado, quanto para o de traço.

De acordo com a tabela 12 , os subgrupos gerados conforme maior ou menor nível de estado de ansiedade não mostraram diferenças significativas quanto aos dados gerais (idade, escolaridade, tempo de exposição e de afastamento ao vapor de mercúrio e concentração urinaria) e testes neuropsicológicos. Nos inventários aplicados, foi encontrada diferença significante somente no inventário de estado de ansiedade $(p<0,01)$, relevância esperada. 
Tabela 12

Comparação dos dados gerais e escores brutos obtidos nos testes e inventários dos subgrupos com maior e menor índice de estado de ansiedade.

Escore Total para Estado de Ansiedade

\begin{tabular}{|c|c|c|c|c|c|}
\hline \multirow[b]{2}{*}{ Variáveis } & \multicolumn{2}{|c|}{$>49(n=19)$} & \multicolumn{2}{|c|}{$<49(n=7)$} & \multirow[b]{2}{*}{$P$} \\
\hline & Md & $M \pm D P$ & Md & $M \pm D P$ & \\
\hline Idade & 41 & $40,7 \pm 6$ & 42 & $43,5 \pm 6,4$ & 0,285 \\
\hline Escolaridade & 8 & $8,6 \pm 1,5$ & 11 & $9,8 \pm 2,3$ & 0,213 \\
\hline Tempo de exposição ao vapor de $\mathrm{Hg}^{0}$ (anos) & 10 & $9,9 \pm 3,9$ & 10 & $13,3 \pm 9,5$ & 0,435 \\
\hline Tempo de afastamento ao vapor $\mathrm{de}^{\mathrm{Hg}}$ (anos) & 5 & $6,7 \pm 5,5$ & 5 & $5,7 \pm 2,5$ & 0,862 \\
\hline $\mathrm{HgU}(\mu \mathrm{g} / \mathrm{g} \mathrm{Cr})$ & 2,2 & $2 \pm 1$ & 1,3 & $1,3 \pm 0,4$ & 0,643 \\
\hline \multicolumn{6}{|l|}{ IDATE } \\
\hline Estado & 61 & $61 \pm 7,2$ & 41 & $39,8 \pm 4,6$ & $<0,001$ \\
\hline Escores nos Testes e Demais Inventários & - & - & - & - & n.s.* \\
\hline
\end{tabular}

*não significante

A tabela 13 mostra os resultados referentes aos subgrupos de pacientes com maior $(>49)$ ou menor escore total no IDATE para traço de ansiedade. Observou-se diferença significante somente para a variável em que era esperada, correspondente os escore total no IDATE para traço de ansiedade $(p<0,001)$.

Tabela 13

Comparação dos dados gerais e escores brutos obtidos nos testes e inventários dos subgrupos com maior e menor índice de traço de ansiedade.

Escore Total para Traço de Ansiedade

\begin{tabular}{|c|c|c|c|c|c|}
\hline \multirow[b]{2}{*}{ Variáveis } & \multicolumn{2}{|c|}{$>49(n=18)$} & \multicolumn{2}{|c|}{$<49(n=8)$} & \multirow[b]{2}{*}{$P$} \\
\hline & Md & $\mathrm{M} \pm \mathrm{DP}$ & Md & $\mathrm{M} \pm \mathrm{DP}$ & \\
\hline Idade & 38,5 & $41 \pm 7$ & 42 & $42,5 \pm 3,6$ & 0,575 \\
\hline Escolaridade & 8,5 & $9 \pm 1,6$ & 8 & $8,6 \pm 2,2$ & 0,330 \\
\hline Tempo de exposição ao vapor de $\mathrm{Hg}^{0}$ (anos) & 8 & $9,7 \pm 4,1$ & 12 & $13,5 \pm 8,5$ & 0,222 \\
\hline Tempo de afastamento ao vapor de $\mathrm{Hg}^{0}$ (anos) & 5 & $6 \pm 4,5$ & 5 & $7,3 \pm 5,7$ & 0,578 \\
\hline $\mathrm{HgU}(\mu \mathrm{g} / \mathrm{g} \mathrm{Cr})$ & 2,25 & $2 \pm 0,9$ & 1,2 & $1,2 \pm 0,6$ & 0,229 \\
\hline \multicolumn{6}{|l|}{ IDATE } \\
\hline Traço & 57 & $60,8 \pm 9,6$ & 45 & $42 \pm 5,6$ & $<0,001$ \\
\hline Escores nos Testes e Demais Inventários & - & - & - & - & n.s. ${ }^{*}$ \\
\hline
\end{tabular}




\subsection{Uso de Medicamentos Psicotrópicos}

A literatura mostra alterações decorrentes do tratamento medicamentoso com substâncias psicotrópicas, caracterizadas por redução de vigilância, prejuízos psicomotores e de memória em casos do uso de antidepressivos tricíclicos e decréscimos na acuidade visual, em funções executivas e tarefas atencionais de cancelamento ou procura de alvos na utilização de ansioliticos benzodiazepínicos (McKim, 2000). Para a verificação de possíveis diferenças de desempenho neuropsicológico associadas ao uso destas substâncias, os indivíduos expostos ao mercúrio foram divididos em 2 subgrupos, entre pacientes que fazem uso de medicamento antidepressivo e/ou ansiolítico e aqueles que não utilizam tratamento desta natureza. A tabela 14 mostra os dados gerais e valores de $p$ e ilustra a inexistência de diferenças estatísticas entre os grupos em quaisquer medidas comparativas realizadas.

Tabela 14

Comparação dos dados gerais e escores brutos obtidos nos testes e inventários dos subgrupos com ou sem uso de antidepressivo e/ou ansiolítico.

Uso de Medicamentos Psicotrópicos

\begin{tabular}{|c|c|c|c|c|c|}
\hline \multirow[b]{2}{*}{ Variáveis } & \multicolumn{2}{|c|}{$\operatorname{Sim}(n=16)$} & \multicolumn{2}{|c|}{ Não $(n=10)$} & \multirow[b]{2}{*}{$P$} \\
\hline & Md & $M \pm D P$ & Md & $M \pm D P$ & \\
\hline Idade & 41 & $40,6 \pm 6,0$ & 42 & $42,8 \pm 6,3$ & 0,356 \\
\hline Escolaridade & 8,5 & $9,2 \pm 1,9$ & 8 & $8,5 \pm 1,6$ & 0,291 \\
\hline Tempo de exposição ao vapor de $\mathrm{Hg}^{0}$ (anos) & 9 & $10,1 \pm 4,3$ & 8 & $12,1 \pm 7,9$ & 0,635 \\
\hline Tempo de afastamento ao vapor de $\mathrm{Hg}^{0}$ (anos) & 5 & $6,2 \pm 4,9$ & 4,5 & $6,8 \pm 5,0$ & 0,874 \\
\hline $\mathrm{HgU}(\mu \mathrm{g} / \mathrm{g} \mathrm{Cr})$ & 1,8 & $2,1 \pm 0,8$ & 1,5 & $1,6 \pm 0,6$ & 0,662 \\
\hline Escore nos testes neuropsicológicos & - & - & - & - & n.s. ${ }^{*}$ \\
\hline Escores nos inventários de depressão e ansiedade & - & - & - & - & n.s. ${ }^{*}$ \\
\hline
\end{tabular}

*não significante 


\subsection{Discussão}

A análise estatística dos resultados obtidos na avaliação neuropsicológica dos pacientes expostos ao vapor de mercúrio revelou diferenças significativas $(p<0,05)$ em vários testes, indicando os seguintes prejuízos: lentificação psicomotora (teste de Stroop partes 1 e 2), déficit de evocação espontânea de informações verbais (total de palavras evocadas, recuperação e armazenamento de longo prazo, recuperação consistente de longo prazo e tardia, referentes ao SRT), fluência verbal reduzida (FAS) e prejuízo motor quanto à destreza manual (Grooved Pegboard). Além disso, os escores totais obtidos pelos indivíduos expostos nos inventários de depressão (BDI) e ansiedade (IDATE) foram significantemente mais altos. Tratam-se de prejuízos observados em ex-trabalhadores de fábricas de lâmpadas, com diagnóstico de mercurialismo crônico ocupacional e históricos de exposição ao vapor de mercúrio metálico durante 10,2 anos $(\mathrm{DP}=3,8)$ e afastamento de trabalho há 6 anos $(\mathrm{DP}=4,7)$ em média, além de níveis normais de mercúrio urinário $(1,8 \pm 0,9 \mu \mathrm{g} / \mathrm{g} \mathrm{Cr})$, uma vez que as concentrações medidas um ano sem o contato crônico com o metal já se encontravam dentro dos limites estabelecidos para a população geral.

O grupo exposto apresentou lentificação psicomotora verificada através de maior média de tempo para a execução da tarefa de Stroop nas partes 1 e 2, as quais requerem velocidade adequada de processamento de informações para um desempenho satisfatório. Na parte 3 do teste, que avalia a capacidade de controle inibitório, não houve diferença significativa de tempo entre os grupos, o que sugere a preservação desta habilidade entre os pacientes expostos ao mercúrio.

Entre os ex-trabalhadores, também se observou lentificação psicomotora através dos tempos significantemente maiores para a execução da tarefa de destreza manual (Grooved Pergboard). Embora dentre os 26 indivíduos expostos, 
13 (50\% da amostra) tenham tido diagnóstico de tendinite, a comparação entre os pacientes com e sem a doença não revelou diferença significativa $(p<0,05)$ nos testes que requerem habilidade motora (Grooved Pegboard e Cubos), indicando que não há associação entre a tendinite e a disfunção motora observada nesses pacientes. Uma vez que a literatura refere a remissão da alteração neurológica caracterizada por tremor com o cessar da exposição (Rodriguez e Rodriguez, 1982; Kishi et al., 1994), inferimos que os nossos pacientes apresentam uma seqüela motora, caracterizada por déficit da destreza manual e coordenação motora. A persistência da disfunção desta natureza está de acordo com achados prévios da literatura que apontam a função motora como a principal afetada na intoxicação mercurial (Meyer-Baron et al., 2002).

No exame de memória verbal (SRT), o grupo exposto demonstrou desempenho compatível com déficit de evocação espontânea de palavras, mantendo, porém, preservada a capacidade de fixação da informação verbal, evidenciada pela etapa de reconhecimento, em que não houve diferença significativa entre os grupos. Além disso, os ex-trabalhadores não apresentaram prejuízos para recuperação randômica de longo prazo, que se refere às palavras evocadas aleatoriamente, isto é, em tentativas não consecutivas, o que somado às falhas de evocação espontânea referidas, sugerem um processo de armazenamento de informações verbais menos eficiente nesses os pacientes.

A redução da fluência verbal observada, também reflete dificuldade na evocação/geração espontânea de palavras, além de lentificação na velocidade de processamento de informações.

Nossos dados corroboram os de Mathiesen et al. (1999) e Frumkim et al. (2001). O primeiro estudo verificou alteração motora no Grooved Pegboard e lentificação psicomotora no teste de tempo de reação em ex-trabalhadores de fábricas de cloro-álcalis $(7,9 \pm 6,8$ anos de exposição; 12,7 $\pm 11,7$ anos de 
afastamento e concentração urinária atual de mercúrio de 1,8 $\pm 1,3 \mathrm{nmol} / \mathrm{mmol} \mathrm{Cr}$ ). Os índices de exposição mostram tratar-se de indivíduos com menor duração da exposição e maior tempo decorrido após o cessar do trabalho na indústria, em relação aos nossos pacientes.

No segundo estudo (Frumkim et al., 2001), ex-trabalhadores de fábricas de cloro-álcalis expostos ao mercúrio elementar por pelo menos um ano (afastamento do trabalho de $5,73 \pm 6,5$ anos; concentração urinária de mercúrio de $3,42 \pm 2,54$ $\mu \mathrm{g} / \mathrm{gCr}$ ) apresentaram lentificação psicomotora e comprometimento da destreza manual no teste de tempo de reação e no Grooved Pegboard, além de dificuldade de memória no teste de aprendizagem de lista de palavras (Frumkim et al., 2001).

Os escores altos de depressão e ansiedade obtidos pelo grupo exposto são esperados na medida em que estas alterações de humor compõem o conjunto de sintomas relativos ao eretismo presente no mercurialismo crônico ocupacional, cujas manifestações persistem apesar da interrupção da exposição ao vapor de mercúrio (Faria, 2003). Entretanto, deve-se também considerar o contexto de vida atual desses indivíduos, que envolve fatores de risco para o desenvolvimento de transtornos do humor, como desemprego, aposentadoria por invalidez ou afastamento do trabalho devido a problemas de saúde, além de enfermidades decorrentes da exposição ao mercúrio e do trabalho repetitivo na linha de produção de lâmpadas. Assim, os sintomas de depressão e ansiedade podem manifestar-se de maneira reativa às situações descritas.

Entretanto, uma vez que dados prévios da literatura mostram que a depressão está relacionada a déficit de memória (Fossati et al., 2002), lentificação na velocidade de processamento de informação alterações nas funções executivas (Grant et al., 2001), seria difícil certificar-se da associação entre a exposição ao vapor de mercúrio e os prejuízos observados nos pacientes mercuriais. Se este fosse o único ou fator principal envolvido, haveria uma relação entre depressão e os 
prejuízos descritos. Entretanto, a comparação dos subgrupos de ex-trabalhadores com e sem depressão (conforme ponto de corte 20 no BDI) não revelou diferença entre os escores obtidos no teste de Stroop, SRT, FAS ou Grooved Pegboard, apesar do teste de Spearman mostrar correlação entre pior recuperação consistente de longo prazo e maiores escores no BDI, indicando uma associação entre sintomas de depressão e dificuldade de memória verbal nestes pacientes.

O estudo das funções neuropsicológicas de pacientes com diagnóstico de mercurialismo crônico é difícil devido à depressão, presente como um dos sintomas da síndrome. Além disso, os déficits encontrados nos pacientes deste estudo se assemelham às alterações observadas em indivíduos deprimidos. Nos estudos prévios citados (Mathiesen et al., 1999; Frumkin et al., 2001), não há referências sobre diagnóstico de mercurialismo. A correspondência de nossos resultados e os desses estudos somados ao fato de não encontramos diferenças entre os subgrupos com maior ou menor escore de depressão quanto às funções afetadas na comparação com os controles, sugerem a associação entre a exposição ao mercúrio e os déficits observados nos pacientes. Também deve-se ressaltar que as comparações entre subgrupos gerados a partir dos índices de ansiedade e uso de medicamentos psicotrópicos não mostrou diferenças, indicando homogeneidade entre os grupos gerados.

Por outro lado, não foram detectadas alterações nos pacientes expostos ao mercúrio. A comparação de escores entre os grupos exposto e controle não mostrou diferenças quanto à memória de curto prazo (Dígitos Diretos) e controle mental (Dígitos Indiretos), controle inibitório (Stroop parte 3), memória visual (Reprodução Visual), função viso-espacial (Cubos), funções executivas (teste de Wisconsin) e conhecimento semântico (Vocabulário), indicando a preservação dessas funções entre os ex-trabalhadores. Para Mathiesen et al. (1999), a exposição crônica ao mercúrio não afeta a habilidade intelectual geral ou a 
capacidade de resolução de problemas, mas provocaria um efeito no SNC principalmente nas funções motoras e de atenção.

$\mathrm{Na}$ análise das variáveis específicas do grupo de pacientes expostos, o aumento da concentração urinária de mercúrio acompanhou a progressão dos escores de traço de ansiedade (IDATE). Estudos mostram a prevalência de sintomas subjetivos relacionados a alterações de humor e personalidade mediante concentrações baixas de mercúrio (Langworth et al., 1992). Mulheres com obturações odontológicas de amálgama de mercúrio tiveram escores significantemente superiores no IDATE em relação àquelas sem restaurações nas questões indicativas de baixa auto-confiança (Siblerud et al., 1994).

Os tempos de exposição ao vapor de mercúrio e de afastamento da fonte de exposição não tiveram correlações com as variáveis dos testes e inventários aplicados. Também não houve diferença de desempenho entre os subgrupos com maior ou menor tempos de exposição ou afastamento. Entretanto, é preciso qualificar que são índices de exposição imprecisos, pois estes dependem do cargo de trabalho ocupado pelo paciente. Ladd et al. (1966) citados por Rodriguez e Rodriguez (1982) não encontraram indícios de correlação entre as concentrações sangüínea e urinária de mercúrio e os sinais clínicos de intoxicação.

A compreensão dos mecanismos responsáveis por estas alterações funcionais depende de um melhor conhecimento dos efeitos do mercúrio no tecido nervoso. Entretanto, existem poucos dados sobre a fisiopatologia do mercúrio SN. No estudo que examinou as características histopatológicas, histoquímicas e de microscopia eletrônica através das autópsias de 2 cérebros de ex-mineradores, não foram encontrados sinais de morte neuronal ou alterações morfofisiológicas do tecido cerebral apesar da grande acumulação de mercúrio (Takahata el al., 1970).

No presente estudo, procurou-se o pareamento quanto ao sexo, à idade e escolaridade entre os grupos examinados para se evitar possíveis diferenças de 
desempenho decorrentes das discrepâncias destas variáveis. Em análises intragrupos, o teste de correlação de Spearman revelou diferentes susceptibilidades dos grupos na comparação das variáveis idade e escolaridade com os escores brutos obtidos em testes e inventários.

A variável idade não teve correlação com os itens em que os indivíduos expostos demonstraram dificuldade quando comparados ao grupo controle. Quanto à escolaridade, de modo geral, é esperado melhor desempenho conforme maior quantidade de anos de estudo, o que foi observado em ambos os grupos. Tanto os pacientes expostos quanto os controles tiveram correlação positiva entre escolaridade e o reconhecimento de palavras (SRT), indicando mais um pareamento entre os grupos.

No presente estudo, também se deve considerar as limitações que representam obstáculos para a interpretação dos dados. O número reduzido de participantes pode mascarar possíveis alterações neuropsicológicas que poderiam ser observadas com maior número de participantes. Além disso, a amostra de pacientes expostos mostrou-se muito heterogênea quanto ao nível ocupacional dos indivíduos, prevalência de tendinite, depressão, ansiedade e o uso de medicamentos psicotrópicos, situações estas bem diferentes dos controles. A administração de destes não foi controlada, de modo que não sabemos se os pacientes fazem uso da medicação conforme as instruções médicas. Além disso, foram incluídos participantes tabagistas e não se controlou se fumaram antes da avaliação, o que poderia ocasionar alterações como relaxamento ou mesmo potencialização da habilidade de aprendizagem (McKim, 2000). Por outro lado, o fato de grande parte da amostra encontra-se afastada do trabalho ou aposentada por invalidez pode gerar a hipótese de que os ex-trabalhadores estivessem motivados a mostrar desempenho prejudicado na bateria neuropsicológica com finalidade de obtenção de benefícios judiciários perante a empresa na qual 
trabalharam. Entretanto, os resultados mostraram um perfil coerente segundo o qual seria difícil supor que o grupo como um todo pudesse combinar o mau desempenho, por exemplo, no teste de Stroop somente nas partes 1 e 2 ou no SRT somente nos itens referentes à evocação espontânea de palavras, mas não quanto à fixação das mesmas. Assim, pode-se inferir a participação genuína destes pacientes.

\subsection{Conclusões}

A caracterização do mercurisliamo dificulta os estudo neuropsicológico dos pacientes por incluir sintomas de depressão e ansiedade. Entretanto, após análise com os meios estatísticos do qual dispomos, o mercurialismo crônico mostrou associação a alterações neuropsicológicas caracterizadas por redução da velocidade de processamento de informações e prejuízo motor. O déficit de evocação espontânea de conteúdo verbal memória verbal pode relacionar-se também à sintomatologia depressiva.

Os tempos de exposição e afastamento do vapor de mercúrio não apresentaram correlações com testes neuropsicológicos e mostram constituir medidas imprecisas de exposição, uma vez que não refletem o cargo ocupado pelo paciente. A concentração urinária de mercúrio demonstrou associação com alteração de personalidade quanto ao traço de ansiedade. 


\section{Avaliação Neuropsicológica de PACIENTES DIABÉTICOS DO TIPO 2}

\subsection{Introdução}

\subsection{Considerações Gerais}

Diabetes Mellitus (DM) corresponde a uma grave alteração do metabolismo dos hidratos de carbono (açúcares) como conseqüência da produção e secreção insuficientes de insulina. Trata-se de uma doença crônica comum (Coker \& Shumaker, 2003) de cura ainda desconhecida, mas que pode ser tratada e controlada, evitando as complicações que comprometem a qualidade ou a duração de vida dos pacientes. Trata-se de um distúrbio metabólico associado a alterações estruturais e funcionais de vários sistemas (Mooradian, 1988a). Fatores genéticos, insuficiência de exercícios físicos e a má qualidade da alimentação podem se relacionar à gênese deste processo patológico.

A insulina é o hormônio produzido no pâncreas cuja função é de reduzir a concentração de glicose na circulação sangüínea, transportando o açúcar do plasma sangüíneo até o interior das células, onde será convertido em energia para o organismo. Caso contrário, a glicose permanece circulante no sangue.

O primeiro sintoma do DM é o excesso de glicose no sangue (hiperglicemia), geralmente acompanhado do excesso de glicose na urina (glicosúria) e da eliminação de grandes volumes de urina (poliúria). Observa-se também fome e sede intensas, além de perda de peso acentuada.

Em longo prazo, surgem sintomas secundários como a degeneração das paredes dos vasos sangüíneos, retinopatia diabética (alteração dos vasos 
sangüíneos irrigadores da retina, provocando cegueira), insuficiência renal,

arteriosclerose (obstrução das artérias que pode levar ao enfarte, derrame cerebral ou gangrena dos membros inferiores) e perda de sensibilidade nos pés e nas mãos. Sem o tratamento adequado, a acumulação dos agentes tóxicos originados da alteração do metabolismo pode levar o paciente ao coma diabético. O tratamento deve manter a concentração de glicose sangüínea dentro dos limites normais, o que impede ou retarda o aparecimento de alterações vasculares e demais complicações.

Como conseqüências graves do DM não controlada tem-se: cegueira e catarata, enfarte do miocárdio, neuropatia, gangrena, impotência sexual masculina, insuficiência renal, hipertensão arterial, doenças pulmonares e circulatórias.

A concentração limite de glicose sangüínea indicativa do diabetes é de 126 $\mathrm{mg} / \mathrm{dL}$ de sangue, sendo que a taxa normal em jejum é de 70 a $100 \mathrm{mg} / \mathrm{dL}$, conforme sugerido pelo Expert Committe on the Diagnosis and Classificatation of Diabetes Mellitus (2003).

Com base em semelhanças bioquímicas e fisiológicas entre humanos e animais idosos e pacientes diabéticos, foi elaborada a hipótese de que o diabetes pode constituir um modelo de aceleração do processo de envelhecimento. Os mecanismos que sustentam esta hipótese são baseados em evidências de que alterações características do avanço da idade como a modificação de proteínas e ácidos nucléicos, opacificação das lentes e rigidez no colágeno em vários tecidos, também são observadas em indivíduos diabéticos não idosos. Entretanto, há controvérsias à esta teoria devido às diferenças de mudanças fenotípicas distintas no processo de envelhecimento normal e no diabetes, uma vez que neste, as alterações não são uniformes em todos os tecidos (Mooradian, 1988b).

Os principais tipos de DM são os tipos 1 e 2. 


\subsection{Diabetes Tipo 1}

Também conhecido como Diabetes Juvenil ou Insulino Dependente, o diabetes tipo 1 é caracterizado pela destruição das células beta do pâncreas, produtoras de insulina, devido ao ataque do sistema imunológico, o que ocorre com maior freqüência em crianças, adolescentes e jovens adultos.

O tratamento consiste na administração de medicamentos que reduzem o nível sangüíneo de glicose (hipoglicêmicos) ou a aplicação da insulina via injeção subcutânea para que possa ser absorvida pelo sangue. Entretanto, a reposição de insulina deve ser controlada, pois em quantidade elevada pode ocasionar a hipoglicemia (Heller \& Macdonald, 1996), podendo conduzir o paciente ao coma nos casos mais graves.

\subsection{Diabetes Tipo 2}

O diabetes tipo 2 corresponde a um distúrbio comum entre indivíduos adultos, em que há a produção de insulina endógena em quantidade parcial, mas também a dificuldade das células musculares, adiposas e do fígado em metabolizar a glicose e convertê-la em energia. Com isso, tem-se o acúmulo do açúcar na corrente sangüínea. O sub-aproveitamento da insulina pelas células é denominado "resistência insulínica" (Watson \& Craft, 2003).

Trata-se da forma mais comum de expressão do diabetes, com sintomas mais brandos que o DM tipo 1. Os pacientes diabéticos do tipo 2 não são dependentes de insulina, e por este motivo, a doença também é conhecida como Diabetes Não Insulino Dependente, embora a substância pode ser utilizada no tratamento. Acomete principalmente indivíduos adultos com antecedentes familiares de diabetes ou excesso de peso, apesar dos tipos de diabetes não se associarem 
rigidamente à idade. Alimentação adequada, exercícios físicos, controle de peso e medicamentos ajudam no controle da doença.

A prevalência do diabetes tipo 2 vem aumentando de modo exponencial nos últimos anos. Estima-se que em 2025, 64 milhões de pessoas serão acometidas pela doença nas Américas (Sartorelli \& Franco, 2003).

O diabetes encontra-se entre os principais problemas de saúde de todo o mundo, devido ao número de pessoas afetadas, morbidade associada, custos envolvidos no controle e tratamento das complicações, incapacitações que produz nos indivíduos acometidos e mortalidade prematura. Fatores como aumento da taxa de urbanização, sedentarismo, industrialização, obesidade, alimentação de má qualidade e o aumento da expectativa de vida contribuem para o surgimento de novos casos da doença e refletem a importância que o diabetes vem demonstrando nas últimas décadas (Franco, Mameri, Pagliaro, lochida \& Goldenberg, 1998).

No Brasil observa-se número crescente de hospitalizações devido ao diabetes, em proporções superiores àquelas decorrentes de outras causas. A mortalidade devido ao diabetes também tem mostrado crescimento relevante. Além disso, tem-se uma subnotificação dos casos de morte decorrente do diabetes pois geralmente os paciente vêm a óbito por complicações crônicas, registradas como causa do óbito (Sartorelli \& Franco, 2003).

Portanto, o estudo sobre as alterações que acompanham o diabetes propicia diagnóstico precoce e diminuição na complexidade e nos custos do tratamento, tanto para o paciente quanto para a rede hospitalar.

\subsection{Fisiopatologia do DM e o Sistema Nervoso}

No sistema nervoso, a hiperglicemia crônica provoca danos nos tecidos e órgãos através de lesão vascular (Cosway et al., 2001) e nos nervos, levando à 
morte neuronal, diminuição da velocidade de condução nervosa e alterações neuroquímicas (Mooradian, 1988a).

As neuropatias diabéticas mais conhecidas envolvem o sistema nervoso periférico (SNP) e autônomo (SNA), constituindo uma série de síndromes que afetam regiões distintas, sozinhas ou combinadas (Vinik, Park, St ansberry, \& Pittenger, 2000) que ocorrem, geralmente, de 8 a 10 anos após o início da doença (Huntley, 1995). Podem não acarretar sintomas, com alterações detectáveis somente por diagnóstico eletrofisiológico e testes sensoriais ou se manifestar através de sinais clínicos com maior ou menor gravidade. Em geral, atacam as extremidades, como os pés, e nos casos mais graves, provocam ulceração, alargamento dos membros, podendo levar à necessidade de amputação do membro. Trata-se de um distúrbio heterogêneo que inclui uma série de anormalidades afetando nervos sensoriais e motores, além do SNA (Vinik et al., 2000).

Não há tratamento efetivo para as neuropatias diabéticas periférica e autonômica. O controle do nível glicêmico sangüíneo tem se mostrado eficiente em retardar a progressão dos sintomas. A causa é desconhecida, embora a prédisposição genética pareça estar relacionada. O diagnóstico da neuropatia é baseado em sintomas e no exame físico. A severidade das manifestações varia de um paciente para outro.

Os efeitos do diabetes no sistema nervoso central (SNC) são menos conhecidos. Verificam-se, na literatura científica, especulações e observações experimentais relacionadas.

Há evidências de que a encefalopatia decorrente do diabetes caracteriza-se por alterações nos vasos (microangiopatia), acompanhadas pela desmielização das fibras e degeneração das substâncias branca e cinzenta. Foi demonstrado que a hiperglicemia produz a elevação dos níveis de glutamato extracelular no neocórtex, 
associada à morte neuronal nesta região (Watson \& Craft, 2003). Também foram observados depósito de cálcio nas paredes de vasos sangüíneos, degeneração de células ganglioares e perda de axônios em pacientes diabéticos (Bloodworth \& Greider,1982 citados por Mooradian, 1988a).

A maioria das patologias do SNC parecem secundárias às doenças vasculares (Grunnet, 1963). Entretanto, para Affolter et al. (1986), a microangiopatia desempenha um papel relativamente pequeno na encefalopatia diabética. Segundo esses autores, mudanças estruturais podem ser atribuídas a complicações agudas do diabetes como a hipoglicemia, que pode causar perda necrose (Warre et al., 1966).

Uma variedade de mecanismos patológicos decorrentes do diabetes podem contribuir para a disfunção central: problemas vasculares (acidentes cerebrovasculares e disfunção da barreira hemato-encefálica); metabólicos (hiperglicemia, hipoglicemia, quetose, acidose, hipóxia, anormalidades eletrolíticas e alterações neuroquímicas); e outras causas (neuropatia periférica e autonômica, hipertensão, falência renal e problemas visuais) (Mooradian, 1988a).

\subsection{Retinopatia Diabética}

A retinopatia diabética corresponde a uma complicação microvascular crônica do diabetes, que geralmente ocorre 20 após o início da doença, acomete cerca de $60 \%$ d os pacinetes com diabetes tipo 2 e constitui a principal causa de cegueira em adultos (Boelter, Azevedo, Gross \& Lavinsky, 2003; Varma et al., 2004).

A hipóxia no tecido acompanhada da perda de auto-regulação dos vasos da retina é fator desencadeante da retinopatia diabética, embora os mecanismos da gênese da doença microvascular retiniana ainda não estejam bem estabelecidos na 
literatura. A hiperglicemia aliada a outros fatores como dano celular mediado por alterações metabólicas de enzimas e viscosidade sangüínea são relacionados nesta complicação (Boelter et al., 2003).

Nas Américas, a prevalência da retinopatia varia de 18 a $40 \%$, conforme a população estudada. Aproximadamente $85 \%$ dos casos se apresentam em pacientes a partir de 40 anos e apenas 5\% em jovens abaixo de 20 anos (Corrêa, Freitas \& Marcon, 2003).

O risco de desenvolvimento da retinopatia se relaciona a fatores genéticos, aliados à maior duração da doença. A cegueira está relacionada à fase avançada, representada pela retinopatia proliferativa e as manifestações de hemorragia préretiniana ou vítrea, proliferação fibro-vascular, descolamento da retina e glaucoma vascular (Boelter et al., 2003).

\subsection{DM Tipo 2 e a Avaliação Neuropsicológica}

Estudos sugerem que há risco de disfunções cognitivas (Grodstein, Chen, Wilson, Manson, \& Nurses' Health Study, 2001) e demência em indivíduos diabéticos, embora o mecanismo fisiopatológico subjacente seja desconhecido (Bruce, Harrington, Davis, \& Davis, 2001).

Em uma de revisão de literatura, Stewart \& Liolitsa (1999) encontraram evidência epidemiológica substancial para sugerir a associação entre diabetes tipo 2 e déficit de memória e funções executivas e ao maior risco do desenvolvimento de demência. Para os autores, há a possibilidade da DM tipo 2 se relacionar a disfunções focais que não atingem a totalidade dos domínios neuropsicológicos.

Entretanto, dentre os resultados de estudos que investigaram o funcionamento neuropsicológico de pacientes diabéticos do tipo 2, ora são descritas 
disfunções cerebrais difusas (Grodstein et al., 2001), ora déficits em funções específicas (Lowe et al., 1994; Stewart \& Liolitsa 1999; Ryan \& Geckle 2000; Vanhanen et al. 1999), ou ainda não são constatadas associações entre diabetes tipo 2 e déficits neuropsicológicos (Cosway et al., 2001), o que sugere a necessidade de maior investigação nesse âmbito.

O DM tipo 2 parece provocar menor prejuízo nas funções neuropsicológicas do que o tipo 1, embora os danos sejam progressivos conforme o aumento do tempo de evolução da doença (Stewart \& Liolitsa, 1999). As disfunções mais severas parecem associar-se a grupos de diabéticos dependentes de insulina, devido à reação da hipoglicemia cerebral.

A seguir apresentam-se resultados de estudos que realizaram a avaliação das funções neuropsicológicas de indivíduos diabéticos adultos não idosos (média de idade < 60 anos) em comparação com grupos controles e nível de significância ajustado em $p<0,05$.

Lowe et al. (1994) examinaram 80 pacientes diabéticos do tipo 2 com idades de $59,3 \pm 0,9$ anos, duração da doença de 6,9 anos $(\mathrm{DP}=0,8)$ e $8,1 \% \pm 0,3$ quanto ao nível de hemoglobina glicada. A amostra incluiu $63,8 \%$ de indivíduos hipertensos. Comparados com 81 sujeitos controles, os pacientes diabéticos apresentaram escores significantemente inferiores nos testes de fluência verbal e formação de conceitos verbais, enquanto os resultados referentes a memória verbal, visual e de curto prazo, controle mental e função viso-espacial se mostram sem diferenças. Sintomas depressivos se associaram à redução da fluência verbal entre os indivíduos diabéticos.

Zaslavsky et al. (1995) investigaram a memória de pacientes diabéticos do tipo 2 comparando um grupo sem neuropatia autonômica $(n=29$, idade $=59,5 \pm 1,5$; duração do diabetes $=8,2 \pm 0,9$ anos, hemoglobina glicada $=8,6 \pm 0,4 \%$ ) e outro com esta complicação ( $n=20 ; 60,5 \pm 1,4$ anos de idade; duração do diabetes $=11,4$ 
$\pm 1,7$ anos, hemoglobina glicada $=8,5 \pm 0,4 \%$ ), além de 34 controles não diabéticos. Os pacientes com a neuropatia mostraram desempenhos significantemente inferiores aos demais grupos em testes de memória visual, enquanto as habilidades para memória verbal e de curto prazo se mostraram inalteradas. As freqüências de retinopatia e angiopatia entre os pacientes com neuropatia autonômica também foram significantemente superiores em relação ao outro grupo diabético.

No exame neuropsicológico de 28 pacientes diabéticos do tipo 2 (idade=46,7 \pm 5,6 anos, duração da doença de 8,3 \pm 3,2 anos, concentração sangüínea de glicose $=109,8 \pm 17,7 \mathrm{mg} / \mathrm{dL}$ e $8,01 \% \pm 0,94$ de hemoglobina glicada) e 28 controles, foram encontrados déficits de atenção e memória, além da preservação das habilidades de compreensão, nomeação, construção e cálculos entre os pacientes diabéticos. Em ambos os grupos houve a prevalência de 11 indivíduos $(39,3 \%)$ com hipertensão e $3(10,7 \%)$ com doença cardíaca isquêmica. No grupo diabético, 6 (21,4\%) indivíduos apresentavam retinopatia (Dey et al., 1997).

Ryan \& Geckle (2000) estudaram 50 pacientes diabéticos não insulino dependentes de meia idade ( $M=50,8 ; D P=7,7$ anos), duração média do diabetes de 8,1 anos $(\mathrm{DP}=5,9)$ e controle metabólico representado por $10,2 \%$ de hemoglobina glicada $(\mathrm{DP}=2,4 \%$ ), incluindo na amostra $6 \%$ de indivíduos com doença vascular periférica, $28 \%$ com neuropatia diabética periférica e $16 \%$ com retinopatia, dos $6 \%$ eram do tipo proliferativa. Comparados com 50 controles, os pacientes apresentaram lentificação psicomotora, enquanto as habilidades de aprendizagem, memória e resolução de problemas se mostraram inalteradas.

Cosway et al. (2001) examinaram 38 pacientes com diagnóstico de diabetes tipo 2 (idades de 40 a 75 anos, média=57,7) por pelo menos 2 anos (média=6 anos), 7,6\% de hemoglobina glicada em média, incluindo 10 indivíduos que fazem 
uso de insulina, 6 com histórico de episódios de hipoglicemia, 1 participante com neuropatia sensório-motora, 2 com neuropatia periférica e 2 com retinopatia. Comparados com 38 controles, os pacientes diabéticos não demonstraram quaisquer alterações neuropsicológicas, tendo sido examinados: a habilidade mental pré-mórbida estimada, raciocínio abstrato, memória verbal e visual de curto e longo prazo, tempo de reação e percepção e processamento de informação visual.

Em um estudo de meta-análise, De Groot, Anderson, Freedland, Clouse e Lustman (2001) encontraram associação entre as complicações da DM (retinopatia, nefropatia, neuropatia, alterações vasculares e disfunções sexuais) e sintomas de depressão em paciente diabéticos do tipo 2. 


\subsection{Objetivos}

\subsection{Geral}

- Examinar a hipótese da ocorrência de disfunções neuropsicológicas em pacientes com diagnóstico de diabetes tipo 2 e sem retinopatia diabética.

\subsection{Específicos}

- Testar a hipótese de associação entre maior duração do diabetes tipo 2 e pior desempenho neuropsicológico.

- Examinar a possibilidade de melhor resultado na bateria neuropsicológica conforme menor a porcentagem de hemoglobina glicada nos pacientes diabéticos do tipo 2 .

- Verificar se existe associação entre o desempenho neuropsicológico e a concentração da glicose sangüínea capilar. 


\subsection{Materiais e Métodos}

Os participantes do estudo foram submetidos a uma sessão de avaliação neuropsicológica com as etapas de anmnese, aplicação de testes neuropsicológicos e inventários de depressão e ansiedade. A bateria neuropsicológica incluiu medidas de memória operacional e controle mental (Dígitos), atenção e controle inibitório (teste de Stroop), memória verbal (teste de Buschke), e visual (Reprodução Visual), fluência verbal (FAS), destreza manual (Grooved Pegboard), funções viso-espaciais (Cubos) e executivas (teste de Wisconsin), conhecimento semântico (Vocabulário), além de sintomas de depressão (DBI) e ansiedade (IDATE). As descrições detalhadas dos procedimentos de testagem realizados, medidas neuropsicológicas utilizadas e aspectos éticos foram apresentadas anteriormente (vide itens 3,31 e 3,32).

Além dos procedimentos referidos, os pacientes diabéticos e integrantes do grupo controle foram submetidos ao exame da concentração de glicose sangüínea capilar através do aparelho Acuchek Advantage II (Roche), imediatamente antes da aplicação dos testes neuropsicológicos.

Para a verificação da presença de retinopatia, os pacientes diabéticos foram submetidos ao exame de fundo de olho, realizado no Hospital Universitário da USP. Somente os pacientes sem o diagnóstico desta complicação foram encaminhados para o presente estudo. Dados referentes à porcentagem de hemoglobina glicada e valores de microalbuminúria dos pacientes diabéticos foram coletados nos prontuários dos mesmos, localizados no HU.

\subsection{Análise Estatística dos Resultados}

As comparações entre os resultados obtidos pelos grupos nos testes neuropsicológicos e quanto à diferença de "escolaridade" foram realizadas 
conforme estatística não paramétrica, através do teste de Mann-Whitney. Para as análises dos escores de depressão e ansiedade e quanto à diferença de "idade" entre pacientes diabéticos e grupo controle, utilizou-se o teste paramétrico $t$ de Student para amostras independentes, uma vez que os dados tiveram distribuição normal e mesma variância.

Para a verificação da possibilidade de associação entre variáveis intragrupos (idade, escolaridade, concentração de glicose sangüínea capilar, hemoglobina glicada, duração do diabetes, escores de depressão e ansiedade) e os escores dados obtidos nos testes neuropsicológicos, utilizou-se o teste de correlação de Spearman.

Utilizou-se o programa estatístico Jandel Sigma-Stat Software 2.0 (Jandel Corporation, 1992) para a execução dos cálculos e adotou-se $p<0,05$ como limiar de significância. 


\subsection{Casuística}

Dezenove pacientes diabéticos do tipo 2 (15 homens e 4 mulheres) sem diagnóstico de retinopatia conforme exame oftalmológico prévio, foram encaminhados pelo Hospital Universitário da USP, onde realizam tratamento ambulatorial. Conforme os dados da tabela 15, o grupo tem idade média de 50,7 \pm 9,6 anos; 8,9 \pm 4,4 anos de escolaridade e concentração glicêmica sangüínea (medida imediatamente antes do exame neuropsicológico) de 148,2 $\pm 31,5 \mathrm{mg} / \mathrm{dL}$ (tabelas 15). São pacientes destros, sem queixas de neuropatia diabética, que apresentaram porcentagem de hemoglobina glicada com média de $7 \pm 1,3 \%$, valores de microalbuminúria dentro da normalidade $(<20 \mu \mathrm{g} / \mathrm{min})$, que não fazem uso de insulina como tratamento, dos quais 9 (47\%) são hipertensos (tabela 16). Constituíram critérios de exclusão deste grupo: diagnóstico de retinopatia diabética, históricos de distúrbios neurológicos, exposição crônica a agentes tóxicos, lesão ou cirurgia cerebral, abuso de álcool ou uso de drogas.

O grupo controle foi composto por 20 indivíduos destros (17 homens e 3 mulheres) com idades de 47,5 \pm 8,4 anos, nível de escolaridade de 9,8 $\pm 2,3$ anos e concentração glicêmica de 127,1 $\pm 67,3 \mathrm{mg} / \mathrm{dL}$ (tabela 15). São funcionários dos Institutos de Psicologia e de Biociências e do Centro de Práticas Esportivas da USP. Histórico de distúrbios psiquiátricos, neurológicos, endócrinos, metabólicos ou vasculares, exposição crônica a substâncias tóxicas, lesão ou cirurgia cerebral, abuso de álcool e uso de drogas constituíram critérios de exclusão.

Os pacientes diabéticos participaram de um estudo prévio realizado em nosso laboratório em que foram encontradas perdas visuais de discriminação de cores com padrão difuso e de sensibilidade ao contraste com processamento cromático mais afetado, indicando perdas visuais precoces, apesar de não apresentarem retinopatia detectável por exame de fundo de olho (Gualtieri, 2004). 


\subsection{Resultados}

A tabela 15 apresenta os dados gerais dos participantes referentes ao sexo, idade, nível de educação formal, concentração glicêmica sangüínea, tabagismo, hipertensão. Verificou-se diferença significante entre os valores do nível de glicose sangüínea $(p=0,005)$.

Tabela 15

Características gerais dos participantes diabéticos do tipo 2 e grupo controle

\begin{tabular}{|c|c|c|c|c|c|c|c|c|c|}
\hline & \multicolumn{4}{|c|}{ Grupo Diabético $(n=19)$} & \multicolumn{4}{|c|}{ Grupo Controle $(n=20)$} & \multirow[b]{2}{*}{$\boldsymbol{P}$} \\
\hline & $\mathbf{N}$ & Md & $M \pm D P$ & $\%$ & $\mathbf{N}$ & Md & $M \pm D P$ & $\%$ & \\
\hline Sexo & 19 & & & 100 & 20 & & & 100 & \\
\hline Masculino & 14 & & & 74 & 17 & & & 85 & \\
\hline Feminino & 5 & & & 26 & 3 & & & 15 & \\
\hline Idade (anos) & & 50 & $50,7 \pm 9,6$ & & & 48,5 & $47,5 \pm 8,4$ & & 0,136 \\
\hline Escolaridade (anos) & & 10 & $8,9 \pm 4,4$ & & & 11 & $9,8 \pm 2,3$ & & 0,254 \\
\hline Glicemia (mg/dL) & & 147,5 & $147,2 \pm 31,5$ & & & 119 & $127,1 \pm 67,3$ & & 0,005 \\
\hline \multicolumn{10}{|l|}{ Tabagismo } \\
\hline Tabagistas & 1 & & & 4 & 2 & & & 10 & \\
\hline Ex-tabagistas & 6 & & & 30 & 2 & & & 10 & \\
\hline Não tabagistas & 13 & & & 66 & 16 & & & 80 & \\
\hline
\end{tabular}

Dados específicos sobre o grupo de pacientes diabéticos (duração da doença, porcentagens de hemoglobina glicada, valores de microalbuminúria, freqüência de indivíduos hipertensos e uso de medicamentos) são listados na tabela 16. A duração do diabetes $(M=8,2$ anos, $D P=8,1)$ foi estabelecida a partir do diagnóstico. Dezoito pacientes $(95 \%)$ realizam tratamento farmacológico com a combinação de medicamentos, conforme as seguintes freqüências: 17 indivíduos (89\%) utilizam antidiabéticos (Glibencamida, Metiformina ou a combinação de ambos), 7 (37\%) realizam tratamento para hipertensão (Enalapril, Captopril ou Losartan), 9 (47\%) fazem uso de anticoagulante (AAS), 1 (5\%) indivíduo é tratado 
com antidepressivo (Fluoxetina) e 1 (5\%) não realiza acompanhamento medicamentoso. Deve-se ressaltar que as freqüências descritas não são mutuamente exclusivas e, portanto um mesmo paciente pode fazer uso de um ou mais tipos de tratamentos.

Tabela 16

Variáveis específicas do grupo diabético

\begin{tabular}{|c|c|c|c|c|}
\hline & $\mathbf{N}$ & Md & $M \pm D P$ & $\%$ \\
\hline Duração da doença* (anos) & 19 & 6 & $8,2 \pm 8,1$ & \\
\hline $\mathrm{HbA}_{1 \mathrm{c}}(\%)$ & 19 & 6,9 & $7 \pm 1,3$ & \\
\hline Microalbuminúria $<20 \mu \mathrm{g} / \mathrm{min}$ & 19 & & & 100 \\
\hline Hipertensos & 9 & & & 47 \\
\hline Tratamento Medicamentoso & 18 & & & 95 \\
\hline Antidiabetes & 17 & & & 89 \\
\hline Glibencamida & 5 & & & 26 \\
\hline Metiformina & 4 & & & 21 \\
\hline Combinados & 8 & & & 42 \\
\hline Antihipertensivos & 7 & & & 37 \\
\hline Enalapril & 2 & & & 10 \\
\hline Captopril & 4 & & & 21 \\
\hline Losartan & 1 & & & 5 \\
\hline \multicolumn{5}{|l|}{ Anticoagulante } \\
\hline AAS & 9 & & & 47 \\
\hline \multicolumn{5}{|l|}{ Antidepressivo } \\
\hline Fluoxetina & 1 & & & 5 \\
\hline Nenhum & 1 & & & 5 \\
\hline
\end{tabular}

A tabela 17 mostra a comparação entre os grupos quanto ao desempenho nos testes e inventários da avaliação neuropsicológica, não revelando diferença significativa $(p<0,05)$ entre pacientes diabéticos em quaisquer medidas realizadas. 
Tabela 17

Medianas, médias, desvios e valores de $p$ referentes aos dados brutos obtidos pelos grupos diabético e controle na avaliação neuropsicológica

\begin{tabular}{|c|c|c|c|c|c|}
\hline \multirow[b]{2}{*}{ Testes e Inventários } & \multicolumn{2}{|c|}{$\begin{array}{l}\text { Grupo Diabético } \\
(n=19)\end{array}$} & \multicolumn{2}{|c|}{$\begin{array}{l}\text { Grupo Controle } \\
(n=20)\end{array}$} & \multirow[b]{2}{*}{$P$} \\
\hline & Md & $M \pm D P$ & Md & $\mathrm{M} \pm \mathrm{DP}$ & \\
\hline \multicolumn{6}{|l|}{ Dígitos } \\
\hline Diretos & 6 & $5,8 \pm 1,7$ & 6 & $5,7 \pm 1,8$ & $0,895^{\star}$ \\
\hline Indiretos & 4 & $4,4 \pm 1,4$ & 3 & $3,9 \pm 1,4$ & $0,249^{*}$ \\
\hline \multicolumn{6}{|l|}{ Stroop } \\
\hline Parte 1 & 15 & $16,7 \pm 5,0$ & 14,5 & $15,7 \pm 4,5$ & $0,736^{*}$ \\
\hline Parte 2 & 20 & $20,7 \pm 6,3$ & 18,5 & $20,5 \pm 7,2$ & $0,790^{*}$ \\
\hline Parte 3 & 29 & $32,1 \pm 9,1$ & 28,5 & $31,2 \pm 9,7$ & $0,613^{*}$ \\
\hline Efeito Stroop & 2 & $3,1 \pm 5,0$ & 1,8 & $2,0 \pm 0,7$ & $0,833^{*}$ \\
\hline \multicolumn{6}{|l|}{ SRT } \\
\hline Total de Recuperação & 108 & $104,3 \pm 20,3$ & 110 & $98,6 \pm 31,2$ & $0,653^{*}$ \\
\hline Recuperação de Longo Prazo & 103 & $90,0 \pm 34,9$ & 96,5 & $91,0 \pm 25,3$ & $0,536^{*}$ \\
\hline Armazenamento de Longo Prazo & 111 & $93,4 \pm 37,7$ & 105 & $100,9 \pm 26,0$ & $0,833^{*}$ \\
\hline Recuperação Consistente de Longo Prazo & 63 & $59,1 \pm 30,4$ & 75,5 & $66,8 \pm 28,1$ & $0,299^{*}$ \\
\hline Recuperação Randômica de Longo Prazo & 31 & $27,9 \pm 15,3$ & 23,5 & $26,1 \pm 14,0$ & $0,623^{*}$ \\
\hline Intrusões & 0 & $1,2 \pm 2,8$ & 0 & $1,3 \pm 2,3$ & $0,955^{\star}$ \\
\hline Recuperação Tardia (após 30 min.) & 10 & $8,7 \pm 2,7$ & 10,5 & $9,9 \pm 1,7$ & $0,211^{*}$ \\
\hline Total de Reconhecimento & 11 & $11,0 \pm 1,0$ & 11 & $12 \pm 1,5$ & $0,150^{*}$ \\
\hline \multicolumn{6}{|l|}{ Reprodução Visual } \\
\hline Imediata & 24,9 & $24,9 \pm 9,3$ & 25,3 & $28,5 \pm 5,8$ & $0,307^{*}$ \\
\hline Tardia (após 30 min.) & 21,6 & $21,6 \pm 9,1$ & 18,4 & $20,7 \pm 8,2$ & $0,300^{*}$ \\
\hline \multicolumn{6}{|l|}{ FAS } \\
\hline Letra F & 12 & $11,1 \pm 4,7$ & 13 & $12,0 \pm 3,4$ & $0,661^{*}$ \\
\hline Letra A & 8 & $8,8 \pm 4,1$ & 10 & $10,2 \pm 2,8$ & $0,237^{*}$ \\
\hline Letra S & 9 & $8,3 \pm 4,6$ & 9 & $9,5 \pm 3,4$ & $0,397^{*}$ \\
\hline Total & 30 & $28,7 \pm 12,6$ & 33 & $31,8 \pm 8,4$ & $0,431^{*}$ \\
\hline \multicolumn{6}{|l|}{ Grooved Pegboard } \\
\hline Mão Dominante & 78 & $79,9 \pm 13,9$ & 75,5 & $79,2 \pm 14,1$ & $0,736^{*}$ \\
\hline Mão Não Dominante & 77 & $87,4 \pm 22,7$ & 81 & $86,7 \pm 17,2$ & $0,536^{*}$ \\
\hline Cubos & 16 & $18,4 \pm 10,1$ & 18 & $21,0 \pm 10,7$ & $0,511^{*}$ \\
\hline \multicolumn{6}{|l|}{ Wisconsin } \\
\hline Total de Erros & 70 & $58,5 \pm 24,4$ & 55 & $55,5 \pm 24,9$ & $0,415^{*}$ \\
\hline Respostas Perseverativas & 39 & $41,0 \pm 24,9$ & 27 & $37,7 \pm 30,0$ & $0,384^{*}$ \\
\hline Erros Perseverativos & 37 & $34,9 \pm 19,9$ & 23,5 & $29,9 \pm 22,3$ & $0,211^{*}$ \\
\hline Erros Não Perseverativos & 23 & $21,9 \pm 14,7$ & 21 & $22,1 \pm 17,9$ & $0,844^{*}$ \\
\hline Respostas de Nível Conceitual & 43 & $47,4 \pm 16,5$ & 51 & $49,2 \pm 20,4$ & $0,884^{*}$ \\
\hline Categorias Completas & 2 & $3,2 \pm 1,7$ & 3,5 & $3,3 \pm 2,0$ & $0,955^{*}$ \\
\hline Tentativas para Completar a $1^{\circ}$ Categoria & 19 & $30,8 \pm 25,8$ & 11 & $24,8 \pm 31,1$ & $0,140^{*}$ \\
\hline Perdas de Meta & 1 & $1,0 \pm 1,4$ & 1 & $1,0 \pm 0,7$ & $0,465^{*}$ \\
\hline Vocabulário & 28 & $32,5 \pm 17,4$ & 29 & $29,3 \pm 11,5$ & $0,582^{*}$ \\
\hline BDI & 9 & $9,8 \pm 7,8$ & 6 & $6,2 \pm 3,7$ & $0,197^{\star *}$ \\
\hline \multicolumn{6}{|l|}{ IDATE } \\
\hline Estado & 32,5 & $34,8 \pm 9,1$ & 36 & $35,0 \pm 5,9$ & $0,514^{* *}$ \\
\hline Traço & 37 & $39,4 \pm 10,6$ & 34,5 & $36,2 \pm 6,0$ & $0,357^{\star *}$ \\
\hline
\end{tabular}


A tabela 18 mostra as análises intragrupos das variáveis idade, escolaridade, escores de depressão e ansiedade e concentração glicêmica sangüínea capilar comparadas com os resultados quantitativos obtidos nos testes neuropsicológicos, conforme o teste de correlação de Spearman $(p<0,05)$. Para $o$ grupo diabético, também foram realizadas análises para a verificação de possíveis associações entre os índices da evolução da doença (porcentagem de hemoglobina glicada e duração do diabetes) e os escores relativos aos testes.

As descrições detalhadas dos dados apresentados nas tabelas 17 e 18, respectivamente, encontram-se a seguir (vide item 4.51). 
Tabela 18

Teste de correlação de Spearman com resultado significativo entre variáveis intragrupos, coeficiente de correlação (rS) e valor de $p$

\begin{tabular}{|c|c|c|c|c|c|}
\hline \multirow[b]{2}{*}{ Variáveis } & \multirow[b]{2}{*}{ Variáveis } & \multicolumn{2}{|c|}{ Grupo Diabético } & \multicolumn{2}{|c|}{ Grupo Controle } \\
\hline & & rS & $P$ & rS & $P$ \\
\hline \multirow[t]{5}{*}{ Idade } & Stroop & & & & \\
\hline & Parte 3 & - & - & 0,505 & 0,023 \\
\hline & FAS & & & & \\
\hline & Letra $A$ & - & - & $-0,558$ & 0,013 \\
\hline & Cubos & - & - & $-0,630$ & 0,003 \\
\hline \multirow[t]{15}{*}{ Escolaridade } & Dígitos Diretos & - & - & 0,484 & 0,047 \\
\hline & Stroop & & & & \\
\hline & Parte 1 & $-0,472$ & 0,040 & - & - \\
\hline & Parte 2 & $-0,476$ & 0,039 & - & - \\
\hline & SRT & & & & \\
\hline & Recuperação de Longo Prazo & - & - & 0,545 & 0,019 \\
\hline & Armazenamento de Longo Prazo & - & - & 0,558 & 0,015 \\
\hline & Recuperação Consistente de Longo Prazo & - & - & 0,497 & 0,035 \\
\hline & Recuperação Tardia & - & - & 0,661 & 0,002 \\
\hline & FAS & & & & \\
\hline & Letra $\mathrm{F}$ & 0,546 & 0,015 & - & - \\
\hline & Letra A & 0,483 & 0,035 & - & - \\
\hline & Letra S & 0,488 & 0,033 & - & - \\
\hline & Total & 0,584 & 0,008 & - & - \\
\hline & Vocabulário & 0,653 & 0,004 & 0,633 & 0,011 \\
\hline \multicolumn{6}{|l|}{ BDI (Escore Bruto) } \\
\hline & Stroop & & & & \\
\hline & Parte 1 & 0,527 & 0,024 & - & - \\
\hline & Stroop & & & & \\
\hline & Parte 2 & - & - & 0,454 & 0,049 \\
\hline & SRT & & & & \\
\hline & Armazenamento de Longo Prazo & - & - & $-0,470$ & 0,041 \\
\hline & FAS & & & & \\
\hline & Letra "F" & - & - & $-0,614$ & 0,006 \\
\hline & Letra "A" & - & - & $-0,765$ & 0,000 \\
\hline & Letra "S" & - & - & $-0,479$ & 0,043 \\
\hline & Total & - & - & $-0,658$ & 0,002 \\
\hline \multicolumn{6}{|l|}{ IDATE - Estado (Escore Bruto) } \\
\hline & Grooved Pegboard & & & & \\
\hline & Mão Dominante & - & - & 0,477 & 0,038 \\
\hline IDATE - Traço (Escore Bruto) & * & * & * & * & * \\
\hline
\end{tabular}


Tabela 18

Teste de correlação de Spearman com resultado significativo entre variáveis intragrupos, coeficiente de correlação (rS) e valor de $p$

\begin{tabular}{|c|c|c|c|c|c|}
\hline \multirow[b]{2}{*}{ Variáveis } & \multirow[b]{2}{*}{ Variáveis } & \multicolumn{2}{|c|}{ Grupo Diabético } & \multicolumn{2}{|c|}{ Grupo Controle } \\
\hline & & rS & $P$ & rS & $P$ \\
\hline \multirow[t]{8}{*}{ Glicemia } & Reprodução Visual Tardia & 0,593 & 0,014 & - & - \\
\hline & SRT & & & & \\
\hline & Rec. Consistente de Longo Prazo & - & - & 0,650 & 0,015 \\
\hline & Wisconsin & & & & \\
\hline & Total de Erros & - & - & 0,614 & 0,023 \\
\hline & Erros Perseverativos & - & - & 0,658 & 0,013 \\
\hline & Respostas de Nível Conceitual & - & - & $-0,723$ & 0,004 \\
\hline & Categorias Completas & - & - & $-0,616$ & 0,023 \\
\hline \multirow[t]{3}{*}{$\mathrm{HbA}_{1 \mathrm{c}}$} & FAS & & & & \\
\hline & Letra A & $-0,611$ & 0,015 & $* *$ & ** \\
\hline & Total & $-0,543$ & 0,035 & ** & ** \\
\hline \multirow[t]{14}{*}{ Duração da Doença } & $\mathrm{HbA}^{1} \mathrm{C}$ & 0,569 & 0,032 & ** & ** \\
\hline & Reprodução visual Imediata & $-0,604$ & 0,007 & $* *$ & ** \\
\hline & Reprodução visual Tardia & $-0,632$ & 0,004 & ** & ** \\
\hline & FAS & & & & \\
\hline & Letra F & $-0,542$ & 0,020 & ** & ** \\
\hline & Letra A & $-0,498$ & 0,034 & $* *$ & ** \\
\hline & Letra S & $-0,468$ & 0,049 & ** & ** \\
\hline & Total & $-0,490$ & 0,038 & ** & ** \\
\hline & Grooved Pegboard & & & & \\
\hline & Mão Dominante & 0,701 & 0,001 & ** & ** \\
\hline & Mão Não Dominante & 0,649 & 0,003 & ** & ** \\
\hline & Cubos & $-0,489$ & 0,039 & ** & ** \\
\hline & Wisconsin & & & & \\
\hline & $N^{\circ}$ de Tentativas para $a 1^{\circ}$ Categoria & 0,492 & 0,037 & ** & ** \\
\hline
\end{tabular}




\subsection{Apresentação dos Domínios Examinados}

\subsection{Atenção}

No teste Dígitos, a análise não revelou diferença estatística $(p<0,05)$ entre os grupos, tanto para a ordem direta $(0,895)$ como para a ordem inversa $(0,249)$. As figuras 46 e 47 apresentam a distribuições dos dados relativos a Dígitos Diretos e Indiretos, respectivamente. No grupo controle, variável "escolaridade" teve correlação positiva ( $r S=0,484 ; p=0,047)$ com Dígitos Diretos (tabela 18), indicando melhor desempenho conforme maior o nível de educação formal.

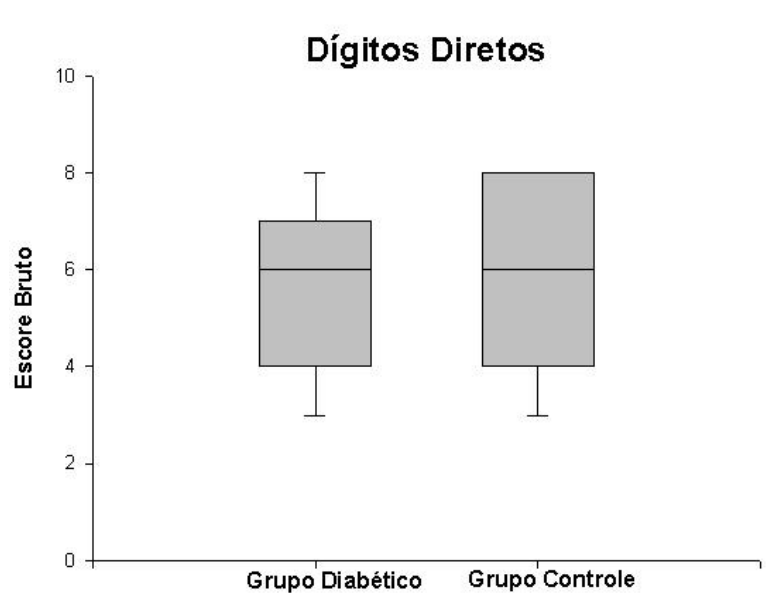

Figura 46. Mediana, $1^{\circ}$ e $3^{\circ}$ quartis, percentil 5 e 95 dos escores brutos obtidos pelo grupo de pacientes diabéticos do tipo 2 e o grupo controle em Dígitos Diretos.

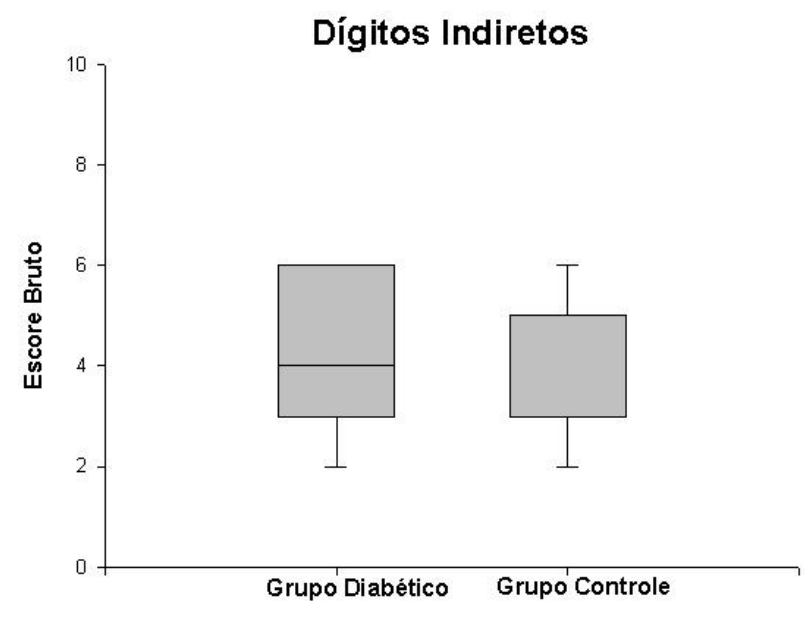

Figura 47. Mediana, $1^{\circ}$ e $3^{\circ}$ quartis, percentil 5 e 95 dos escores brutos obtidos pelo grupo de pacientes diabéticos do tipo 2 e o grupo controle em Dígitos Indiretos.

No teste de Stroop não houve diferença no desempenho do grupo de pacientes diabéticos em relação ao grupo controle nas partes $1(p=0,736)$ (figura 48), $2(p=0,790)$ (figura 49) e $3(p=0,613)$ (figura 50), além do efeito stroop $(p=0,833)$ (figura 51). A variável "idade" correlacionou-se com o resultado em Stroop parte 3 ( $r S=0,505 ; p=0,023$ ), evidenciando redução da habilidade de controle inibitório conforme o aumento da idade; enquanto no grupo diabético, a 
"escolaridade" teve associação significativa com as partes 1 ( $r S=-0,472 ; p=0,040)$ e 2 ( $r S=-0,476 ; p=0,039)$, indicando maior velocidade na execução da tarefa entre os indivíduos mais jovens (tabela 18).

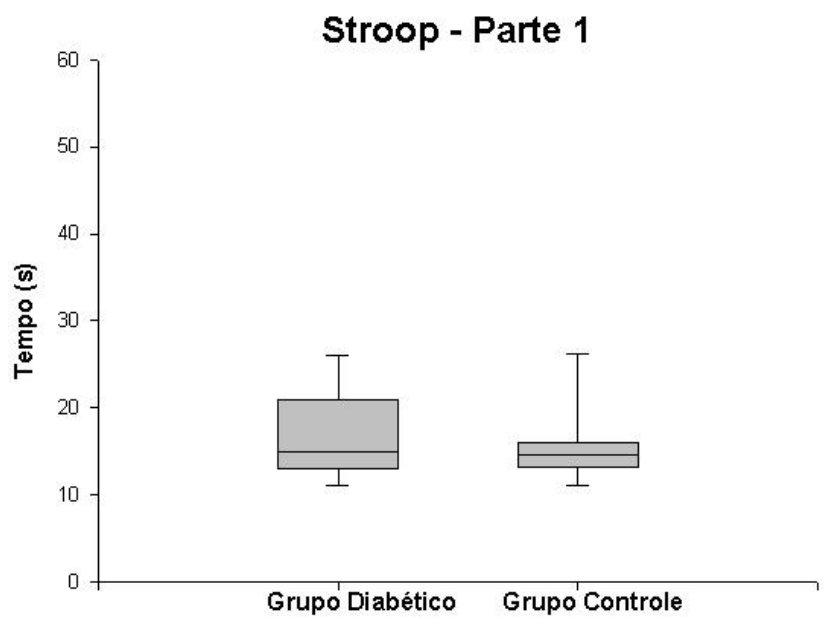

Figura 48. Mediana, $1^{\circ}$ e $3^{\circ}$ quartis, percentil 5 e 95 dos tempos obtidos pelo grupo de pacientes diabéticos do tipo 2 e o grupo controle em Stroop Parte 1.

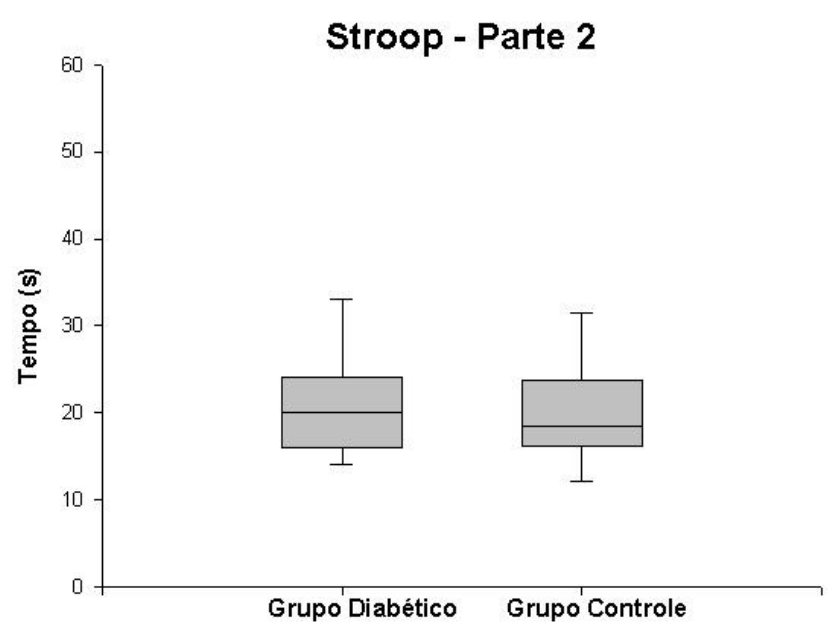

Figura 49. Mediana, $1^{\circ}$ e $3^{\circ}$ quartis, percentil 5 e 95 dos tempos obtidos pelo grupo de pacientes diabéticos do tipo 2 e o grupo controle em Stroop Parte 2.

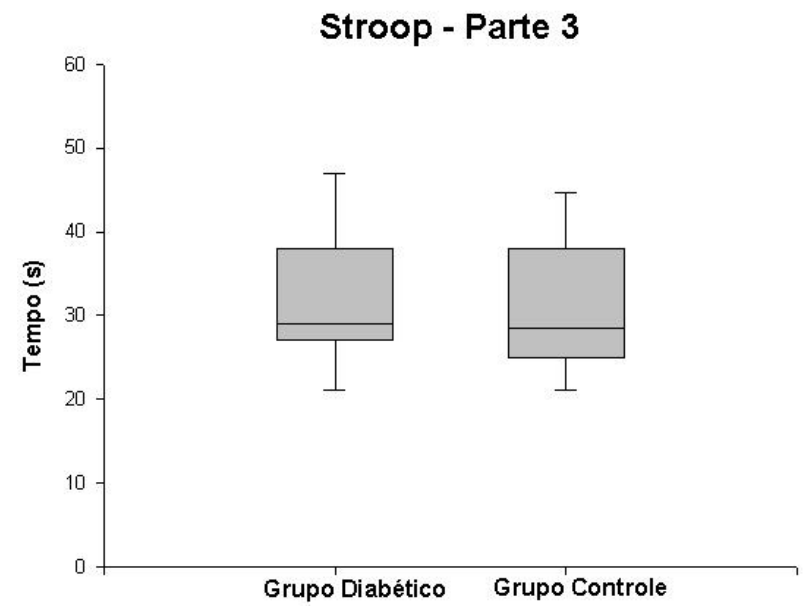

Figura 50. Mediana, $1^{\circ}$ e $3^{\circ}$ quartis, percentil 5 e 95 dos tempos obtidos pelo grupo de pacientes diabéticos do tipo 2 e o grupo controle em Stroop Parte 3.

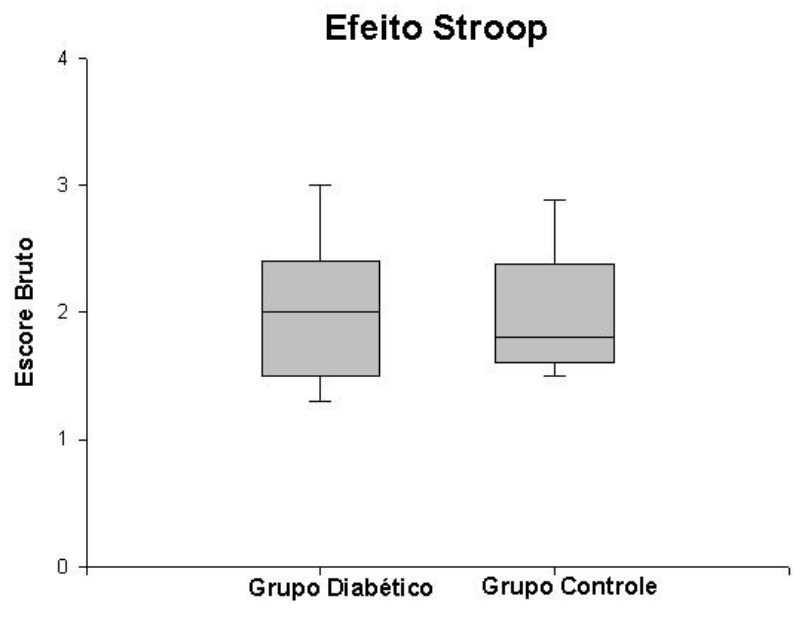

Figura 51. Mediana, $1^{\circ}$ e $3^{\circ}$ quartis, percentil 5 e 95 dos escores brutos obtidos pelo grupo de pacientes diabéticos do tipo 2 e o grupo controle Efeito Stroop.

\subsection{Memória}

O SRT, medida de memória verbal, não mostrou diferença significante entre os resultados dos grupos para todos os itens examinados: total de recuperação $(p=0,563)$ (figura 52), recuperação de longo prazo $(p=0,536)$ (figura 53), armazenamento de longo prazo $(p=0,833)$ (figura 54), recuperação consistente de longo prazo $(p=0,299)$ (figura 55$)$, recuperação randômica de longo prazo $(p=0,623)$ 
(figura 56), número de intrusões $(p=0,955)$ (figura 57), recuperação tardia $(p=0,211)$

(figura 58) e total de reconhecimento $(p=0,150)$ (figura 59). No grupo controle, o teste de correlação de Spearman mostrou escores maiores para recuperação de longo prazo ( $r S=0,545 ; p=0,019)$, armazenamento de longo prazo ( $r S=0,558$; $p=0,015)$, recuperação consistente de longo prazo $(r S=0,497 ; p=0,035)$ e recuperação tardia $(r S=0,661 ; p=0,002)$ conforme maior "escolaridade", além da correlação positiva entre o aumento da "concentração de glicose sangüínea" e melhor recuperação consistente de longo prazo ( $r S=0,650 ; p=0,015)$ (tabela 18).

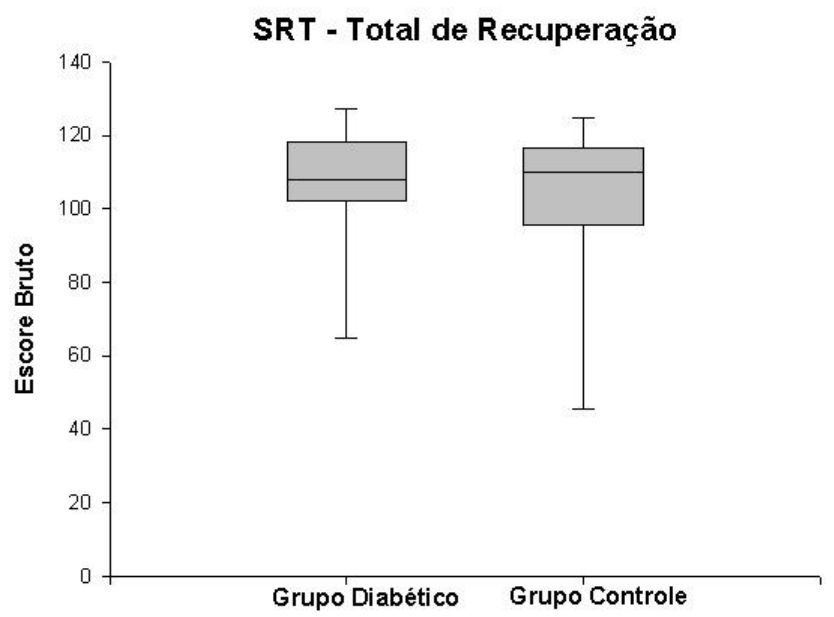

Figura 52. Mediana, $1^{\circ}$ e $3^{\circ}$ quartis, percentil 5 e 95 dos escores brutos obtidos pelo grupo de pacientes diabéticos do tipo 2 e o grupo controle no SRT em Total de Recuperação.

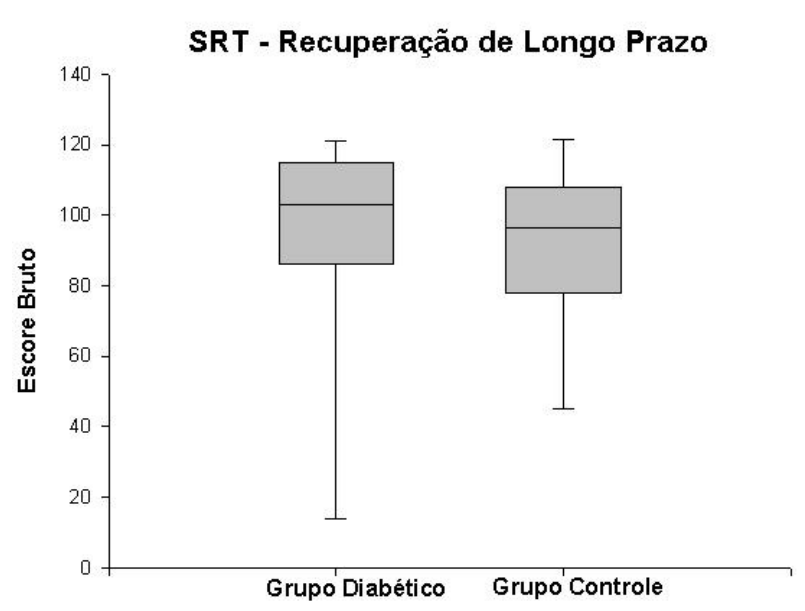

Figura 53. Mediana, $1^{\circ}$ e $3^{\circ}$ quartis, percentil 5 e 95 dos escores brutos obtidos pelo grupo de pacientes diabéticos do tipo 2 e o grupo controle no SRT em Total de Recuperação de Longo Prazo.

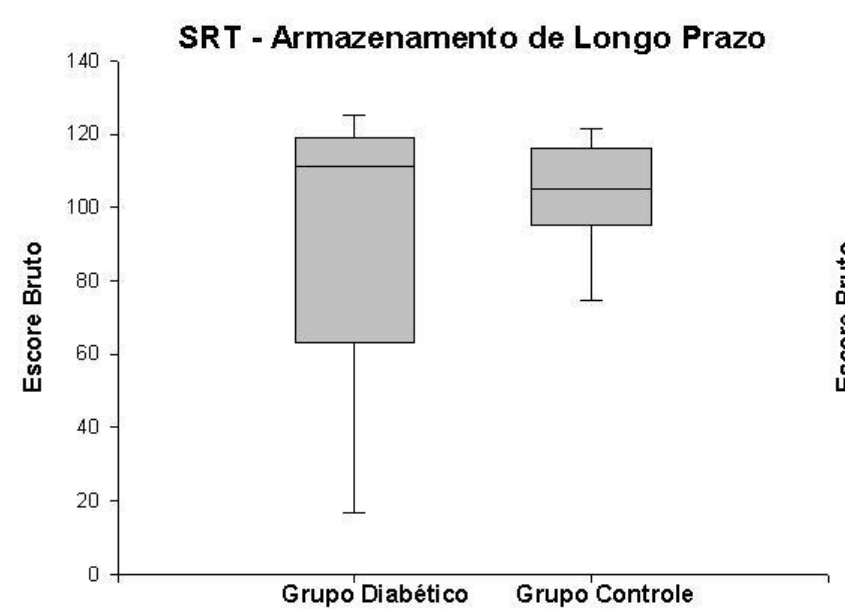

Figura 54. Mediana, $1^{\circ}$ e $3^{\circ}$ quartis, percentil 5 e 95 dos escores brutos obtidos pelo grupo de pacientes diabéticos do tipo 2 e o grupo controle no SRT em Armazenamento de Longo Prazo.

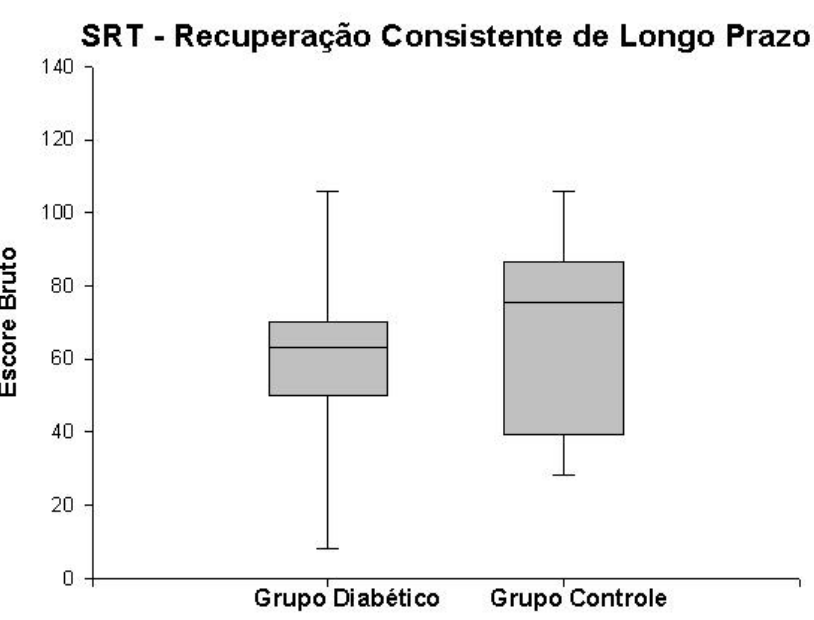

Figura 55. Mediana, $1^{\circ}$ e $3^{\circ}$ quartis, percentil 5 e 95 dos escores brutos obtidos pelo grupo de pacientes diabéticos do tipo 2 e o grupo controle no SRT em Recuperação Consistente de Longo Prazo. 


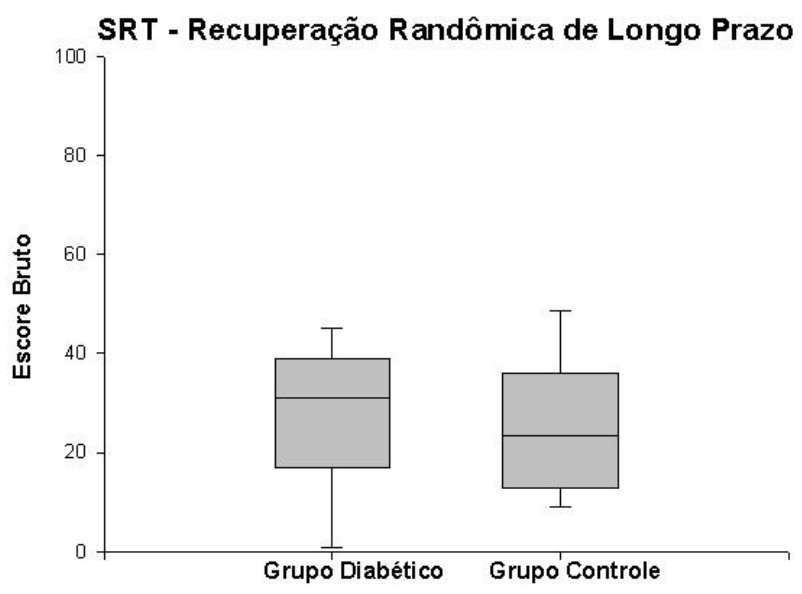

Figura 56. Mediana, $1^{\circ}$ e $3^{\circ}$ quartis, percentil 5 e 95 dos escores brutos obtidos pelo grupo de pacientes diabéticos do tipo 2 e o grupo controle no SRT em Recuperação Randômica de Longo Prazo.

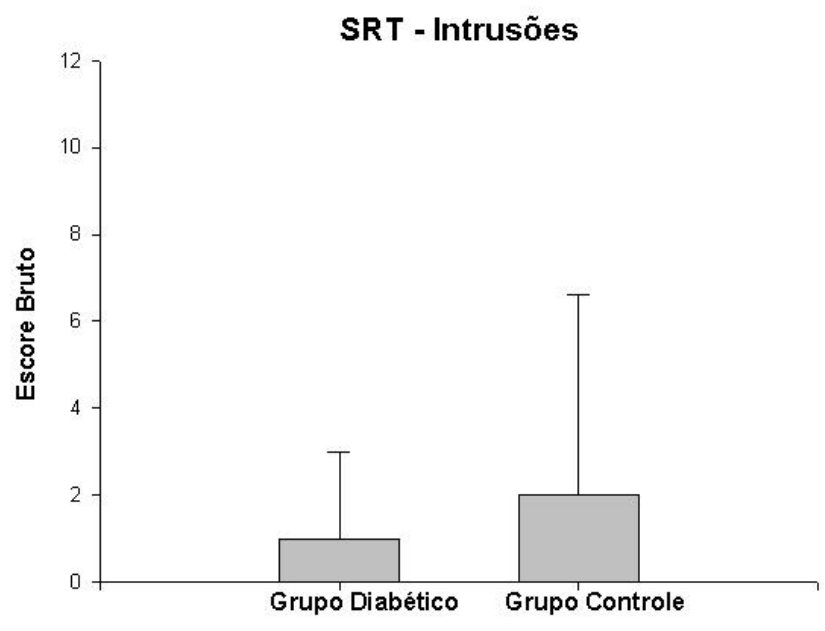

Figura 57. Mediana, $1^{\circ}$ e $3^{\circ}$ quartis, percentil 5 e 95 dos escores brutos obtidos pelo grupo de pacientes diabéticos do tipo 2 e o grupo controle no SRT para o $n^{\circ}$ de intrusões.

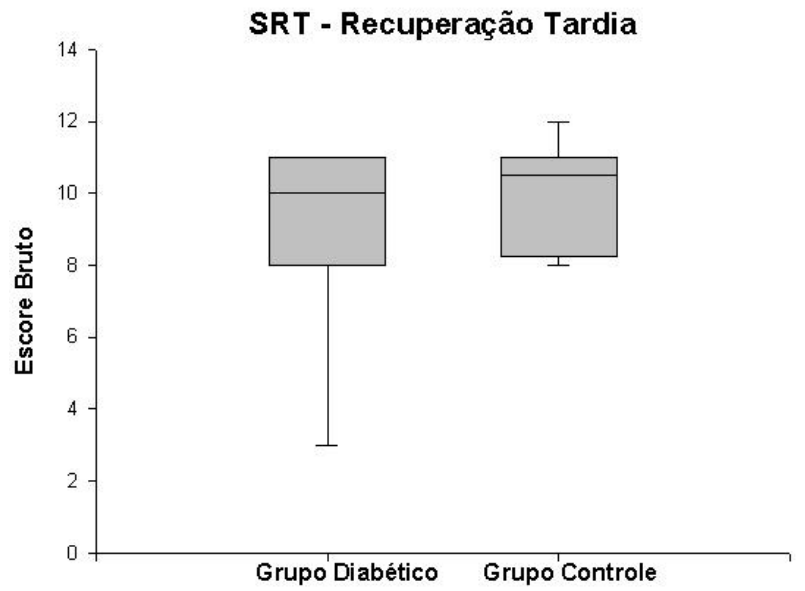

Figura 58. Mediana, $1^{\circ}$ e $3^{\circ}$ quartis, percentil 5 e 95 dos escores brutos obtidos pelo grupo de pacientes diabéticos do tipo 2 e o grupo controle no SRT em Recuperação Tardia.

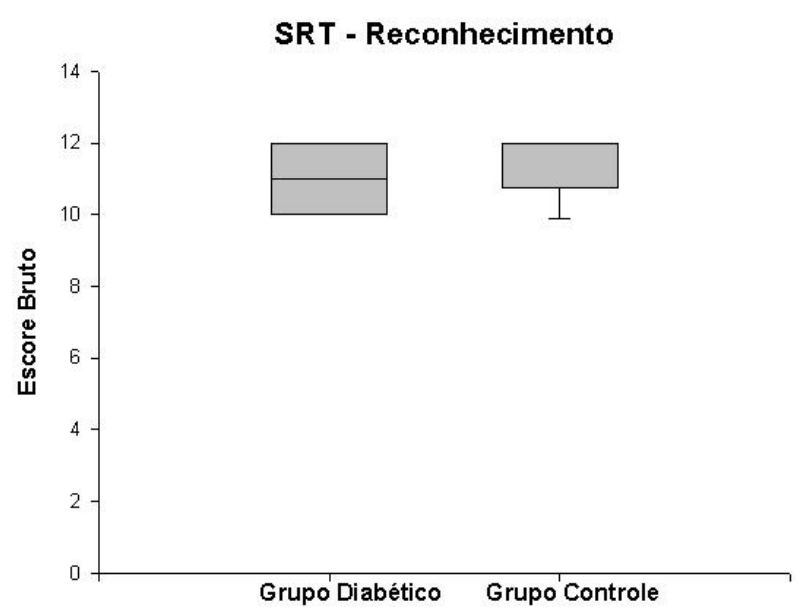

Figura 59. Mediana, $1^{\circ}$ e $3^{\circ}$ quartis, percentil 5 e 95 dos escores brutos obtidos pelo grupo de pacientes diabéticos do tipo 2 e o grupo controle no SRT em Total de Reconhecimento.

Também não houve diferença entre os grupos no teste de memória visual, conforme mostram os dados brutos em Reprodução Visual Imediata $(p=0,307)$ (figura 60) e Tardia ( $p=0,300$ ) (figura 61). No grupo diabético, o aumento do "nível de glicose sangüínea" teve correlação com escores maiores em no teste para a fase tardia ( $r S=0,593 ; p=0,014)$, enquanto maior "duração da doença" indicou pior desempenho tanto para a etapa imediata $(r S=-604 ; p=0,007)$, quanto a tardia ( $r S=$ 632; $p=0,004)$ (tabela 18). 


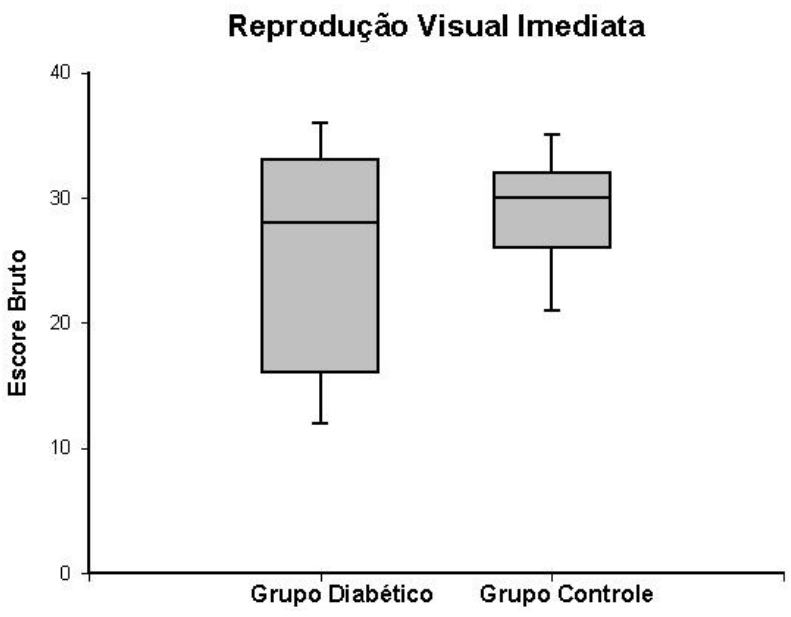

Figura 60. Mediana, $1^{\circ}$ e $3^{\circ}$ quartis, percentil 5 e 95 dos escores brutos obtidos pelo grupo de pacientes diabéticos do tipo 2 e o grupo controle em Reprodução Visual Imediata.

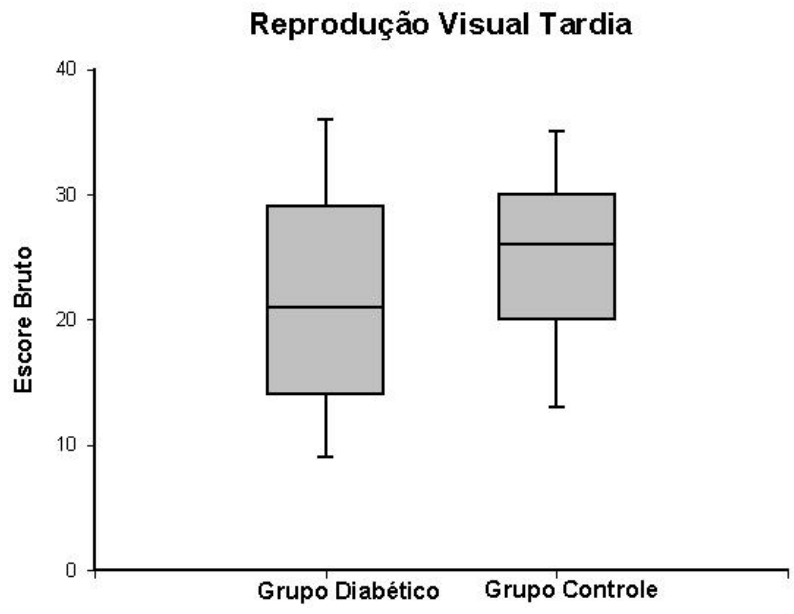

Figura 61. Mediana, $1^{\circ}$ e $3^{\circ}$ quartis, percentil 5 e 95 dos escores brutos obtidos pelo grupo de pacientes diabéticos do tipo 2 e o grupo controle em Reprodução Visual Tardia.

\subsection{Fluência Verbal}

No teste FAS, o grupo de pacientes diabéticos não revelou diferença estatística para as letras " $F$ " ( $p=0,661)$ (figura 62), "A" $(p=0,237)$ (figura 63), "S" $(p=0,397)$ (figura 64) e o escore total $(p=0,431)$ (figura 65). Entre os controles, foram evocadas mais palavras iniciadas com a letra "A" conforme menor a idade dos participantes $(r S=-0,558 ; p=0,013)$. No grupo diabético, o aumento da "escolaridade" acompanhou maior número de palavras de iniciais " $F$ " ( $r S=0,546$; $p=0,015), \quad$ "A" $(r S=0,483 ; p=0,035), \quad$ $S$ " $(r S=0,488 ; p=0,033)$, além do total ( $r S=0,584 ; p=0,008)$. Neste mesmo grupo, o teste de correlação de Spearman mostrou a associação entre maior porcentagem de "hemoglobina glicada" e a emissão de menor número de palavras iniciadas por "A" $(r S=-0,611 ; p=0,015)$ e o escore total $(r S=-0,543 ; p=0,035)$. A "duração da doença" correlacionou-se com desempenho prejudicado segundo a configuração: letra " $F$ " $(r S=-0,542 ; p=0,020)$, letra "A" ( $r S=-0,498 ; p=0,034)$, letra "S" ( $r S=-0,468 ; p=0,049)$ e o total de palavras geradas $(r S=-0,490 ; p=0,038)($ tabela 18$)$. 
FAS - Letra "F"

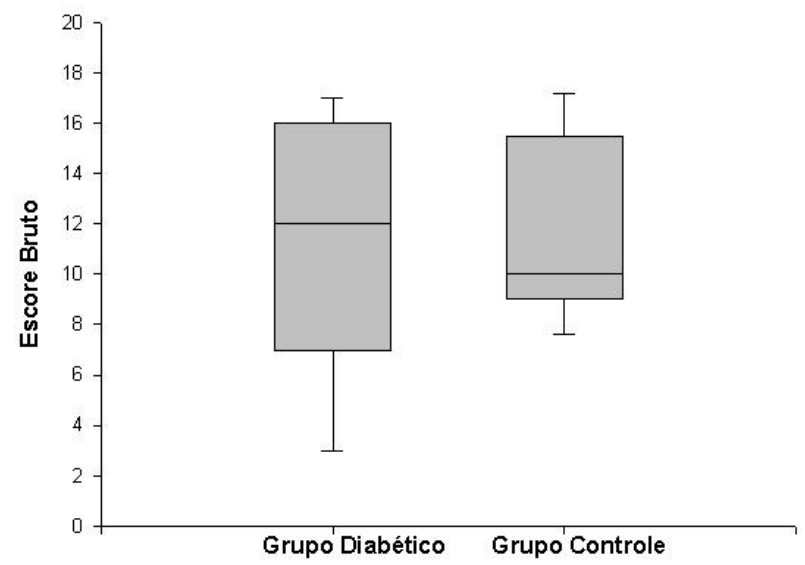

Figura 62. Mediana, $1^{\circ}$ e $3^{\circ}$ quartis, percentil 5 e 95 dos escores brutos obtidos pelo grupo de pacientes diabéticos do tipo 2 e o grupo controle em FAS para o total de palavras geradas com a letra "F".

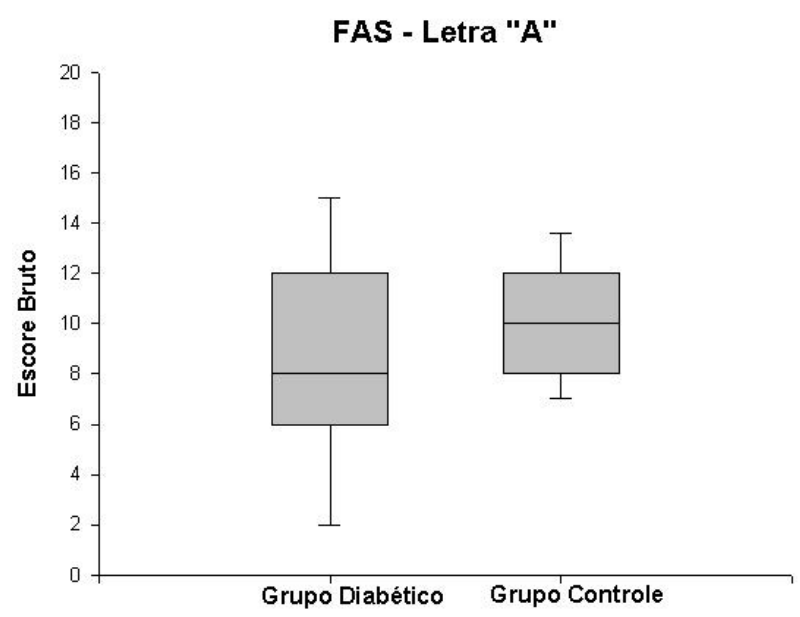

Figura 63. Mediana, $1^{\circ}$ e $3^{\circ}$ quartis, percentil 5 e 95 dos escores brutos obtidos pelo grupo de pacientes diabéticos do tipo 2 e o grupo controle em FAS para o total de palavras geradas com a letra "A".

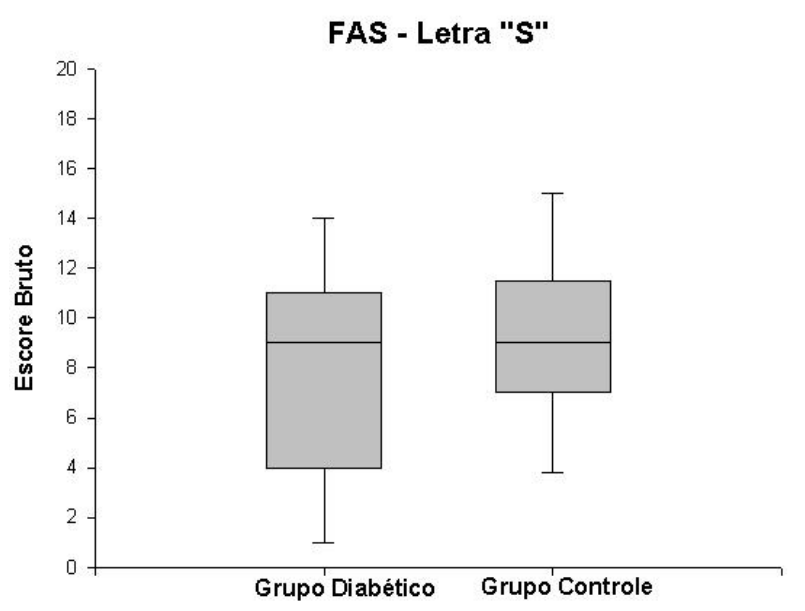

Figura 64. Mediana, $1^{\circ}$ e $3^{\circ}$ quartis, percentil 5 e 95 dos escores brutos obtidos pelo grupo de pacientes diabéticos do tipo 2 e o grupo controle em FAS para o total de palavras geradas com a letra "S".
FAS - Total

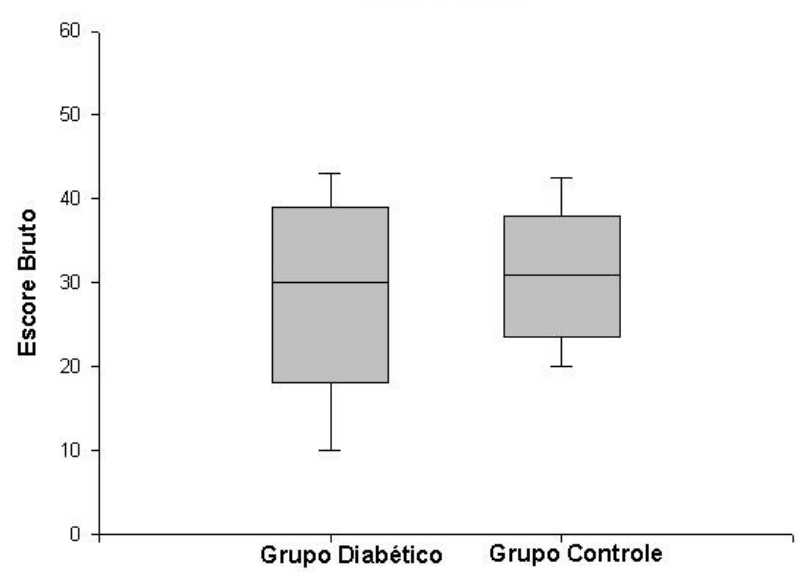

Figura 65. Mediana, $1^{\circ}$ e $3^{\circ}$ quartis, percentil 5 e 95 dos escores brutos obtidos pelo grupo de pacientes diabéticos do tipo 2 e o grupo controle em FAS para o total de palavras geradas no teste.

\subsection{Destreza Manual}

Os tempos obtidos pelos grupos para a execução do teste de destreza manual, Grooved Pegboard, não demonstram diferenças estatísticas para ambas as mãos: dominante $(p=0,736)$ (figura 66$)$ e não dominante $(p=0,536)$ (figura 67$)$. A "duração da doença" se associu ao pior desempenho (maior tempo para a realização da tarefa) tanto para a mão dominante $(r S=0,701 ; p=0,001)$, quanto para a mão não dominante $(r S=0,649 ; p=0,003)$, como mostra a tabela 18. 


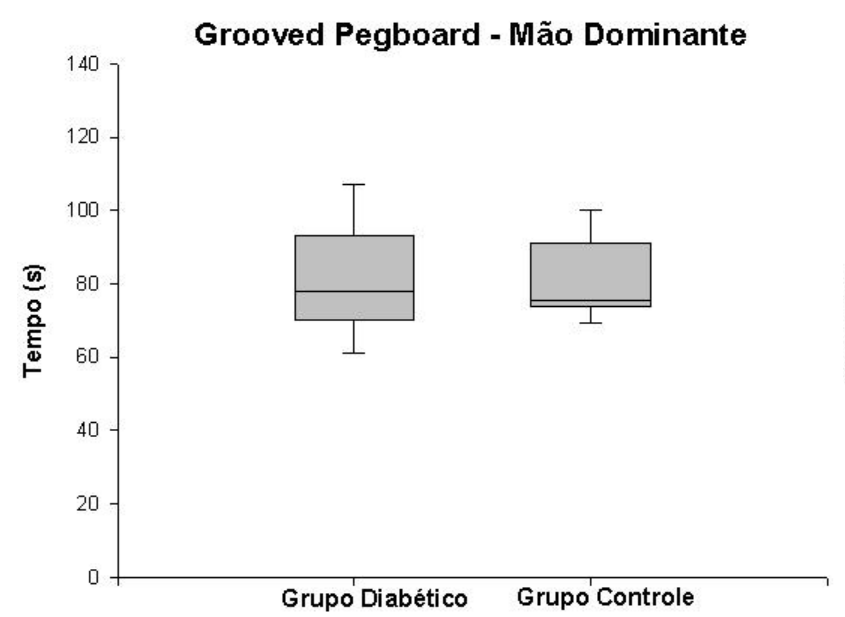

Figura 66. Mediana, $1^{\circ}$ e $3^{\circ}$ quartis, percentil 5 e 95 dos tempos obtidos pelo grupo de pacientes diabéticos e o grupo controle em Grooved Pegboard para a mão dominante.

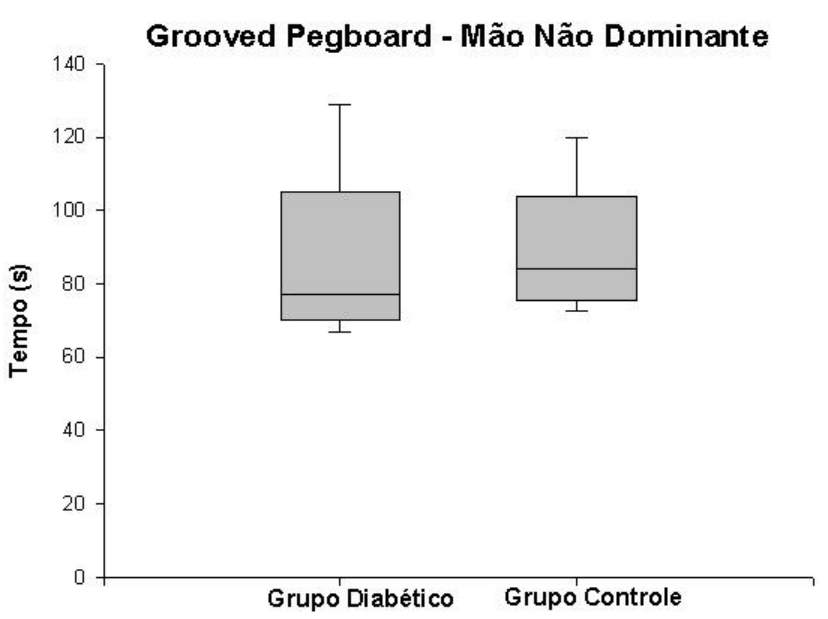

Figura 67. Mediana, $1^{\circ}$ e $3^{\circ}$ quartis, percentil 5 e 95 dos tempos obtidos pelo grupo de pacientes diabéticos e o grupo controle em Grooved Pegboard para a mão não dominante.

\subsection{Função Viso-motora}

Não houve diferença significante de desempenho entre os grupos no teste Cubos ( $p=0,511)$ (figura 68). Observou-se correlação caracterizada por redução dos escores brutos conforme os aumentos da "duração da doença" entre os pacientes diabéticos ( $r S=-0,489, p=0,039)$ e da "idade" no grupo controle ( $r S=-0,630$; $p=0,003$ ) e de acordo com o aumento (tabela 18).

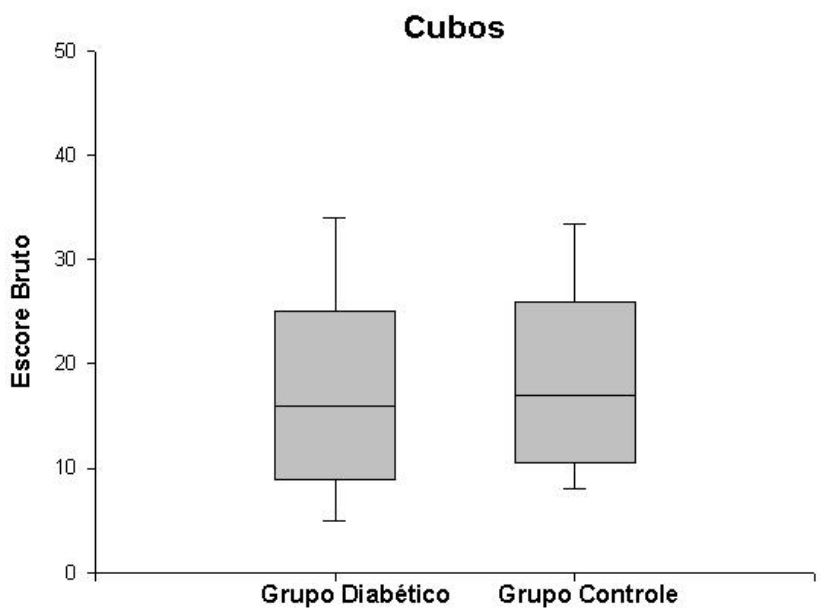

Figura 68. Mediana, $1^{\circ}$ e $3^{\circ}$ quartis, percentil 5 e 95 dos escores brutos obtidos pelo grupo de pacientes diabéticos do tipo 2 e o grupo controle em Cubos. 


\subsection{Funções Executivas}

Os resultados no teste de Wisconsin não mostram diferenças significantes em todos os itens examinados: total de erros $(p=0,415)$ (figura 69$)$, respostas perseverativas $(p=0,384)$ (figura 70), erros perseverativos $(p=0,211)$ (figura 71), erros não perseverativos $(p=0,844)$ (figura 72 ), respostas de nível conceitual $(p=0,884)$ (figura 73), categorias completas $(p=0,955)$ (figura 74), tentativas para completar a $1^{\circ}$ categoria $(p=0,140)$ (figura 75$)$ e perdas de meta $(0,465)$ (figura 76 ). No grupo de pacientes diabéticos, o maior $0 \mathrm{n}^{\circ}$ de tentativas para completar a $1^{\circ}$ categoria acompanhou a maior "duração da doença" ( $r S=0,492 ; p=0,037$, indicando pior resultado. No grupo controle, o aumento da "concentração glicêmica sangüínea" se associou significantemente com desempenho prejudicado nos seguintes itens: total de erros $(r S=0,614 ; p=0,023)$, erros perseverativos $(r S=0,656$; $p=0,013)$, respostas de nível conceitual $(r S=-0,723 ; p=0,004)$ e categorias completas $(r S=-0,616 ; p=0,023)$ (tabela 18$)$.

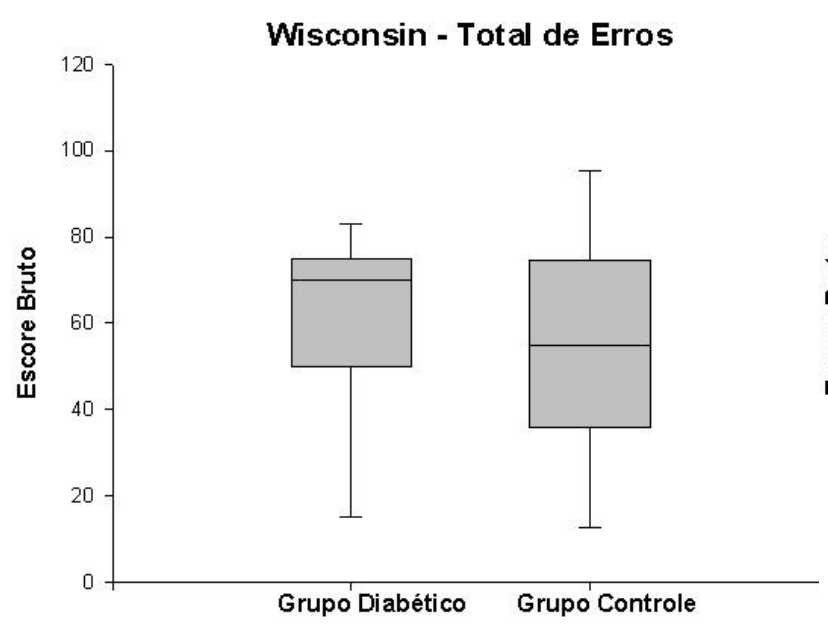

Figura 69. Mediana, $1^{\circ}$ e $3^{\circ}$ quartis, percentil 5 e 95 dos escores brutos obtidos pelo grupo de pacientes diabéticos do tipo 2 e o grupo controle no teste de Wisconsin para o total de erros.

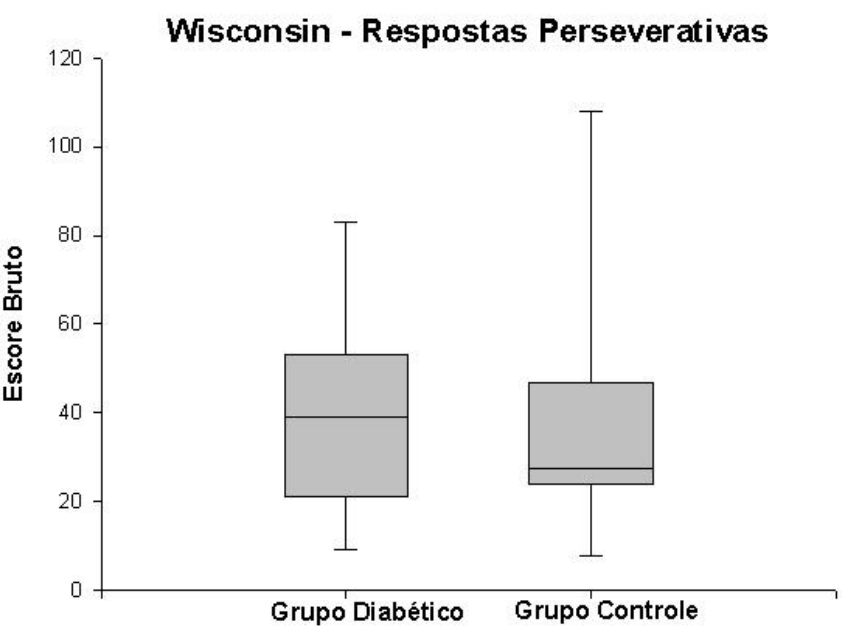

Figura 70. Mediana, $1^{\circ}$ e $3^{\circ}$ quartis, percentil 5 e 95 dos escores brutos obtidos pelo grupo de pacientes diabéticos do tipo 2 e o grupo controle no teste de Wisconsin para o total de respostas perseverativas. 
Wisconsin - Erros Perseverativos

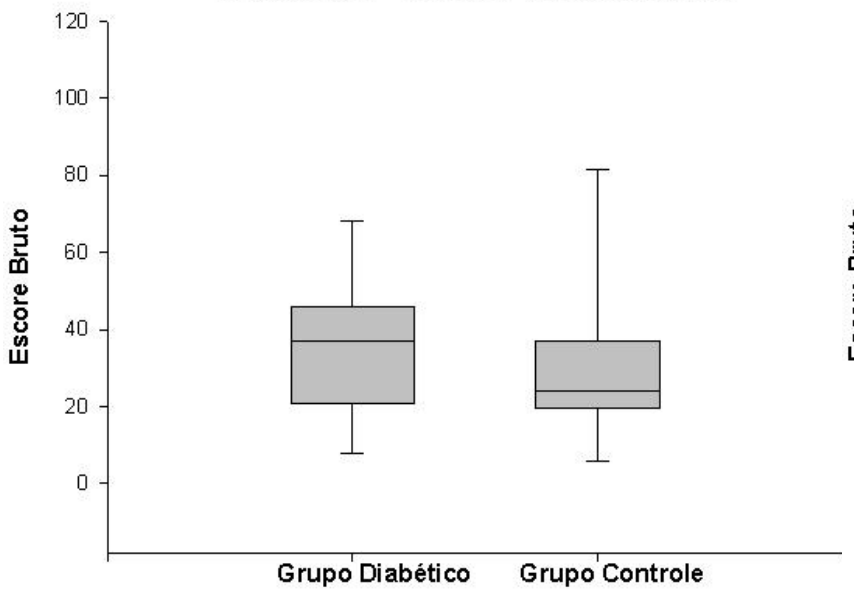

Figura 71. Mediana, $1^{\circ}$ e $3^{\circ}$ quartis, percentil 5 e 95 dos escores brutos obtidos pelo grupo de pacientes diabéticos do tipo 2 e o grupo controle no teste de Wisconsin para erros perseverativos.

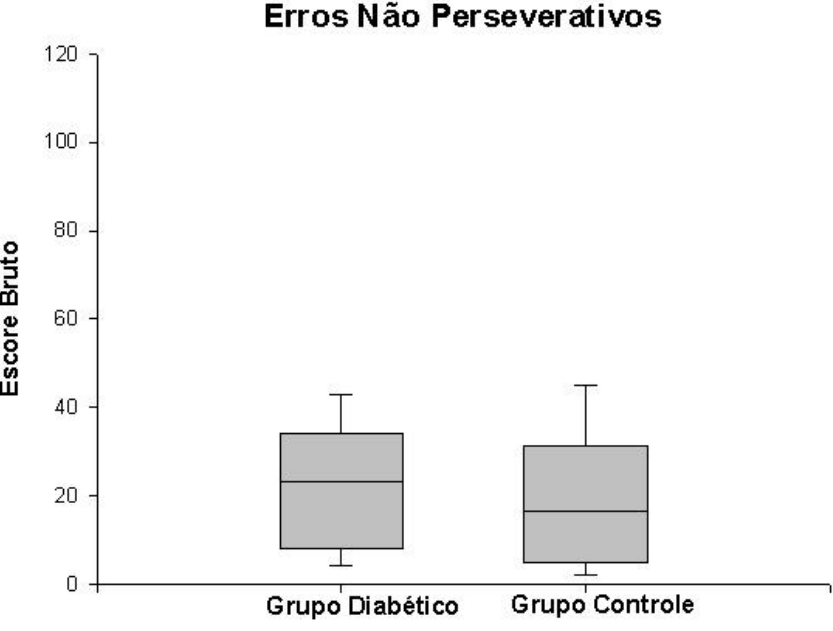

Figura 72. Mediana, $1^{\circ}$ e $3^{\circ}$ quartis, percentil 5 e 95 dos escores brutos obtidos pelo grupo de pacientes diabéticos do tipo 2 e o grupo controle no teste de Wisconsin para erros não perseverativos.

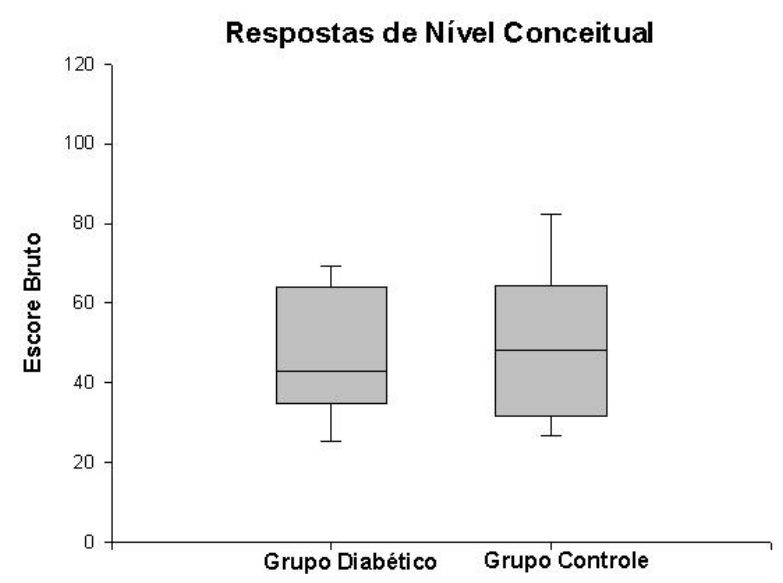

Figura 73. Mediana, $1^{\circ}$ e $3^{\circ}$ quartis, percentil 5 e 95 dos escores brutos obtidos pelo grupo de pacientes diabéticos do tipo 2 e o grupo controle no teste de Wisconsin para o $n^{\circ}$ de respostas de nível conceitual.

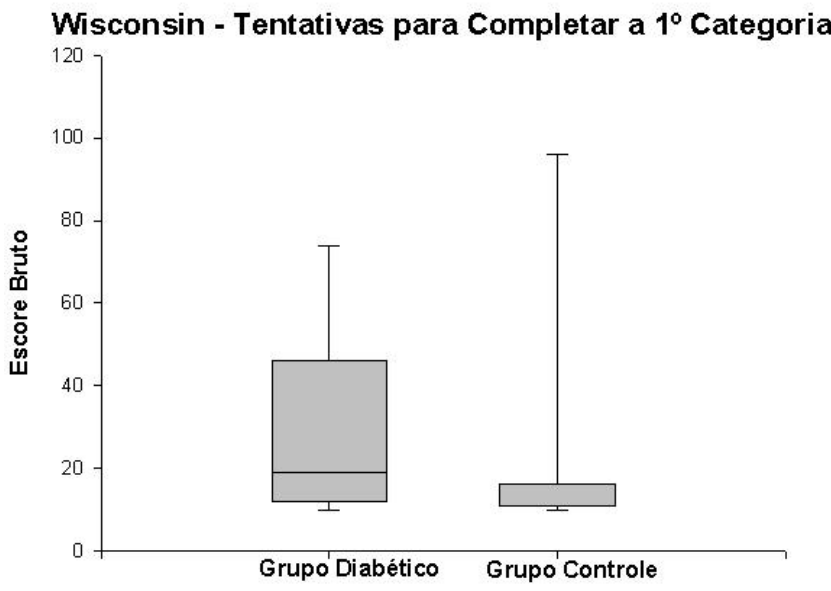

Figura 75. Mediana, $1^{\circ}$ e $3^{\circ}$ quartis, percentil 5 e 95 dos escores brutos obtidos pelo grupo de pacientes diabéticos do tipo 2 e o grupo controle no teste de Wisconsin para o $n^{\circ}$ de tentativas para completar a $1^{\circ}$ categoria.

\section{Wisconsin - Categorias Completas}

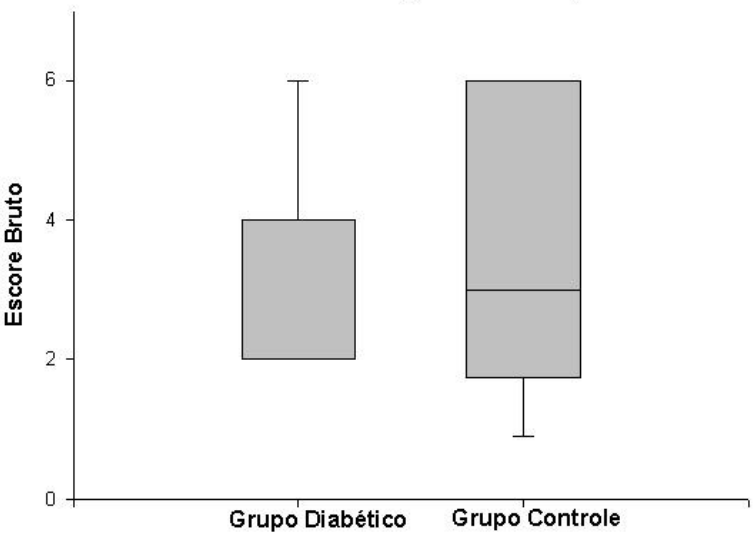

Figura 74. Mediana, $1^{\circ}$ e $3^{\circ}$ quartis, percentil 5 e 95 dos escores brutos obtidos pelo grupo de pacientes diabéticos do tipo 2 e o grupo controle no teste de Wisconsin para o $\mathrm{n}^{\circ}$ de categorias completas.

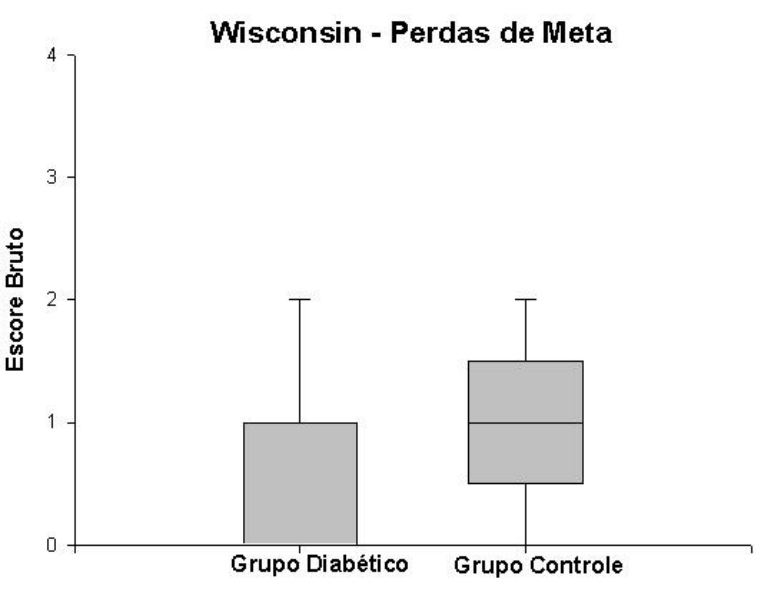

Figura 76. Mediana, $1^{\circ}$ e $3^{\circ}$ quartis, percentil 5 e 95 dos escores brutos obtidos pelo grupo de pacientes diabéticos do tipo 2 e o grupo controle no teste de Wisconsin para o $n^{\circ}$ de tentativas para perdas de meta. 


\subsection{Conhecimento Semântico}

Não houve diferença significante entre os grupos no teste de Vocabulário $(p=0,197)$ (figura 77). Houve correlação indicativa de maiores escores brutos seguindo maior "escolaridade", tanto no grupo de pacientes diabéticos ( $r S=0,653$; $p=0,004)$, quanto controle ( $r S=0,633 ; p=0,011)$, como mostra a tabela 18 .

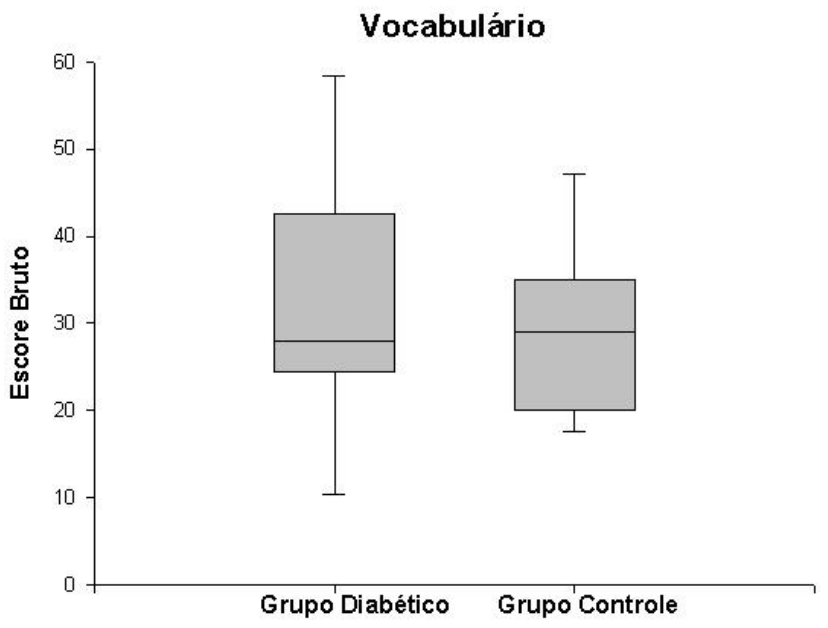

Figura 77. Mediana, $1^{\circ}$ e $3^{\circ}$ quartis, percentil 5 e 95 dos escores brutos obtidos pelo grupo de pacientes diabéticos do tipo 2 e o grupo controle em Vocabulário.

\subsection{Depressão}

Os escores do BDI não demonstram diferença estatística entre diabéticos e controles $(p=0,197)$ (figura 78). Escores altos de depressão associaram-se significantemente ao desempenho prejudicado em Stroop parte 1 ( $r S=0,527$; $p=0,024)$ entre os pacientes diabéticos e no grupo controle para os resultados do Stroop parte 2 ( $r S=0,454 ; p=0,049)$, armazenamento de longo prazo referente ao SRT ( $r S=-0,470 ; p=0,041)$ e no teste de fluência verbal para todos os itens examinados: palavras iniciadas com as letras " $F$ " ( $r S=-0,614 ; p=0,006)$, "A" ( $r S=-$ $0,765 ; p=0)$ e "S" ( $r S=-0,479 ; p=0,043)$, além do escore total $(r S=-0,658 ; p=0,002)$. 


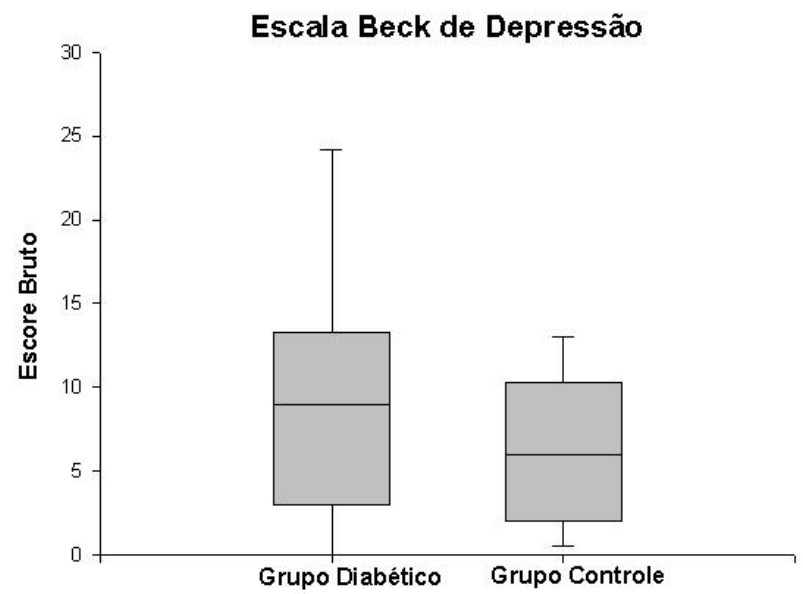

Figura 78. Mediana, $1^{\circ}$ e $3^{\circ}$ quartis, percentil 5 e 95 dos escores brutos obtidos pelo grupo de pacientes diabéticos do tipo 2 e o grupo controle no BDI.

\subsection{Ansiedade}

Os escores do IDATE do grupo de pacientes diabéticos também se mostraram inalterados tanto para estado $(p=0,514)$ (figura 79$)$ quanto para traço $(p=0,357)$ (figura 80$)$ de ansiedade. No grupo controle, escores altos para "estado" de ansiedade teve correlação compatível com maior tempo para execução da tarefa com a mão dominante no Grooved Pegboard ( $r S=0,477 ; p=0,038)$, conforme apresentado na tabela 18.

IDATE - Estado

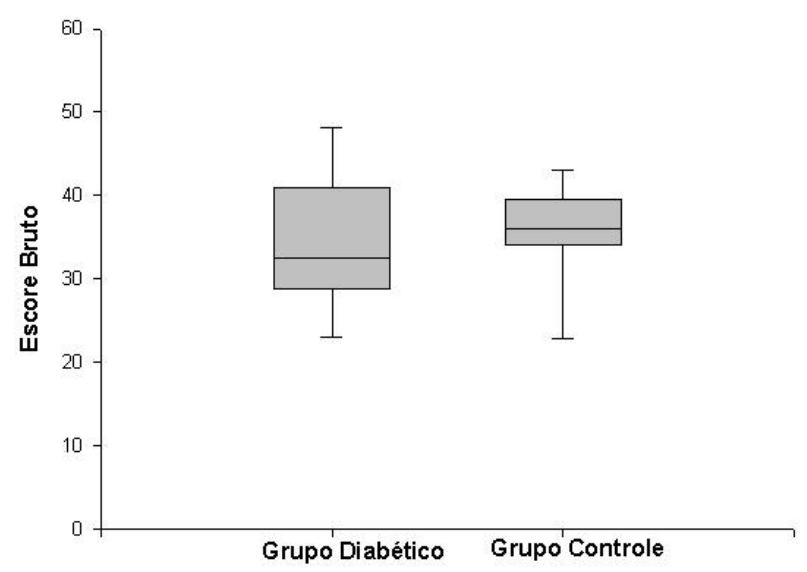

Figura 79. Mediana, $1^{\circ}$ e $3^{\circ}$ quartis, percentil 5 e 95 dos escores brutos obtidos pelo grupo de pacientes diabéticos do tipo 2 e o grupo controle no IDATE para estado de ansiedade.
IDATE - Traço

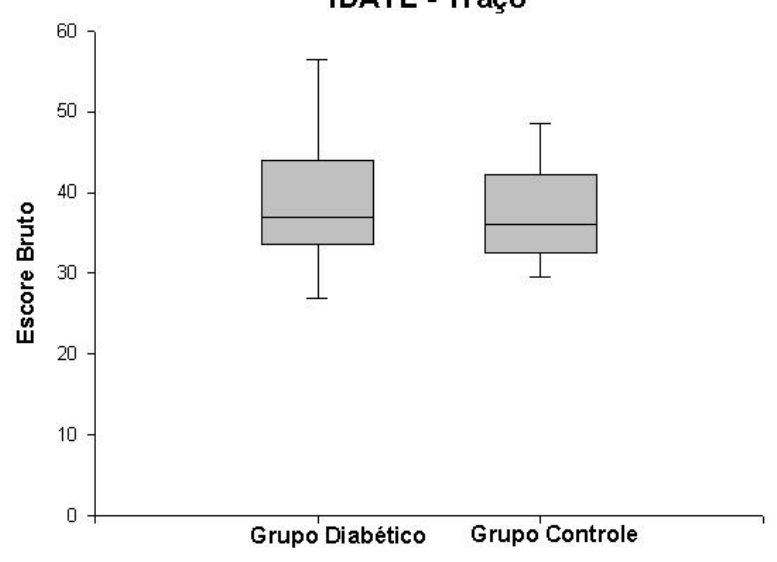

Figura 80. Mediana, $1^{\circ}$ e $3^{\circ}$ quartis, percentil 5 e 95 dos escores brutos obtidos pelo grupo de pacientes diabéticos do tipo 2 e o grupo controle no IDATE para traço de ansiedade. 
Segundo a tabela 18, a análise de correlação também mostrou associação significativa entre maior duração da doença e maior porcentagem de hemoglobina glicada $(r S=0,569 ; p=0,032)$.

\subsection{Hipertensão}

Para exame da hipótese de que participantes hipertensos possam apresentar desempenho inferior nos testes ou maior índice de depressão e ansiedade nos inventários, os pacientes diabéticos foram divididos em dois subgrupos, com e sem diagnóstico de hipertensão. Utilizou-se o teste $t$ de Student para amostras independentes na comparação dos dados paramétricos (idade, duração do diabetes, concentração sangüínea de glicose, hemoglobina glicada e os escores totais nos inventários de depressão e ansiedade) e o teste de MannWhitney para análise dos dados não paramétricos (escolaridade e os escores nos testes neuropsicológicos), considerando-se $p<0,05$ como nível de significância em ambos os casos. A tabela 19 mostra os dados gerais dos subgrupos, as médias, medianas e desvios padrões referentes aos resultados obtidos nos testes e inventários e o valor de $p$ correspondente. Conforme os valores da tabela 19, nenhuma significância $(p<0,05)$ foi observada.

Tabela 19

Comparação dos dados gerais e escores obtidos nos testes e inventários de pacientes diabéticos com e sem diagnóstico de hipertensão

\begin{tabular}{|c|c|c|c|c|c|}
\hline \multirow[b]{3}{*}{ Variáveis } & \multicolumn{4}{|c|}{ Hipertensão } & \multirow[b]{3}{*}{$\boldsymbol{P}$} \\
\hline & \multicolumn{2}{|c|}{$\operatorname{Sim}(N=9)$} & \multicolumn{2}{|c|}{ Não (N=10) } & \\
\hline & Md & $M \pm D P$ & Md & $M \pm D P$ & \\
\hline Idade & 54 & $52,8 \pm 8,6$ & 48,5 & $48,8 \pm 10,6$ & 0,438 \\
\hline Escolaridade & 11 & $8,5 \pm 4,3$ & 8 & $9 \pm 4,7$ & 0,935 \\
\hline Duração da Doença & 8 & $9,7 \pm 8,9$ & 5 & $6,9 \pm 7,5$ & 0,087 \\
\hline Glicemia & 148 & $155,8 \pm 32,1$ & 138 & $136,1 \pm 29,3$ & 0,368 \\
\hline $\mathrm{HbA}_{1 \mathrm{C}}$ & 7 & $6,8 \pm 0,7$ & 6,9 & $7,1 \pm 1,9$ & 0,397 \\
\hline Escores brutos nos Testes Neuropsicológicos & - & - & - & - & n.s. ${ }^{*}$ \\
\hline $\begin{array}{l}\text { Escores totais nos Inventários de depressão e } \\
\text { ansiedade }\end{array}$ & - & - & - & - & n.s.* \\
\hline
\end{tabular}

*não significante 


\subsection{Depressão e Ansiedade}

A literatura mostra que a depressão corresponde a uma comorbidade em pacientes diabéticos e atinge $20 \%$ dos indivíduos afetados. Para a verificação de possíveis alterações neuropsicológicas associadas à depressão, a amostra foi subdividida quanto aos resultados obtidos no inventário de depressão (BDI), adotando-se o escore total 20 como ponto de corte indicativo de depressão, conforme recomendado por estudo prévio (Gorenstein et al., 1999). Os 2 subgrupos gerados foram comparados quanto aos dados gerais (idade, escolaridade, duração do diabetes, glicemia, hemoglobina glicada) e dados brutos obtidos nos testes neuropsicológicos e inventários de humor. Segundo a tabela 20, 3 pacientes diabéticos atingiram o ponto de corte estabelecido. Os subgrupos tiveram diferença significante $(p<0,001)$ quanto aos escores de depressão, conforme esperado. Entretanto, o mesmo não foi observado para quaisquer variáveis referentes aos dados gerais, resultados de testes neuropsicológicos ou para o inventário de ansiedade.

\section{Tabela 20}

Comparação dos dados gerais e escores obtidos nos testes e inventários de pacientes diabéticos com e sem níveis indicativos de depressão.

\begin{tabular}{|c|c|c|c|c|c|}
\hline \multirow[b]{3}{*}{ Variáveis } & \multirow{2}{*}{\multicolumn{2}{|c|}{$\begin{array}{l}\text { Escore Total de } \\
\text { Depressão } \\
\geq 20 \quad(\mathrm{~N}=3)\end{array}$}} & \multirow{2}{*}{\multicolumn{2}{|c|}{$<20(\mathrm{~N}=16)$}} & \multirow[b]{3}{*}{$P$} \\
\hline & & & & & \\
\hline & Md & $\mathrm{M} \pm \mathrm{DP}$ & Md & $\mathrm{M} \pm \mathrm{DP}$ & \\
\hline Idade & 41 & $41,3 \pm 5,5$ & 53,5 & $52,4 \pm 9,3$ & 0,065 \\
\hline Escolaridade & 11 & $10 \pm 1,7$ & 8 & $8,6 \pm 4,7$ & 0,618 \\
\hline Duração da Doença & 1 & $2,7 \pm 2,9$ & 7,5 & $9,2 \pm 8,4$ & 0,093 \\
\hline Glicemia & 178,5 & $178,5 \pm 13,4$ & 142,5 & $142,7 \pm 31$ & 0,138 \\
\hline $\mathrm{HbA}^{1} \mathrm{C}$ & 6,9 & $7,8 \pm 2,5$ & 6,9 & $6,7 \pm 0,7$ & 0,791 \\
\hline Testes Neuropsicológicos & - & - & - & - & n.s. ${ }^{*}$ \\
\hline \multicolumn{6}{|l|}{ Inventários } \\
\hline BDI & 4 & $3,8 \pm 1,4$ & 24 & $23,3 \pm 3$ & $<0,001$ \\
\hline IDATE & - & - & - & - & n.s. ${ }^{*}$ \\
\hline
\end{tabular}


A ansiedade também corresponde a uma alteração de humor e, conforme mencionado anteriormente, pode relacionar-se aos prejuízos neuropsicológicos. Entretanto, nos inventários de estado e traço de ansiedade (IDATE), apenas um paciente diabético atingiu resultados superiores ao ponto de corte (escore total = 49) estabelecido na literatura prévia como indicador de ansiedade patológica (Gorenstein et al., 1995), tornando desnecessária e inviável a análise dos pacientes diabéticos conforme este tipo de alteração de humor. 


\subsection{Discussão}

Os resultados da avaliação dos pacientes diabéticos do tipo 2 não mostraram alterações neuropsicológicas detectáveis pelos testes e inventários aplicados, o que concorda com achados prévios da literatura na medida em que há a possibilidade de que os déficits descritos nesses pacientes estejam associados a outros fatores como as complicações clínicas do diabetes, controle metabólico ruim e/ou idade avançada.

Zaslavsky et al (1994) encontraram déficit de memória visual em uma amostra de pacientes diabéticos do tipo 2 com diagnóstico de neuropatia do SNA que incluiu indivíduos com retinopatia e macroangiopatia, em comparação com um grupo de indivíduos diabéticos sem neuropatia autonômica e um grupo controle não diabético.

Alteração neuropsicológica caracterizada por lentificação psicomotora foi observada em um grupo de pacientes diabéticos do tipo 2 com 10,2\%, de porcentagem média de hemoglobina glicada, além das freqüências de $16 \%$ de indivíduos com retinopatia e 28\% com neuropatia periférica (Ryan \& Geckle, 2000).

Déficits de atenção, memória e habilidade de repetição foram encontrados em pacientes diabéticos do tipo 2 , menores de 55 anos, provavelmente num estágio muito mais avançado que o do presente estudo, pois a maior parte daqueles pacientes (61\%) tinha diagnóstico de polineuropatia (Dey et al. (1997).

O diabetes tipo 2 provoca efeitos mais sutis do que o tipo 1 e fatores relacionados como doença vascular e hipertensão (Cosway et al., 2001), neuropatia do sistema nervoso autônomo (Zaslavsky et al., 1995) parecem contribuir para os déficits nas funções neuropsicológicas destes pacientes.

Vanhanen et al. (1999) sugerem que a DM Tipo 2 por si não se associa a alterações de memória. Em estudos com diabéticos dependentes de insulina, a 
complicação caracterizada por hipoglicemia associou-se a danos no hipocampo e gânglios da base, estruturas fundamentais na aquisição da memória. Além disso, a hipoglicemia altera o fluxo sangüíneo cerebral frontal, provocando uma redução na eficiência mental (Chalmers et al., 1991).

Vários estudos mostram déficits neuropsicológicos em pacientes diabéticos idosos, o que pode relacionar-se ao maior tempo de desenvolvimento da doença. Estudos descreveram déficits de orientação, memória verbal imediata, atenção e fluência verbal (Grodstein et al., 2001); déficits cognitivos leves em memória verbal e flexibilidade mental (Asimakopoulou, Hampson \& Morrish, 2002); memória verbal de longo prazo (Worral, Moulton \& Briffett, 1993) e estado mental geral (Kalmijn et al., 1995), embora Scott et al. (1998) não tenham demonstrado diferenças significantes entre as funções cognitivas de pacientes diabéticos idosos e controles.

Os pacientes do presente estudo mostraram semelhanças com os resultados obtidos por Cosway et al. (2001), que examinaram indivíduos de 40 a 75 anos de idade, com diagnóstico de diabetes tipo 2 há pelo menos 2 anos, sem doença cérebro vascular, hipertensão, embora tenha incluído 2 pacientes com retinopatia diabética e 10 que utilizam insulina como tratamento, dos quais 6 têm histórico de episódio hipoglicêmico. Os autores não encontraram alterações na habilidade mental pré-mórbida estimada, raciocínio abstrato, memória, tempo de reação e processamento de informação visual.

Estudos de revisão mostram inconsistência entre as conclusões sobre existência ou não de alterações neuropsicológicas nos pacientes estudados. Esta discrepância pode ser atribuída a muitos fatores como a participação de populações muito diferentes, além do uso de diferentes baterias de testes e a ausência do controle de variáveis. Muitos testes medem mais de um aspecto da habilidade cognitiva; como conseqüência os resultados de testes diferentes que propõem o 
exame de determinada função podem não ser diretamente comparáveis (Strachan et al., 1997).

Em resumo, as diferenças entre os achados de estudos podem relacionar-se às características heterogêneas e variáveis não controladas dos pacientes diabéticos examinados. Além disso, as diferentes sensibilidades dos testes aplicados podem provocar os resultados conflitantes (Stewart \& Liolitsa, 1999).

Embora hipertensão associada a diabetes pareça relacionar-se ao maior risco de disfunções cognitivas (Elias et al., 1997), a amostra do presente estudo não revelou alterações apesar de incluir 9 (47\%) indivíduos hipertensos. A este respeito, deve-se considerar o tamanho pequeno da amostra (19 pacientes), o que pode mascarar efeitos que seriam manifestados no exame de mais pacientes com as mesmas características. Lowe et al. (1994) descreveram rebaixamento nos testes de fluência verbal e formação de conceitos verbais em uma amostra de indivíduos diabéticos dos quais $63,8 \%$ têm diagnóstico de hipertensão.

Além disso, deve-se considerar as características dos nossos pacientes, que incluíram a ausência de retinopatia diabética e de queixas correspondentes a outras formas de neuropatia diabética, idade dos mesmos, e ainda o fato de não utilizarem insulina como tratamento. Deve ser ressaltado o fato de que os pacientes aqui estudados apresentam bom controle metabólico representado pelos valores de porcentagem de hemoglobina glicada e concentração de glicose capilar situados dentro dos limites aceitáveis para pacientes diabéticos, além de exame de microalbuminíria dentro da normalidade, indicando preservação das funções renais.

Em um estudo de revisão sistemática, a prevalência dos sintomas de depressão em pacientes diabéticos relacionaram-se com pior controle glicêmico, gravidade de complicações clínicas, piora da qualidade de vida e comprometimento dos aspectos sociais, econômicos associados ao diabetes (Moreira et al., 2003). 
Nos testes de correlação, escores aumentados de depressão se relacionaram com redução da velocidade de processamento de informações em ambos os grupos e menor armazenamento de informação verbal e fluência entre os controles, indicando perfil compatível com a sintomatologia depressiva (Antikainenn et al., 2001; Fossati et al., 2002). O grupo controle também mostrou associação entre maiores escores totais para estado de ansiedade e destreza manual, confirmando característica apresentada na literatura prévia (Browndyke et al., 2002).

O aumento da porcentagem de hemoglobina glicada mostrou-se diretamente proporcional à fluência verbal reduzida. Este resultado concorda com o estudo de Ryan \& Geckle (2000), que mostraram a associação entre o controle metabólico $\left(\mathrm{HbA}_{1 \mathrm{c}}\right)$ e lentificação psicomotora, que produz influência sobre a capacidade de fluência verbal.

A maior duração da doença mostrou associação com desempenhos prejudicados nos testes de memória visual, fluência verbal, destreza manual, função viso-motora. Estudos prévios encontraram correlação entre a duração do diabetes e declínio em aprendizagem e memória (Cosway et al., 2001) e na habilidade de formação de conceitos, memória lógica e visual (Elias et al., 1997). Entretanto, deve-se considerar que o diagnóstico do diabetes não reflete o início da doença, pois esta pode manifestar-se sem sintomas.

Também nos testes de correlação, o aumento da variável idade associou-se ao pior desempenho no controle inibitório, fluência verbal e função viso espacial entre os controles. Quanto à escolaridade, houve correlação de maior velocidade psicomotora e melhor desempenho em fluência verbal e conhecimento semântico no grupo diabético e maior controle mental, recuperação de informação verbal e memória semântica no grupo controle. São resultados esperados conforme as tabelas de padronização de testes (Spreen \& Strauss, 1998). 
No caso da diabetes tipo 2, são conhecidas as alterações nervosas centrais em pacientes idosos (Asimakopoulou, Hampson \& Morrish, 2002; Grodstein et al., 2001; Kalmijn et al., 1995; Worral, Moulton \& Briffett, 1993) o que pressupõe que a associação entre essas alterações e a duração da doença.

Curiosamente, houve correlação positiva entre a concentração sangüínea de glicose e os escores de memória visual (Reprodução Visual Tardia) no grupo diabético e memória verbal no grupo controle. A este respeito pode haver o efeito descrito por Mooradian (1988a), segundo o qual a curva de desempenho em memória e aprendizagem em função da glicemia aguda se comporta como uma curva em "U" crescente, com declínio a partir de $300 \mathrm{mg} / \mathrm{dL}$. Entretanto, a associação foi de pior habilidade de abstração conforme maior a concentração glicêmica capilar entre os controles, indicando susceptibilidade das funções frontais.

Para Dey et al. (1997), a disfunção neuropsicológica em diabéticos é uma complicação relacionada à duração da doença, mesmo em indivíduos relativamente jovens. Entretanto, a duração da doença com base no diagnóstico é um dado impreciso, pois a diabetes pode manifestar-se durante anos sem sinais percebidos pelo paciente.

Devido às alterações metabólicas, neuroquímicas e da barreira hematoencefálica, e a possível lentificação na velocidade de condução nervosa no SNC, seria de se esperar que existissem problemas neuropsicológicos e neurofisiológicos em pacientes diabéticos. Embora a maioria das alterações do SNC na diabetes sejam secundárias a acidentes vasculares e alterações agudas do nível de glicose no plasma, alterações específicas nas funções dos neurotransmissores e no transporte pela barreira hemato-encefálica podem contribuir para a disfunção cognitiva (Mooradian, 1988a).

Quanto às limitações do estudo, o número reduzido de participantes pode mascarar possíveis alterações. Além disso, as amostras incluíram indivíduos 
tabagistas, que, caso tenham fumado antes da avaliação, podem ter apresentado efeitos agudos de potencialização de funções (McKim, 2000). Também vale ressaltar que os nossos pacientes apresentaram alteração visual sensorial precoce (Gualtieri, 2004), apesar do exame de fundo de olho não ter detectado retinopatia. De forma análoga, podem haver disfunções neuropsicológicas precoces verificáveis por testes mais sensíveis.

A questão que se coloca para pesquisas posteriores é a verificação do momento ou estágio da doença em que surgem as alterações neuropsicológicas, e para tanto é necessário o controle das diferentes complicações que acompanham a progressão do diabetes. São recomendados estudo de indivíduos diabéticos do tipo 2 com maior controle de variáveis relacionadas às complicações do diabetes e abordagem longitudinal, para a verificação da instalação de possíveis alterações neuropsicológicas.

\subsection{Conclusões}

Não foram encontradas disfunções neuropsicológicas ou sintomas de depressão e ansiedade em pacientes diabéticos do tipo 2 sem diagnóstico de retinopatia diabética e com bom controle metabólico. Complicações clínicas como retinopatia, neuropatia, e episódios de hipoglicemia constituem fatores de risco para o desenvolvimento de disfunções neuropsicológicas e alterações de humor em pacientes diabéticos. A concentração glicêmica aguda se mostrou compatível com potencialização da memória e da aprendizagem, porém redução da capacidade de abstração. Maior duração da doença ou porcentagem de hemoglobina glicada são fatores associados ao pior desempenho neuropsicológico. 


\section{REFERÊNCIAS BIBLIOGRÁFICAS}

Affolter, V., Boujon, P., Bestetti, G., \& Rosi, G.L. (1986). Hypothalamic and cortical neurons of normotensive and spontaneously hypertensive rats are differently affected by streptozotocin diabetes. Acta Neuropathologic, 70, 13-.

Agency for Toxic Substance and Disease Registry. (1992). Mercury toxicity. Environmental Medicine, 46(6), 1731-1741.

Albers, J.W., Kallenbach, L.R., Fine, L.J., Langolf, G.D., Wolfe, R.A., Donofrio, P.D., et al. (1988). Neurological abnormalities associated with remote occupational elemental mercury exposure. Annals of Neurology, 24(5), 651-659.

Antikainen, R., Hänninen, T., Honkalampi, K., Hintikka, J., Koivumaa-Honkanen, H., Tanskanen, A. et al., (2001). Mood improvement reduces memory complaints in depressed patients. European Archives of Psychiatry and Clinical Neuroscience, 251: 6-11.

Asimakopoulou K.G., Hampson S.E., \& Morrish N.L. (2002). Neuropsychological functioning in older people with Type 2 diabetes: the effect of controlling for confounding factors. Diabetic Medicine, 19, 311-316.

Austin, E., \& Deary, .I.J. (1999). Effects of repeated hypoglycemia on cognitive function. Diabetes Care, 22(8), 1273-1277.

Azevedo, F.A. (2003). Toxicologia do mercúrio. São Paulo: InterTox.

Bennett, D.A. (2000). Diabetes and change in cognitive function. American Medical Association Editorial, 160(2), 141-143.

Biaggio, A.M.B., \& Natalício, L. (1979). Manual do Inventário de Ansiedade Traço. Rio de Janeiro: CEPA.

Bittner, A.C., Echeverria, D., Woods, J.S., Aposhian, H.V., Naleway, C., Martin, M.D., et al. (1998). Behavioral effects of low-level exposure to $\mathrm{Hg}^{0}$ among dental professionals: A cross-study evaluation of psychomotor effects. Neurotoxicology and Teratology, 20(4), 429-439.

Boelter, M.C., Azevedo, M.J., Gross, J.L., Lavinsky, J. (2003). Risk factors for diabetic retinopathy. Arquivos Brasileiros de Oftalmologia, 66, 239-247.

Brown, I.A. (1954). Chronic mercurialism: a cause of the clinical syndrome of amyotrofic lateral sclerosis. Archives of Neurology and Psychiatry, 72, 674-681.

Browndyke, J.N., Albert, A.L., Malone, W., Schatz, P., Paul, R.H., Cohen, R.A., et al. (2002). Computer-related anxiety: examining the impact of technology-specific affect on the performance of a computerized neuropsychological assessment measure. Applied Neuropsychology, 9(4), 210-218.

Bruce, D.G., Harrington, N., Davis, W.A., \& Davis, T.M.E. (2001). Dementia and its associations in type 2 diabetes mellitus: The fremantle diabetes study. Diabetes Research and Clinical Practice, 53, 165-172.

Buckelew SP \& Hannay HJ. (1986). Relationships among anxiety, defensiveness, sex, task difficulty, and performance on various neuropsychological tasks. Percept Mot Skills, 63, 711-718.

Chalmers, J., Risk, M., Kean, D., Grant, R., Ashworth, B., \& Campbell, I. (1991). Severe amnesia after hypoglycemia. Diabetes Care, 14, 922-925.

Coker, L.H., \& Shumaker, S.A. (2003). Type 2 diabetes mellitus and cognition: An understudied issue in women's health. Journal of Psychosomatic Research, 54, 129-139.

Corrêa, Z.M.S., Freitas, A.M., \& Marcon, I.M., (2003). Risk factors related to the severity of diabetic retinopathy. Arquivos Brasileiros de Oftalmologia, 66, 739-743.

Cosway R., Strachan, M.W., Dougall, A., Frier, B.M., Deary, I.J. (2001). Cognitive function and information processing in type 2 diabetes. Diabetic Medicine, 18(10), 803-810.

Cunha, JA. (2001). Manual da versão em português das Escalas Beck. São Paulo: Casa do Psicólogo. 
Cunha, J.A., Freitas, N.K., \& Raymundo, M.G.B (1993). Psicodiagnóstico-R. Porto Alegre: Artes Médicas.

De Groot M, Anderson R, Freedland KE, Clouse RE, Lustman PJ. (2001). Association of depression and diabetes complications: a meta-analysis. Psychosomatic medicine, 63(4), 619-30.

Dey, J., Misra, A., Desai, N.G., Mahapatra, A.K., \& Padma, M. (1997). Cognitive function in younger type II diabetes. Diabetes Care, 20(1), 32-35.

Drasch, G., Bose-O'Reilly, S., Beinhoff, C., Roider, G., \& Maydl S. (2000). The Mt Diwata study on the Phillippines 1999: Assessing mercury intoxication of the population by small scale gold mining. The Science of the Total Environment, 21(1-3), 151-158.

Echeverria, D., Aposhian, H.V., Woods, J.S., Heyer, N.J., Aposhian, M.M., Bittner, A.C. et al. (1998). Neurobehavioral effects from exposure to dental amalgam $\mathrm{Hg}^{0}$ : New distinctions between recent exposure and $\mathrm{Hg}$ body burden. FASEB JOURNAL, 12, 971-980.

Echeverria, D., Heyer, N.J., Martin, M.D., Naleway, C.A., Woods, J.S., Aposhian, H.V., et al. (1995). Behavioral effects of low-level exposure to $\mathrm{Hg}^{0}$ among dentists. Neutotoxicology and Teratology, 17(2), 161-168.

Elias, P.K., Elias, F.M., D’Agostinho, R.B., Cupples, L.A., Wilson, P.W., Silbershatz, H., et al. (1997). NIDDM and blood pressure as risk factors for poor cognitive performance: The Framingham study. Diabetes Care, 20(9), 1388-1395.

Ellingsen, D.G., Bast-Pettersen, R., Efskind, J., \& Thomassen, Y. (2001). Neuropsychological effects of low mercury vapor exposure in chloralkali workers. Neurotoxicology, 22(2), 249258.

Faria, M.A.M. (2003). Mercurialismo metálico crônico ocupacional. Revista de Saúde Pública, 37(1), 116-127.

Feinberg, T.E. \& Farah, M.L. (1997). Behavioral Neurology and Neuropsychology. New York: McGraw-Hill.

Foo, S.C., Ngim, C.H., Salleh, I., Jeyaratnam, J., \& Boey, K.W. (1993). Neurobehavioral effects in occupational chemical exposure. Environmental Research, 60, 267-273.

Fossati, P., Coyette, F., Ergis, A-M., \& Allilaire, J-F. (2002). Influence of age and executive functioning on verbal memory of inpatients with depression. Journal of Affective Disorders, 68, 261-271.

Franco, L.J., Mameri, C., Pagliaro, H., lochida, L.C., Goldenberg, P. (1992). Diabetes como causa básica ou associada de morte no Estado de São Paulo, Brazil. Revista de. Saúde Pública, 32(3), 237-245.

Frumkin, H., Letz, R., Williams, P.L., Gerr, F., Pierce, M., Sanders, A., et al. (2001). Health effects of long-term mercury exposure among chloralkali plant workers. American Journal of Industrial Medicine, 39, 1-18.

Gil, R. (2002). Neuropsicologia hoje ( $2^{\mathrm{a}}$ ed). São Paulo: Santos.

Gorenstein, C., \& Andrade, L. (2000). Inventário de Depressão de Beck: Propriedades psicométricas da versão em português. In C. Gorenstein, L. Andrade \& A. Zuardi (Orgs.), Escalas de Avaliação Clínica em Psiquiatria e Psicofarmacologia (pp. 89-95). São Paulo: Lemos-Editorial.

Gorenstein, C., Pompéia, S., \& Andrade, L. (1995). Scores of brazilian university students on the Beck Depression Inventory and the State-Trait Inventories. Psychological Reports, 77, 635-641.

Gorenstein, C., Andrade, L., Vieira Filho, A.H.G., Tung, T.C., \& Artes, R. (1999). Psychometric properties of the portuguese version of the Beck Depression Inventory on brazilian college students. Journal of Clinical Psychology, 55, 553-562.

Gouveia, P.A., \& Fabrício, A., M. (2004). Avaliação neuropsicológica em traumatismo cranioencefálico. In V. Andrade, F.H. dos Santos, O.F.A. Bueno (Orgs.), Neuropsicologia Hoje. (pp. 304). São Paulo: Artes Médicas.

Grant, M.M., Thase, M.E., \& Sweeney, J.A. (2001). Cognitive disturbance in outpatient depressed younger adults: evidence of modest impairment. Biological Psychiatry, 50, 3543. 
Grodstein, F., Chen, J., Wilson, R.S., Manson, J.E. \& Nurses' Health Study. (2001). Type 2 diabetes and cognitive function in community-dwelling elderly women. Diabetes Care, 24(6), 1060-1065

Grunnet, M.L. (1963). Cerebrovascular disease: diabetes and cerebral athorosclerosis. Neurology, 13, 486.

Gualtieri, M. (2004). Visão de cores e sensibilidade ao contraste em indivíduos com diabete melito: avaliação psicofísica e eletrofisiológica. São Paulo.

Hassan, A., Velazquez, E., Belmar, R., Coye, M., Drucker, E., Landrigan, P.J., et al. (1981). Mercury poisoning in Nicaragua: A case study of the export of environmental and occupational health hazards by a multinational corporation. International Journal of Health Services, 11(2), 221-227.

Heaton, R.K., Chelune, G.J., Talley, J.L., Kay, G.G., \& Curtis, G. (1993). Wisconsin Card Sorting Test: Manual revised and expanded. Odessa: Psychological Assessment Resources.

Heller, S.R., \& Macdonald, I.A. (1996). The measurement of cognitive function during acute hypoglycaemia: Experimental limitations and their effect on the study of hypoglycaemia unawareness. Diabetic Medicine, 13, 607-615.

Hua, M.S., Huang, C.C., \& Yang, Y.J. (1995). Chronic elemental mercury intoxication: Neuropsychological follow-up case study. Brain Injury, 10, 377-384.

Huntley, A. (1995). Diabetes Mellitus: Review. Dermatology Online Journal, 1(2). Recuperado em 18 out. 2004: http://dermatology.cdlib.org/.

Jandel Corporation. (1992). Jandel Sigma-Stat Software 2.0 [CD-ROM]. California: Jandel Corporation.

Kalmijn, S., Feskens, E.J.M., Launer, L.J., Stijnen, T., \& Kromhout D. (1994). Glucose intolerance, hyperinsulinaemia and cognitive function in an general population of elderly men. Diabetologia, 38, 1096-1102.

Kishi, R., Doi, R., Fukuchi, Y., Satoh, H., Satoh. T., Ono, A., et al. (1994). Residual neurobehavioral effects associated with chronic exposure to mercury vapour. Occupational and Environmental Medicine, 51, 35-41.

Lafayette Instrument Corporation USA. [1979]. Grooved Pegboard Instruction: Owner's Manual. [S.I.], IN: Lafayette Instruments.

Langolf, G.D., Chafffin, D.B., Henderson, R., \& Whittle, H.P. (1978). Evaluation of workers exposed to elemental mercury using quantitative tests of tremor and neuromuscular functions. American Industrial Hygiene Association Journal, 39, 976-984.

Langolf, G.D., Smith, P.J., Henderson, R., \& Whittle, H. (1981). Measurements of neurological functions in the evaluations of exposure to neurotoxic agents. Annals of occupational hygiene, 24(3), 293-296.

Langworth, S., Almkvist, O., Söderman, E., \& Wikström, B.O. (1992). Effects of occupational exposure to mercury vapour on the central nervous system. British journal of industrial medicine, 49, 545-55.

Lezak, M.D. (1995). Neuropsychological assessment ( $2^{\text {rd }}$ ed). New York: Oxford, 1995.

Liang, Y., Sunn, R., Chen, Z., \& Li, L. (1993). Psychological effects of low exposure to mercury vapor: Application of a computer-administered neurobehavioral evaluation system. Environmental Research, 60, 320-327.

Lindeman, R.D., Romaro, L.J., LaRue, A., Yau, C.L., Schadi, D.S., Baumgartner, R.N., et al. (2001). A biethnic community survey of cognition in participants with type 2 diabetes, impaired glucose tolerance, and normal glucose tolerance. Diabetes Care, 24(9), 15671572.

Lowe, L.P., Tranel, D., Wallace, R.B., \& Welty, T.K. (1994).Type II diabetes and cognitive function: A population-based study of Native Americans. Diabetes Care, 17(8), 891-896.

Lucchini, R., Calza, S., Camerino, D., Carta, P., Decarli, A., Parrinelo, G., et al. (2003). Application of a latent variable model for a multicenter study on early effects due to mercury exposure. NeuroToxicology, 24, 605-616.

Luria, A.R. (1973). The working brain: An introduction to Neuropsycology. New York: Penguin Books. 
Magila, M.C., \& Xavier, G.F. (2000). Interação entre sistemas e processos de memória em humanos. Temas em psicologia da SBP, 8(2), 143-154.

Mathiesen, T., Ellingsen, D.G., \& Kjuus, H. (1999). Neuropsychological effects associated with exposure to mercury vapor among former chloralkali workers. Scandinavian journal of work, environment and health, 25(4), 342-350.

McKim, W.A. (2000). Drugs and behavior: an introduction to pharmacology. New Jersey: Prentice Hall.

Meyer-Baron, M., Schaeper, M., \& Seeber, A. (2002). A meta-analysis for neurobehavioral results due to occupational mercury exposure. Archives of Toxicology, 76: 127-136.

Mooradian, A.D. (1988a). Diabetic complications of the central nervous system (1988). Endocrine Reviews, 9(3), 346-356.

Mooradian, A.D. (1988b). Tissue specificity of premature aging in diabetes mellitus. The role of cellular replicative capacity. Geriatric Bioscience, 36, 831-839.

Moreira, R.O., Papelbaum, M., Appolinario, J.C., Matos, A.G., Coutinho, W.F., Meirelles, R.M.R., et al. (2003). Diabetes mellitus e depressão: uma revisão sistemática. Arquivos Brasileiros de Endocrinologia Metabólica, 47(1), 19-29.

Northam, E., Anderson, P.J,, Werther, G.A., Warne, G.L., Adler, R.G., Andrewes, D. (1998). Neuropsychological complications of IDDM in children 2 years after disease onset. Diabetes Care, 21(3), 379-384.

O'Carroll, R.E., Masterton, G., Dougall, N., Ebmeier, K.P., Goodwin, G.M. (1995). The Neuropsychiatric Sequelae of Poisoning: The Mad Hatter's Disease Revisited. British Journal of Psychiatry, 167, 95-98.

Papelbaum. M., Appolinário, J.C., Moreira, R.O., Ellinger, V.C.M., Kupfer., R., Coutinho, W.F. (2005). Prevalência de transtornos alimentares e comorbidade psiquiátrica em uma amostra clínica com pacientes com diabetes mellitus do tipo 2. Revista brasileirra de psiquiatria, 27(2), 135-138.

Piikivi, L., Hanninen, H., Martelin, T., \& Mantere, P. (1984). Psychological performance and long-term exposure to mercury vapors. Scandinavian journal of work, environment and health, 10(1), 35-41.

Rice, D.C. (1996). Sensory and cognitive effects of developmental methylmercury exposure in monkeys, and a comparison to effects in rodents. Neurotoxicology, 17(1), 139-154.

Rodriguez, Z.C., \& Rodriguez, J.E.L. (1982). Metallic mercury intoxication. Boletin de la Asociación Médica de Puerto Rico, 74(12), 380-382.

Ryan, C.M., \& Geckle, M. (2000). Circunscribed Cognitive Dysfunction in Middle-Aged Adults wtih Type 2 Diabetes. Diabetes Care, 23(10), 1486-1493.

Sartorelli, D.S. \& Franco, L.J. (2003). Tendências do diabetes mellitus no Brasil: o papel da transição nutricional. Cadernos de Saúde Pública, 19(suppl.1), 29-36.

Satoh, H. (2000). Occupational and environmental toxicology of mercury and its compounds. Industrial Health, 38, 153-164.

Scott, R.D., Kritz-Silverstein, D., Barret-Connor, E., \& Wiederholt, W.C. (1998). The association of non-insulin-dependent diabetes mellitus and cognitive function in an older cohort. JAGS, 46(10), 1217-1222.

Shapiro, I.M., Sumner, A.J., Spitz, L.K., Cornblath, D.R., Uzzel, B., \& Ship, I.I. (1982). Neurophisiological and neuropsychological functions in mercury-exposed dentists. The Lancet, 1(8282), 1147-1150.

Siblerud, R.L., Motl, J., \& Kienholz, E. (1994). Psychometric evidence that mercury from silver dental fillings may be an etiological factor in depression, excessive anger, and anxiety. Psychological Reports, 74, 67-80.

Slikker, W. Jr, \& Gaylor, D.W. (1995). Risk assessment strategies for neuropsychological agents. Annals New York Academy of Sciences, 15(765): 198-208.

Smith, P.J., Langolf, G.D., \& Goldberg. J. (1983). Effects of occupational exposure to elemental mercury on short-term memory. British Journal of Industrial Medicine, 40, 413-419. 
Soleo, L., Urbano, M.L., Petrera, V., \& Ambrosi, L. (1990). Effects of low exposure to inorganic mercury on psychological performance. British journal of industrial medicine, 47(2), 105-109.

Spreen, O., \& Strauss E. (1991). A Compendium of Neuropsychological Tests. New York: Oxford.

Stewart, R., \& Liolitsa, D. (1999). Type 2 diabetes mellitus, cognitive impairment and dementia. Diabetic Medicine, 16(2), 93-112.

Strachan, M.W., Deary, I.J., Ewing, F.M., \& Frier, B.M. (2000). Recovery of cognitive function and mood after severe hypoglycemia in adults with insulin-treated diabetes. Diabetes Care, 23(3), 305-312.

Strachan, M.W., Frier, B.M., Deary, I.J. (1997). Cognitive assessment in diabetes: The need for consensus. Diabetical Medicine, 14(6), 421-422.

Takahata, N., Hayashi, H., Watanabe, S., \& Anso, T. (1970). Accumulation of mercury in the brains of two autopsy cases with chronic inorganic mercury poisoning. Folia Psychiatrica et Neurologica Japonica, 24(1), 59-69.

Tirado, V., García, M.A., Moreno, J., Galeano, L.M., Lopera, F., \& Franco, A. (2000). Alteraciones neuropsicológicas por exposición ocupacional a vapores de mercurio en El Bagre (Antioquia, Colombia). Revista de Neurología, 31, 712-716.

Feinberg, T.E. \& Farah, M.L. (1997). Behavioral Neurology and Neuropsychology. New York: McGraw-Hill.

Vanhanen, M., Koivisto, K., Kuusisto, J., Mykkanen, L., Helkala, E.L., Hanninen, T., et al. (1998). Cognitive function in an elderly population with persistent impaired glucose tolerance. Diabetes Care, 21(3), 398-402.

Vanhanen, M., Kuusisto, J., Koivisto, K., Mykkanen, L., Helkala, E.L., Hanninen, T., et al. (1999). Type-2 diabetes and cognitive function in a non-demented population. Acta Neurologica Scandinavica, 100(2), 97-101.

Varma, R., Torres, M., Peña, F., Klein, R., Azen, S.P., \& Los Angeles Latino Eye Study Group. (2004). Prevalence of diabetic retinopathy in adult latinos. Ophthalmology, 111, 1298-1306.

Vassallo, D.V., Massaroni, L., Oliveira, E.M., Rossoni, L.V., do Amaral, S.M., Vassallo PF. (1996). Acute toxic actions of mercury on the cardiovascular system. Arquivos brasileiros de cardiologia, 67(1), 39-45.

Vinik, A.I., Park, T.S., Stansberry, K.B., \& Pittenger, G.L. (2000) Diabetic neuropathies: Review. Diabetologia, 43, 957-973.

Warre, S., LeCompte, \& P.M., Legg, M.A. (1966). The pathology of diabetes mellitus. $\left(4^{\text {th }}\right.$ ed.)Philadelphia: Lea \& Febiger.

Watson, G.S., \& Craft, S. (2003). The role resistance in the pathogenesis of Alzheimer's disease: Implications for treatment. CNS Drugs, 17(1), 27-45.

Wechsler, D. (1981). Wechsler Adult Inteligence Scale Revised Manual. New York: Psychological Corporation.

Wechsler D. (1987). Wechsler Memory Scale-Revised Manual. San Antonio, The Psychological Corporation.

Worral, G., Moulton, N., \& Briffett E. (1993). Effect of Type II Diabetes Mellitus on cognitive function. The Journal of Family Practice, 36(6), 639-643.

Wu, J.H., Haan, M.N., Liang, J., Ghosh, D., Gonzales, H.M., \& Herman, W.H. (2003). Impact of diabetes on cognitive function among older latinos. A population-based cohort study. Journal of clinical Epidemiology, 56, 686-693.

Zaslavsky, L.M.A., Gross, J.L., Chaves, M.L., \& Machado, R. (1995). Memory dysfunction and autonomic neuropathy in non-insulin-dependent (type 2) diabetic patients. Diabetes Research and Clinical Practice, 30, 101-110. 


\section{ANEXos}




\section{ANEXO 1 - Protocolo de Anamnese (página 1 de 2)}

\section{FICHA DE ANAMNESE}

\section{Data}

Nome:

Sexo: Idade: Escolaridade (anos de estudo):

Data de Nasc.: Naturalidade: Estado Civil:

Possui filhos? Quantos? Profissão atual / anterior:

Endereço: CEP:

Cidade: $\mathrm{UF}$ : Telefone:

Grupo (Mercúrio, Diabetes ou Controle):

Se Diabético ou Controle, Exame de Glicemia:

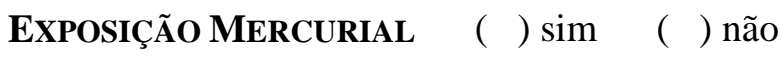

Se sim, durante quanto tempo ?

Quais cargos ocupou na empresa?

Há quanto tempo afastado do trabalho mediante exposição ao Hg ?

Na sua opinião, o contato com o mercúrio influenciou ou prejudicou a sua saúde e/ou comportamento ? De quê maneira ?

Exerceu algum tipo de atividade que o mantivesse em contato constante com outra substância tóxica? ( ) sim ( ) não

Se sim, quais atividades e quais substâncias ?

Diabetes Mellitus ( ) sim ( ) não

Se não, há alguém na família que apresente? Qual grau de parentesco e qual tipo de diabetes ?

Se sim, qual tipo ? Há quanto tempo ? Está controlado?

Apresenta ou já teve alguma complicação relacionada ao diabetes ?

Na sua opinião, o diabetes influenciou ou prejudicou a sua saúde e/ou comportamento ? De quê maneira? 


\section{ANEXO 1 - Protocolo de Anamnese (página 2 de 2)}

Queixas cognitivas e/ou de humor?

$\begin{array}{llll}\text { Memória } & \text { ( ) } & \text { Depressão } & \text { ( ) } \\ \text { Atenção } & \text { ( ) } & \text { Ansiedade } & \text { ( ) } \\ \text { Coordenação Motora } & \text { ( ) } & \text { Irritabilidade } & \text { ( ) }\end{array}$

Outras / Quais?

\section{Antecedentes Clínicos}

Doenças que teve e quando?

Já foi submetido a algum procedimento cirúrgico? ( ) sim ( ) não Se sim, quais e quando ?

Foi vítima de algum acidente em que tenha sido atingida a região da cabeça?( ) sim （ ） não Faz tratamentos atualmente ? Quais?

Toma medicamentos atualmente ? Quais e qual dosagem ?

\section{Dados Complementares}

Consumo de álcool ( ) sim ( ) não Tipo de bebida e freqüência ?

Tabagismo ( ) sim ( ) não Há quanto tempo ?___ Quantidade / dia ?

Uso de drogas ( ) sim ( ) não Tipo de droga e freqüência ?

Observações: 


\section{ANEXO 2 - Termo de Consentimento \\ Universidade de São Paulo \\ Instituto de Psicologia \\ Departamento de Psicologia Experimental \\ Setor de Eletrofisiologia e Psicofísica Visual Clínica \\ TERMO DE CONSENTIMENTO LIVRE E ESCLARECIDO \\ ESTUDO NEUROPSICOLÓGICO DE PACIENTES EXPOSTOS AO VAPOR DE MERCÚRIO E DE PACIENTES DIABÉTICOS DO TIPO 2}

Pesquisadores: Elaine Cristina Zachi, Profa. Dra. Dora Fix Ventura

Você está sendo convidado(a) a participar de um estudo sobre a avaliação neuropsicológica de pacientes diabéticos do tipo 2 e de pacientes expostos, no trabalho (fabricação lâmpadas), ao vapor de mercúrio, substância altamente tóxica.

Serão usados vários testes neuropsicológicos em que serão examinadas as funções de memória, atenção, linguagem, funções motoras, viso-motoras e habilidade de planejamento e serão aplicados questionários de depressão e ansiedade. Estes testes compõem uma bateria de avaliação neuropsicológica que será aplicada em uma única sessão com duração de 1 hora e 30 minutos, aproximadamente. Os testes não são invasivos e não oferecem quaisquer riscos. Caso você tenha interesse em conhecer os seus resultados individuais, poderá marcar entrevista posterior com a psicóloga pesquisadora (Elaine C. Zachi) para a apresentação dos mesmos.

Os resultados serão sigilosos e seu nome não será divulgado.

Você pode esclarecer suas dúvidas sobre qualquer aspecto do estudo, bem como desistir da sua participação, que é totalmente voluntária.

Sua assinatura neste termo de consentimento, após ter lido a informação descrita acima (ou alguém ter lido para você), indica que você concorda em realizar os testes e permite a utilização dos resultados para a pesquisa científica realizada neste instituto.

Assinatura do Voluntário

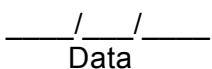

Assinatura do Pesquisador

Nome do Voluntário

Documento de identidade $n^{\circ}$

Endereço

Bairro

CEP

Cidade

Telefones Data de nascimento $\mathrm{N}^{\circ}$ Apto 


\section{APÊNDICE}

\section{Aplicação do Teste de Wisconsin}

EXAMINADOR

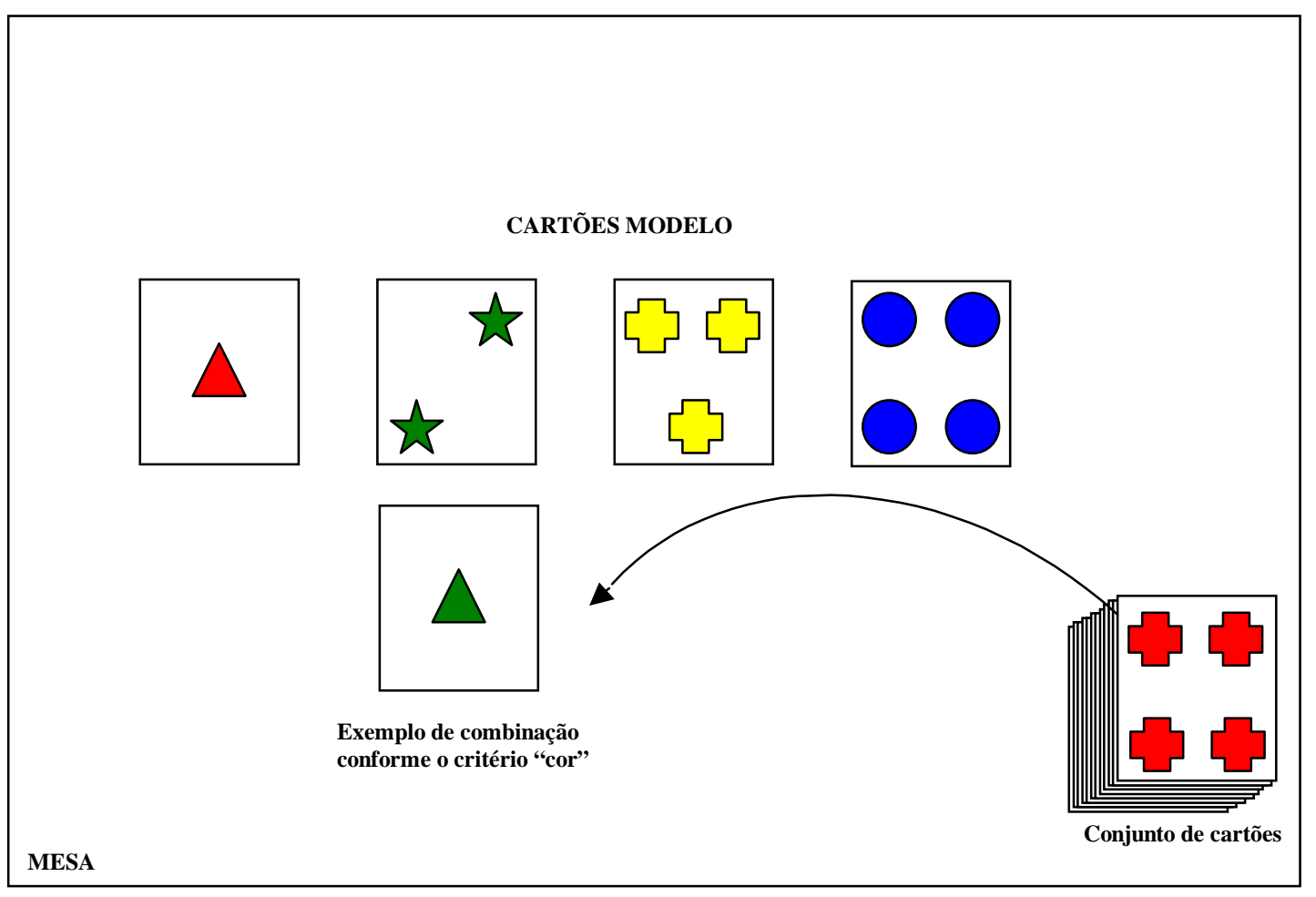

EXAMINANDO 